University of Louisville

ThinkIR: The University of Louisville's Institutional Repository

$12-2018$

\title{
Physical education activity courses: an exploration of how enrollment influences student retention rates.
}

Dylan J. Naeger

University of Louisville

Follow this and additional works at: https://ir.library.louisville.edu/etd

Part of the Health and Physical Education Commons

\section{Recommended Citation}

Naeger, Dylan J., "Physical education activity courses: an exploration of how enrollment influences student retention rates." (2018). Electronic Theses and Dissertations. Paper 3105.

https://doi.org/10.18297/etd/3105

This Doctoral Dissertation is brought to you for free and open access by ThinkIR: The University of Louisville's Institutional Repository. It has been accepted for inclusion in Electronic Theses and Dissertations by an authorized administrator of ThinkIR: The University of Louisville's Institutional Repository. This title appears here courtesy of the author, who has retained all other copyrights. For more information, please contact thinkir@louisville.edu. 

PHYSICAL EDUCATION ACTIVITY COURSES: AN EXPLORATION OF HOW
ENROLLMENT INFLUENCES STUDENT RETENTION RATES

\author{
By \\ Dylan J. Naeger \\ B.S., Southeast Missouri State University, 2001 \\ M.S., University of Louisville, 2005
A Dissertation
Submitted to the Faculty of the
College of Education and Human Development of the University of Louisville in Partial Fulfillment of the Requirements
for the Degree of

Doctor of Philosophy in Educational Leadership and Organizational Development

\author{
Health and Sport Sciences Department \\ University of Louisville \\ Louisville, Kentucky
}

December 2018 
Copyright 2018 by Dylan J. Naeger

All rights reserved 

PHYSICAL EDUCATION ACTIVITY COURSES: AN EXPLORATION OF HOW ENROLLMENT INFLUENCES STUDENT RETENTION RATES

\author{
By \\ Dylan J. Naeger \\ B.S., Southeast Missouri State University, 2001 \\ M.S., University of Louisville, 2005
}

A Dissertation Approved on

November 15, 2018

By the following Dissertation Committee:

T. Christopher Greenwell, Co-Chair

Mary A. Hums, Co-Chair

Evan Frederick

W. Blake Haselton 


\section{DEDICATION}

For Erin, Ayden, \& Kolten-The Three Loves of my Life 


\section{ACKNOWLEDGEMENTS}

I would like to extend my appreciation to my committee for their guidance throughout this process. Your feedback has been invaluable in helping me finish this journey. Each of you are wonderful scholars and educators and it has been a privilege to learn from you. Additionally, I would like to thank all of my colleagues, both past and present, who have been a source of support and encouragement.

To Mom and Dad who taught me at a very young age the importance of hard work, faith, and an education. I am so grateful of the sacrifices you made when I was growing up to ensure I benefited from a quality educational experience, which has helped me during all of my educational pursuits. To all of my other family members, you have been consistent supporters of me throughout my lifetime and especially this journey. Your words of support and prayers have been extremely encouraging and I am blessed to call you family. To Pat and Katie for offering wisdom when I came to you for advice.

To Ayden and Kolten for your frequent hugs and kisses and for bringing so much joy in my life. You two are such amazing boys! You have been so understanding that Daddy had to spend time finishing his "hard paper". While you are not old enough yet to understand the words on these pages or the purpose of Daddy completing his "hard paper", I pray that you will always value your education and never give up on your dreams, no matter how challenging they may be. Be confident in your life pursuits and hold firm in your values and belief system. When faced with life challenges, always 
remember that your family and faith will be with you to help you overcome those hurdles. Always remember, that whatever you do, work at it with all your heart. To Erin for being such a supportive spouse and offering encouragement throughout this process. Additionally, thanks for sharing your wisdom and offering guidance in this journey, but more importantly in our life pursuits. At the end of a hard day, your caress brings a smile to my face. You have been so supportive and patient during this very long journey, while your husband was pulled in many different directions. The one constant through it all has been my love and appreciation for you. Thanks for the prayers during this process and your words of encouragement. Let us both always remember, to let all that we do be done in love. 


\title{
ABSTRACT \\ PHYSICAL EDUCATION ACTIVITY COURSES: AN EXPLORATION OF HOW ENROLLMENT INFLUENCES STUDENT RETENTION RATES
}

\author{
Dylan J. Naeger
}

November 15, 2018

Nationally, student retention rates continue to be a problem, as the National Center for Education Statistics (2018) found the six-year undergraduate graduation rate for students who started college in fall 2010 was around $60 \%$. An area not yet investigated is if any association exists between enrollment in a university physical education activity course (BIP) and academic success. The purpose of this study was to determine how enrollment in a BIP course affected undergraduate student retention rates. This study examined whether enrollment in BIP courses influenced student retention of all first-time, full-time, baccalaureate degree-seeking students enrolled at a public research university during the years of 2014 and $2015(\mathrm{~N}=5,565)$.

Results indicated minority students, students with lower high school GPAs, and students with lower ACT composite scores were more likely to enroll in BIP courses during their first or second year at the institution. Additionally, the Health and Sport Sciences Department requires BIP enrollment for degree completion, so students in HSS enrolled at a higher rate. A significant finding showed students enrolled in BIP courses during their first or second year had 1.65 greater odds of being retained after the second year. Additionally, students enrolled in BIP courses during their second year had 3.22 
greater odds of second year retention. For each additional BIP course enrolled, students had 1.39 greater odds of being retained after the second year. There was a significant interaction between race and first or second year BIP enrollment, as White students enrolled in a BIP course had 1.73 greater odds of second year retention. Finally, there was significant interaction between race and second year BIP enrollment, as White students enrolled in a BIP course had 2.48 greater odds of second year retention. While most institutions no longer require BIP enrollment, the findings in the current study demonstrate an association between BIP enrollment and greater odds of student retention. As a result, schools need to reconsider the importance of BIP enrollment, especially during the second year. The findings also demonstrate value in enrollment in more than one BIP course early in the educational experience. 


\section{TABLE OF CONTENTS}

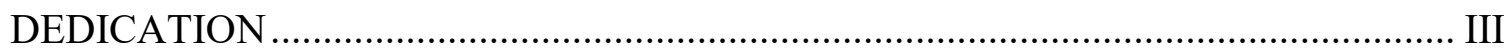

ACKNOWLEDGEMENTS .............................................................................. IV

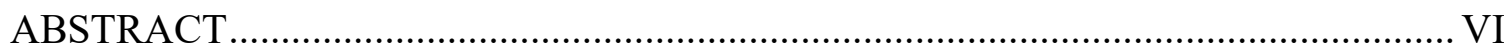

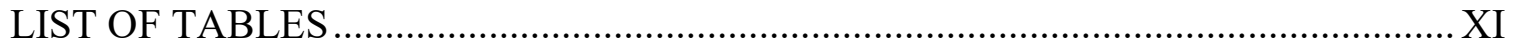

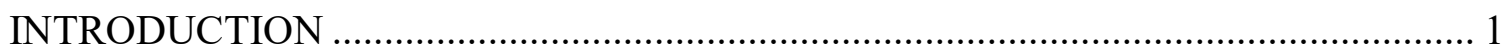

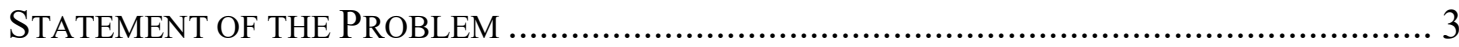

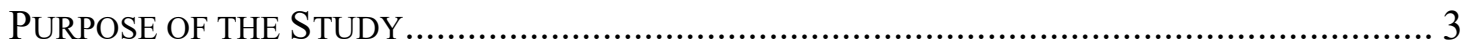

Benefits of Physical Activity Courses .................................................................. 4

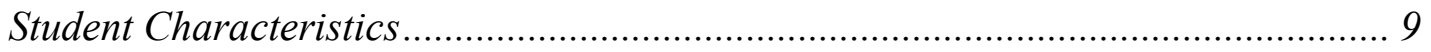

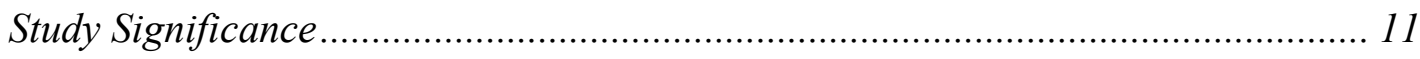

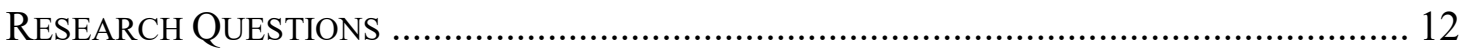

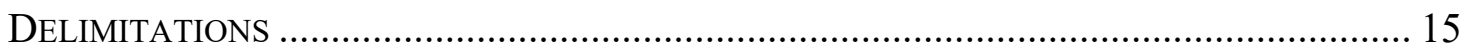

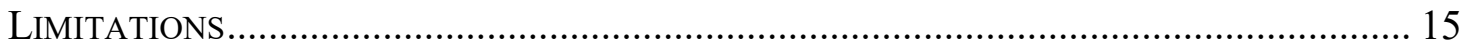

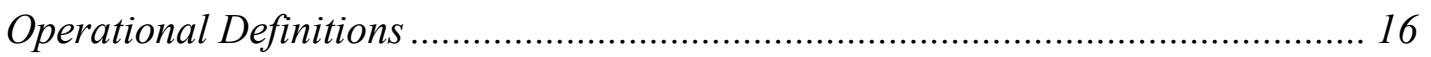

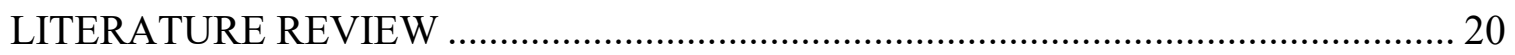

HISTORY OF BASIC INSTRUCTION PROGRAMS ......................................................... 20

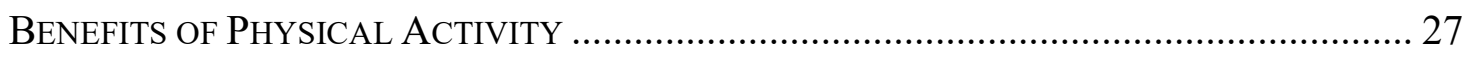

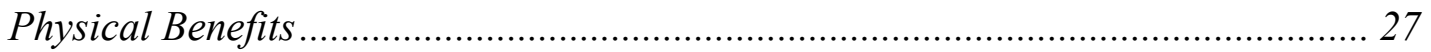

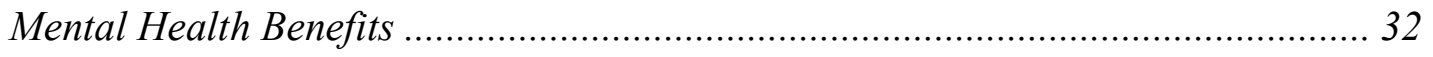




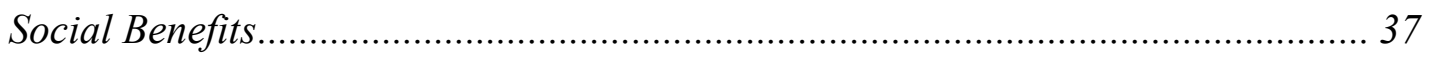

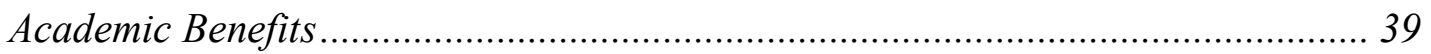

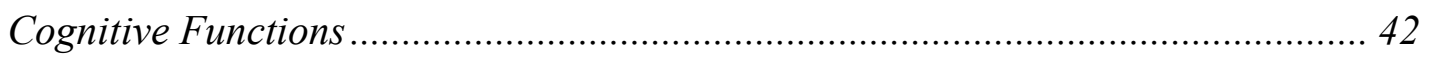

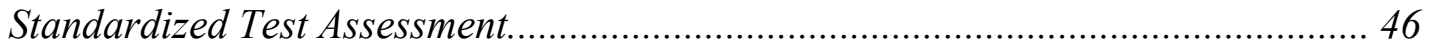

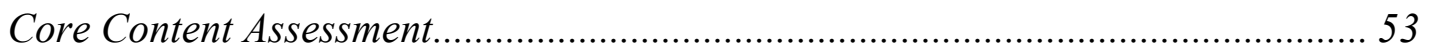

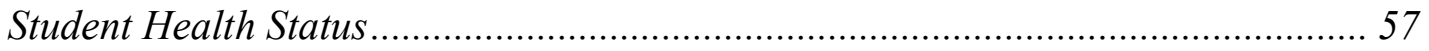

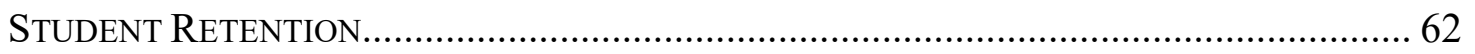

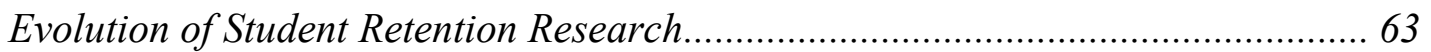

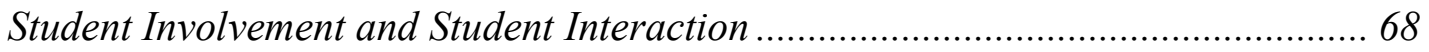

Utilizing Campus Recreation and Physical Activity for Retention.......................... 79

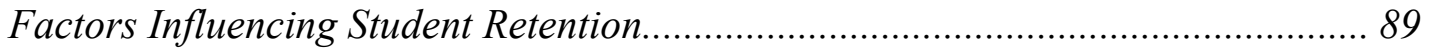

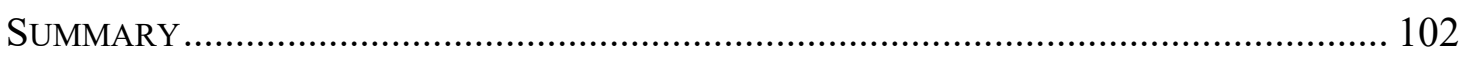

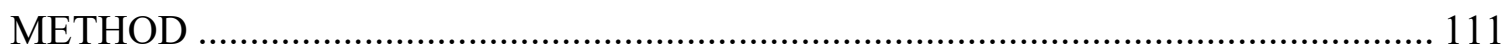

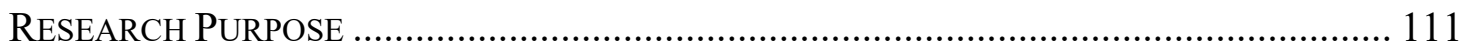

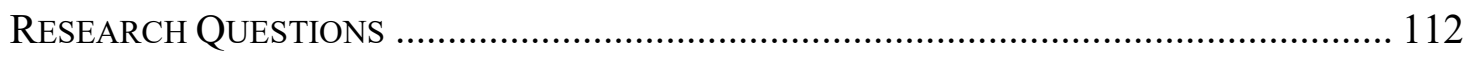

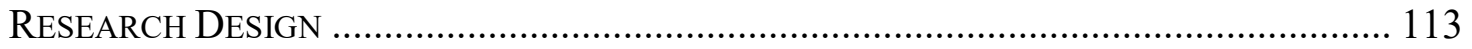

Data Collection and SAmPling Procedure......................................................... 114

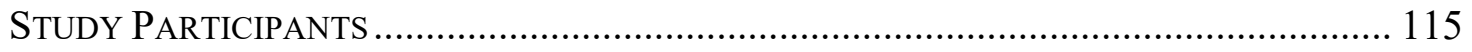

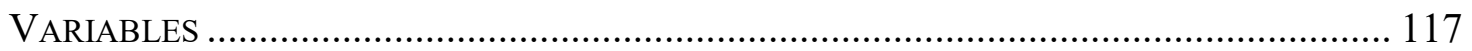

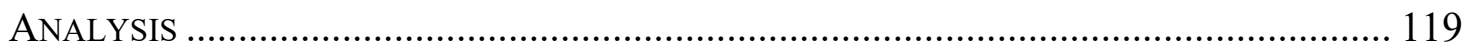

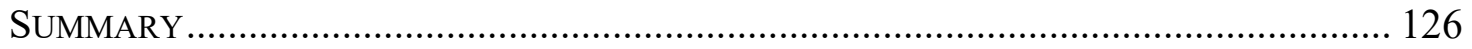

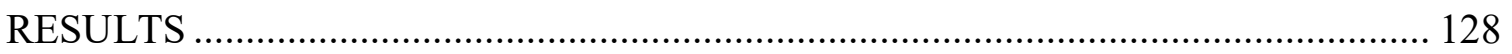

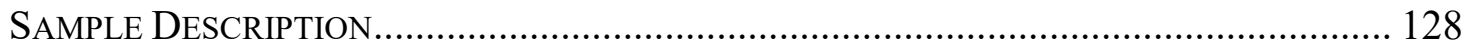




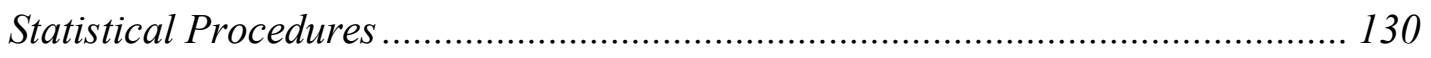

STUDENT CHARACTERISTICS AND BIP ENROLLMENT …......................................... 130

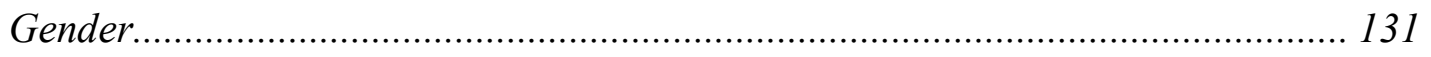

Race

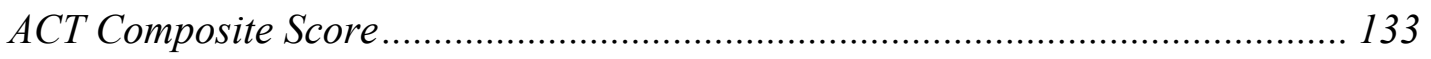

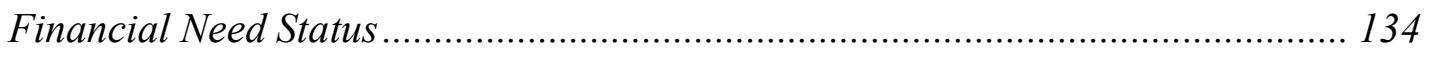

Declared College Major ………………................................................. 135

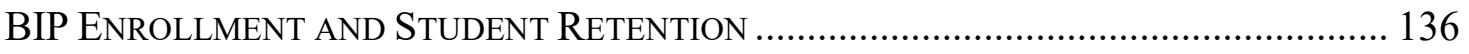

StUdENT CHARACTERISTICS AND STUDENT RETENTION ............................................ 143

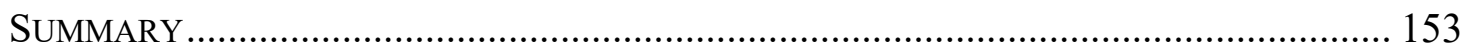

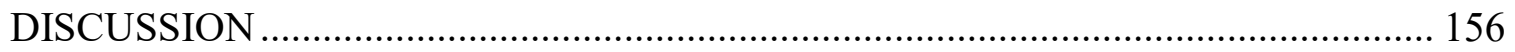

STUDENT CHARACTERISTICS AND BIP ENROLLMENT ……......................................... 158

BIP ENROLLMENT AND STUDENT RETENTION ……………........................................ 162

StUdENT CHARACTERISTICS AND STUDENT RETENTION ............................................. 166

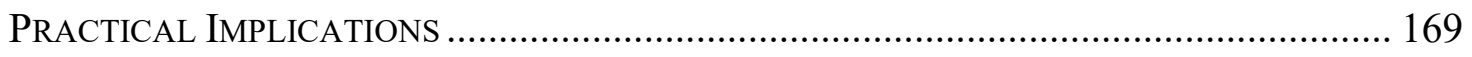

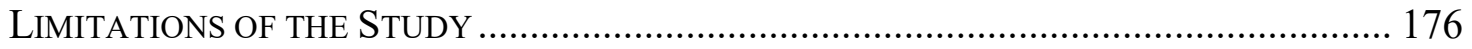

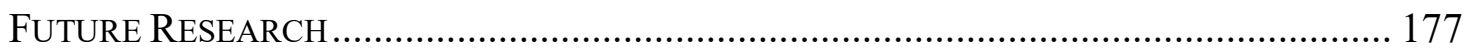

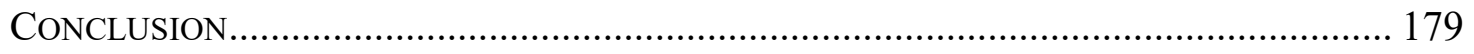

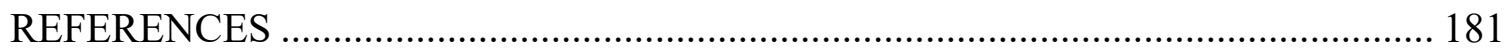

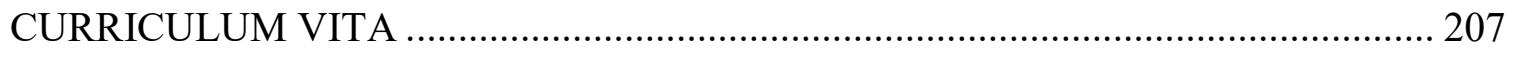




\section{LIST OF TABLES}

TABLE

PAGE

1. Frequency in the Cohorts

129

2. Frequency of BIP Enrollment by Gender

3. Frequency of BIP Enrollment by Race

132

4. Frequency of BIP Enrollment by High School GPA

133

5. Frequency of BIP Enrollment by ACT

134

6. Frequency of BIP Enrollment by PELL Eligibility

135

7. Frequency of BIP Enrollment by College Major

136

8. Logistic Regression Analysis of First Year Retention

by Year One BIP Enrollment

9. Logistic Regression Analysis of Second Year Retention

by Year One BIP Enrollment

10. Logistic Regression Analysis of Second Year Retention

by Year One or Two BIP Enrollment

11. Logistic Regression Analysis of Second Year Retention

by Year Two BIP Enrollment

12. Logistic Regression Analysis of Second Year Retention as a Function of Total \# of BIP Enrolled

13. Frequency Table of Total \# of BIP Courses Enrolled

14. Logistic Regression Analysis of First Year Retention by

First Year BIP Enrollment \& Student Characteristics

15. Logistic Regression Analysis of Second Year Retention by

First Year BIP Enrollment \& Student Characteristics

16. Logistic Regression Analysis of Second Year Retention by

$1^{\text {st }}$ or $2^{\text {nd }}$ Year BIP Enrollment \& Student Characteristics $\quad 150$

17. Logistic Regression Analysis of Second Year Retention by

$2^{\text {nd }}$ Year BIP Enrollment \& Student Characteristics 


\section{CHAPTER I}

\section{INTRODUCTION}

Within the existing literature in student retention research, scholars found many different variables associated with student persistence. While individual studies have shown these variables correlate with student persistence, this line of research has not been able to determine that the presence of one specific variable guarantees $100 \%$ student retention in all cases and at all institutions (Demetriou \& Schmitz-Sciborski, 2011). In fact, Tinto (2006) acknowledged that the field of student retention has been widely studied, yet many areas still require further research. While some institutions have successfully implemented student retention programs, many schools are still searching for the appropriate mix of strategies and programming (Bettinger, Evans, \& Pope, 2013; Carey, 2005a, 2005b; Chen, 2012; Tinto, 2006, 2010).

The National Center for Education Statistics (2005) found slight changes in the national rate of student retention at higher education institutions over the last decade. Additionally, the National Center for Education Statistics (2018) found that the six-year graduation rate of undergraduate students who started college in fall 2010 was approximately $60 \%$. Existing student retention research has demonstrated successful student retention programs incorporated numerous factors and often varied from institution to institution (Bettinger et al., 2013; Tinto, 2006). In other words, student academic success and continued persistence toward degree completion results from the 
presence of many different experiences and student attributes (Berger, 2001; Tinto, 2010).

The extant literature does demonstrate, however, the considerable influence participation in fitness and sports in a campus recreational setting has on the overall academic success and persistence of students (Belch, Gebel, \& Maas, 2001; Henchy, 2011; Lindsey \& Sessoms, 2006; Miller, 2011). Over the last century, many higher education institutions offered physical education courses for academic credit through a basic instruction program or a physical activity program (Carlson, 2015; Fornia, 1959; Hensley, 2000; Trimble \& Hensley, 1984). Initially, these programs had the main goal of producing overall health and wellness and in turn helping shape a healthy student population (Carlson, 2015; Curry, Jenkins, \& Weatherford, 2015; Lumpkin \& Jenkins, 1993).

Additionally, a secondary outcome of these programs was to provide an outlet for students to develop an appreciation for participation in physical activity and sport during the college years and continue participating in like activities after leaving campus (Bray \& Born, 2004; Carlson, 2015; Curry et al., 2015; Ebben \& Brudzynski, 2008; Johnson \& Deshpande, 2000). However, the number of institutions requiring physical education courses as a general education undergraduate degree requirement has dwindled drastically over time. In fact, McCristal and Miller (1939) found 97\% of all college and university students were required to complete physical education courses as a graduation requirement in the 1920s and 1930s. Over time, that number has changed. Cardinal, Sorensen, and Cardinal (2012) reported that only $39.55 \%$ of colleges and universities mandated physical education as a degree requirement in 2010 . 


\section{Statement of the Problem}

One of the most pressing issues in the higher education landscape is addressing and determining effective strategies to increase student retention rates (Kahu \& Nelson, 2018). An overlooked area in the student retention research at higher education institutions is if any positive association exists between enrollment in a university physical education course and academic success. A plethora of research conducted in the K-12 setting demonstrates academic success is positively linked with physical activity at that level. Additionally, research conducted at the university level shows participation in fitness and sports activities in a campus recreation setting has a significant positive influence on the overall academic success of the college student population. One of the major gaps in the literature however, is the limited number of studies conducted on determining if an association exists between university student enrollment in physical education courses and academic success. This gap is problematic given the increased emphasis on student retention.

\section{Purpose of the Study}

The higher education landscape has seen a shift in the significance placed on student retention. This change in emphasis was caused by the decrease in fiscal resources (Browne, 2010; Newman, Couturier, \& Scurry, 2010; Tinto, 2006). Due to decreased state funding levels, institutions are aggressively seeking alternative funding sources (Browne, 2010; Newman et al., 2010). Because of the decrease in fiscal resources available to institutions, Pelletier (2012) found that colleges as well as individual departments must begin to brainstorm for potential revenue sources. Many institutions have even turned to the assistance of consulting firms, which started because of the 
increased demands higher education institutions placed on student retention (Hillman \& Corkery, 2010; Tinto, 2006). As a result, schools are in search of programs and initiatives, which aim to potentially increase overall student retention rates.

Therefore, the purpose of this study was to determine how enrollment in a university physical education activity course affects the overall undergraduate student retention rates at a metropolitan research institution located in the southern region of the United States. The participating university does not currently include enrollment in a physical education course as part of the general education degree requirement.

Undergraduate degrees offered by the Health and Sport Sciences (HSS) Department do, however, include enrollment in two physical education activity courses for a total of two credit hours. The participating institution provides numerous types of physical activity course offerings each semester for elective purposes for the campus population.

\section{Benefits of Physical Activity Courses}

Research has shown physical activity participation promotes physical, mental, social, and academic gains in adolescents (Caterino \& Polak, 1999; Davis et al., 2007; Donnelly et al., 2016; Grissom, 2005; Nelson \& Gordon-Larson, 2006; Rasberry et al., 2011; Tremarche, Robinson, \& Graham, 2007; Wittberg, Northrup, \& Cottrel, 2009). However, limited research exists on the benefits of physical activity participation in the college age population. Sparling (2003) explained the importance of college-aged students participating in physical education courses to effectively promote physical activity and address the ever-growing obesity epidemic in the United States. The rise in occurrences of obesity among college-age students has been exasperated by sedentary lifestyle activities (Bray \& Born, 2004; Curry et al., 2015; Ebben \& Brudzinski, 2008). 
VanKim and Nelson (2013) found that only roughly $50 \%$ of the U.S. college population meets the daily recommendation for exercise. Students gain numerous health benefits from participation in physical education courses at the university setting. By offering and requiring physical education courses in the higher education setting, institutions have the chance to address the lack of physical activity participation by young adults and help combat growing health concerns (Curry et al., 2015). Thus, from a health perspective, it would be beneficial if higher education institutions would go back to earlier degree requirements, when physical education courses were typically a mandatory part of the general education curriculum and a graduation requirement for all students (Sparling, 2003).

Additionally, Leenders, Sherman, and Ward (2003) discussed the opportunity available to colleges and universities to promote healthy behaviors for students to demonstrate the value and worth of physical education Basic Instruction Program (BIP) courses at higher education institutions. Specifically, institutions can instill an interest in physical activity participation by promoting enrollment in physical education BIP courses and structuring the courses in such a manner to either slow or prevent the occurrence of various health related issues (Leenders et al., 2003). Previous research has shown enrollment in physical education activity courses provides a logical setting to educate college age students about lifestyle choices and health risk behaviors (Dale \& Corbin, 2000; Egli, Bland, Meton \& Czech, 2011; Pearman et al., 1997; Sweeney, 2011).

While numerous studies document the positive health gains associated with physical activity participation, it appears most higher education institutions have ignored these findings. In fact, higher education institutions continue to transition to a model that 
has either eliminated or devalued physical education as part of the general education curriculum. Participation levels in physical activity continue to decrease post-high school and then decrease even further post college (Caspersen, Pereira, \& Curran, 2000; Sparling \& Snow, 2002). There is a consistent negative correlation with an increase in an individual's age and participation in fitness activities (Caspersen et al., 2000; Sparling \& Snow, 2002). This negative correlation starts to become apparent post-high school.

The Physical Activity Council published a 2018 Physical Activity Participation Report showing that $28 \%$ of the U.S. population is inactive (Physical Activity Council, 2018). Research has shown one approach to address the negative correlation between age and participation in fitness activities is to get more college aged students enrolled in physical education courses during their academic experience. In fact, graduates from higher education institutions where physical education was a degree requirement were more likely to participate in physical activity and live an active lifestyle post-graduation than graduates of schools lacking this requirement (Adams \& Brynteson, 1992;

Brynteson \& Adams, 1993; Sparling \& Snow, 2002).

The national trend of decreasing the number of physical activity opportunities in academic settings has long lasting physical and psychological consequences. Physical activity involvement helps to address stressful situations and improve self-esteem levels (Joseph, Royse, Benitez, \& Pekmezi, 2014; Sax, 1997). Students, especially those in higher education, find the process of navigating the educational landscape quite stressful and daunting (Abouserie, 1994; Baghurst \& Kelley, 2014; Goodman, 1993; LeRoy, 1987). Students enrolled in college physical education courses displayed higher levels of self-esteem and greater levels of self-worth than those not enrolled (Avery \& Lumpkin, 
1987). The course structure of physical education class offerings is conducive for interactions amongst the students, which is essential since social interactions and experiences with peers affect students' self-esteem and self-worth (Morrow \& Ackermann, 2012; Sax, 1997).

An association or close affiliation with a peer group often positively affects an individual's self-esteem. Student satisfaction with the student experience and the ability to create peer groups is a critical aspect in overall student retention (Douglas, Douglas, McClelland, \& Davies, 2015). Lamont (2010) found new students at college and university campuses had a great need to establish a peer group and socially integrate with others. Physical activity opportunities are often social in nature; thus, many people turn to physical activity settings to associate with peer groups (Sax, 1997). Since universities have decreased the number of required physical education courses, more students visit their campus recreation department and participate in programming and unstructured activities. Many university students visit their respective campus recreation centers and participate in various programming opportunities to address their need for establishing and socializing with a peer group (Elkins, Forrester, Noel-Elkins, 2011).

Bryant and Bradley (1993) found participation in recreational sports programs positively impacted student development and overall self-esteem. Additionally, Lamont (2010) found first and second year students at higher education institutions used recreational facilities at a rate nearly three times greater than upper level students. This finding indicated a need for a social network during the early years at the institution, thus students often turned to the recreational sports setting to fill this void. Artinger et al. (2006) found first-year students demonstrated significantly higher social benefits from 
participating in intramural sports compared to fourth-year students. Finally, Miller (2011) found that frequent users of university campus recreation programs were more socially connected and more likely to be retained.

In addition to research demonstrating social gains from participating in campus recreation programming, researchers have also shown academic gains. Churchill and Iwai (1981) found a significant correlation existed between campus recreation facility usage and the overall persistence levels of students, including those who began at their schools with low GPAs. The retained students with low GPAs frequented campus facilities at a higher rate as compared to the students with low GPAs who withdrew from school (Churchill \& Iwai, 1981).

Belch, Gebel, and Maas (2001) found comparable results, in that student campus recreation users completed a higher number of academic credits during their first academic year than facility non-users. Persistence rates for facility users after the first academic year were higher than for non-users (71\% vs. 64\%) and as the number of visits to the facility increased during the first year, so too did the student GPA and persistence rates. The group of students with 50 or more visits during their first semester on campus had the highest persistence rates (Belch et al., 2001). Additionally, Lindsey and Sessoms (2006) found the presence of a campus recreation facility and its program offerings influenced student decisions to continue their educational pursuits. A correlation existed between the overall levels of student satisfaction and their access to campus recreation facilities and programs (Lindsey \& Sessoms, 2006).

In a similar study, students who frequented campus recreation centers at a frequency that was one standard deviation above the sample average had a predicted 
GPA that was 0.11 greater and had a 1\% greater likelihood of being retained (Huesman, Brown, Lee, Kellogg, \& Radcliffe, 2007). Previous research has shown many benefits (physical, mental, social, and academic) of participating in physical activity. While these findings are significant in understanding successful approaches to increasing retention rates, a closer examination of the specific attributes of individual students is necessary.

\section{Student Characteristics}

Distinguishing characteristics shape students into who they are as individuals. Astin (1993a) classified student entry characteristics as identifiable attributes of the student as well as any previous experiences the students had encountered. Student entry characteristics affect the student's decision to maintain enrollment and continue persisting toward degree completion. In fact, Astin (1993a) determined over $50 \%$ of the explained variance in institutional retention rates was due to characteristics of the student upon admittance to the institution. Similarly, Astin and Oseguera (2005) determined $70 \%$ of the explained variance between the degree completion rates at institutions was due to the students' characteristics upon initial entry at the school. Astin (1993b, 1993c) found student characteristics upon enrollment at the institution including gender, race, and SES contributed to student academic performance. Additionally, Berger (2001) showed a variety of student characteristics contributed to student academic performance.

High school GPA, a frequently used measure of potential academic ability at college, is a significant factor in predicting college student persistence (Astin, 1971, 1973a; Belfield \& Crosta, 2012; Blanchfield, 1971; Chase, 1970; Coker, 1968; Fike \&

Fike, 2008; Jaffe \& Adams, 1970; Komarraju, Ramsey \& Rinella, 2013; Lavin, 1965; Lawhorn, 1971; Panos \& Astin, 1968; Sawyer, 2013; Smith, 1971; St. John, Hu, 
Simmons, \& Musoba, 2001; Taylor \& Hanson, 1970; Tross, Harper, Osher, \& Kneidinger, 2000; Westrick, Le, Robbins, Radunzel, \& Schmidt, 2015). Additionally, the student entry characteristic of high school class rank also has a positive correlation with student persistence (Astin, 1971). Grades earned in classes and class rank were better predictors of college success than standardized tests, as previous educational experiences correspond more closely to the individual's ability to achieve academically and socially in an educational setting (Astin, 1972). Pike and Saupe (2002) found high school academic performance, earned standardized test scores, and types of courses the students completed during high school accounted for $33 \%$ of the explained variance in the grades first-year college students earned. Skinner and Richardson (1988) determined the social atmosphere at predominantly white institutions was problematic for minority students, including those individuals with strong high school academic preparation. Tinto (1987) found the underlying factor in persistence rates in higher education between minorities and non-minority students was academic preparedness. Numerous studies found minority students enrolling in college arrive with weaker academic backgrounds, as compared to non-minority students (Hu \& St. John, 2001; Johnson, 1990; Mingle, 1987; Mow \& Nettles, 1990; Nettles, 1990).

Student entry characteristics affect progress toward degree completion. Additionally, students need to feel accepted and part of a peer social group early in their educational experience (Morrow \& Ackermann, 2012; O'Keeffe, 2013; Torres, 2003; Zurita, 2004). Attinasi (1989), Morrow and Ackermann (2012), and Tinto (1993, 1997) demonstrated student academic success and persistence were impacted by the student's ability to become socially and academically integrated at the institution. The literature 
demonstrated how participation in physical activity is social in nature and allows students the opportunity to interact with peers in a non-intimidating environment (Eime, Young, Harvey, Charity, \& Payne, 2013; Saklofske, Austin, Mastoras, Beaton, \& Osborne, 2012). However, this earlier research failed to examine if physical activity involvement associated with BIP course enrollment influenced student persistence and academic success.

\section{Study Significance}

Even though the study of student retention started many decades ago, this line of research is still very pertinent in the higher education landscape. One could argue student persistence is more critical than ever today for universities. Many public higher education institutions are facing serious financial struggles due in large part to decreased levels of financial assistance from state governments. Universities are searching for ways to compensate for the decrease in state assistance (Sheridan, 2011). As a result, universities have come to realize it is as fiscally responsible and affordable to develop strategies and implement programs designed to increase the persistence rates of existing students as it is to simply look to recruit new students (Sheridan, 2011; Tinto, 2006, 2010). The objective is to improve overall graduation rates and at the same time limit the number of students transferring or dropping out, both of which result in a loss of tuition revenue.

Universities are continually searching for ways to increase student persistence rates and progress toward degree completion (O’Keeffe, 2013; Tinto, 2006). Numerous researchers have linked student academic success with participation in physical activity (Dwyer, Coonan, Leitch, Hetzel, \& Baghurst, 1983; Fejgin, 2001; Pate, Heath, Dowda, \& 
Trost, 1996; Rasberry et al., 2011; Shephard, 1997; Trost, 2007; Trudeau \& Shephard, 2008). Previous studies, however, failed to examine if an association existed between university student enrollment in physical education courses and student retention rates. Since this area of research has been overlooked, the possibility exists the current study may help university administrators better understand how to potentially increase student retention rates. Additionally, the current study may help university administrators understand more fully the importance of a whole-body education and how physical activity helps to develop a culture of academic success.

Students have many identifiable attributes, including student entry characteristics (Astin, 1993a). These characteristics help mold and define each individual student and are also directly linked to student academic success and student retention. Astin (1993a) determined over $50 \%$ of the explained variance in institutional retention rates could be explained by the characteristics of the students upon admittance to the institution.

Similarly, Astin and Oseguera (2005) determined 70\% of the explained variance of degree completion rates at an institution could be explained by student entry characteristics. The research documents the significance of student entry characteristics on student retention. The current study includes student entry characteristics as variables in the research questions.

\section{Research Questions}

In order to examine the role enrollment in physical education activity courses play in academic success and overall student retention rates in a university setting, several research questions were formulated. While many institutions no longer mandate physical education as a degree requirement, many still offer varying numbers of physical 
education courses. Thus, it is important for physical education programs and higher education institutions to identify the type of student who is choosing to enroll in physical education courses for elective purposes. The first research question addressed this need. Specifically, this question states:

RQ1 - Who is enrolling in BIP courses and how do they differ from the rest of the student population?

RQ1a-How does a student's gender influence enrollment in BIP courses?

RQ1b-How does a student's race influence enrollment in BIP courses?

RQ1c- How does a student's high school GPA influence enrollment in BIP courses?

RQ1d- How does a student's ACT composite score influence enrollment in BIP courses?

RQ1e- How does a student's PELL eligibility status influence enrollment in BIP courses?

RQ1f- How does a student's declared college major influence enrollment in BIP courses?

An overlooked area of the literature is if enrollment in BIP courses has any relationship to student retention. Previous research has not examined if the academic year of BIP enrollment altered student retention. Specifically, the present study intended to examine if academic year of enrollment in BIP courses was influential on student persistence. Additionally, the present study intended to examine if the number of BIP courses taken by undergraduate students influenced student retention. Therefore, the second research question looks deeper at the course offering structure of BIP courses and 
if enrollment in such courses had any retention benefits. Specifically, this question states:

RQ2 - How does the year of BIP enrollment and the number of BIP classes enrolled in influence student retention?

Previous literature has shown a direct correlation between student entry characteristics, academic success, and student persistence; thus, the third research question examined the impact student entry characteristics have on the selected study population. Specifically, this question states:

RQ3 - How is the relationship between enrollment in BIP courses and retention influenced by student characteristics?

RQ3a-How does a student's gender influence the relationship between enrollment in BIP courses and retention?

RQ3b-How does a student's race influence the relationship between enrollment in BIP courses and retention?

RQ3c-How does a student's cumulative GPA at the end of his/her freshmen academic year influence the relationship between enrollment in BIP courses and retention?

RQ3d-How does a student's high school GPA influence the relationship between enrollment in BIP courses and retention?

RQ3e-How does a student's combined ACT score evaluated during high school influence the relationship between enrollment in BIP courses and retention? 
RQ3f-How does enrollment in a Health and Sport Sciences (HSS) major (Health \& Human Performance and Sport Administration) influence the relationship between enrollment in BIP courses and retention? RQ3g-How does a student's classification of PELL eligibility influence the relationship between enrollment in BIP courses and retention?

\section{Delimitations}

A few delimitations existed in the current study. First, the sample for the current study was enrolled at one institution. Before attempting to replicate the study or generalize the findings to other institutions, careful consideration regarding the institution's size, location, type, and the profile of the student population must occur. Second, the current study only examined enrollment in specific physical education activity courses offered by one academic department at the institution. Third, the current study only included specific freshman cohorts at the institution during the selected period to keep the sample size manageable.

As a result, if a different or longer period was included in the sample, the current study may have produced different findings. The researcher used only the one institution for the sample due to having access to the data. The researcher is a full-time employee at the institution used in the current study. Additionally, the researcher is the program director of the physical activity program at the institution, and thus has a professional interest in demonstrating any benefits linked with course enrollment.

\section{Limitations}

This study only examined a limited number of freshmen fall cohorts at a single institution. The study only included students who began their enrollment during fall 
semesters. It is unknown if the data set was representative of all freshmen cohorts at the selected institution over an extended period or just illustrative for the specific years of the study. Thus, a limitation of the study was the omission of students who initiated enrollment during the spring and summer semesters. Additionally, a limitation of the study was that it did not include consideration of specific retention initiatives used at the institution, nor did it examine the impact of academic advising. Previous studies on student retention have included a wide range of variables. Due to the considerable number of variables, it was not conceivable to include all previously examined variables in the present study. While the findings from this study are useful and can provide insight on the administrative decision-making process at the included institution, the results may not be applicable to other institutions. It is very possible the findings of the study resulted from the specific attributes of the participants as well as the academic culture at the included institution. An additional limitation of the study was the use of a pre-existing data set, which prevented the researcher from acquiring additional information from the participants. Each freshman cohort has its own unique make-up. These distinguishing characteristics can vary from year to year, thus making it difficult to make accurate comparisons from one cohort to the next.

\section{Operational Definitions}

ACT Test: A standardized nationally normed test used by higher education institutions to determine college readiness of applicants. Scores range from one to 36 , with 36 being the highest possible score. Students are evaluated and given a score ranging from one to 36 on four different content areas including English, Math, Reading and Science. A composite ACT score is reported, as an average of these four tests (ACT, 2018). 
Basic Instruction Program (BIP): Physical education courses offered at higher education institutions. The term can also be used interchangeably with activity program. The structure varies between institutions with some being offered for credit, while others have no credit associated. At some schools, these courses are part of the general education course requirement, while most of the institutions now offer these courses as electives and not part of a degree requirement (Evaul \& Hilsendager, 1993).

Cumulative GPA: The cumulative GPA is the grade point average of all grades a student has secured during their academic pursuits. For the purposes of this study, the cumulative GPA at the end of the first-year will be utilized.

Campus recreation: Includes programs and services designed to address the health, wellness, recreation, social, and entertainment needs of the students. Intramural sports are an example of one program organized and run by campus recreation departments (Forrester, 2014).

First-time student: A student who enters a higher education institution for his/her first educational experience.

First-year student: A student who enrolls into higher education institution as a firsttime, full-time student.

Freshman: The term is used interchangeably with first-year student. Higher education institutions use this classification for students that are first-time degree seekers with less than 30 hours of credit (University of Louisville, 2018).

Grade point average (GPA): A number representing the average of the accumulated earned grades over a specific time. GPA is often reported on a semester or term basis. 
High school GPA: The cumulative GPA of the student at the completion of his/her high school enrollment.

Moderate physical activity: Any physical activity that uses three to six times more energy than that expended at rest (Pate et al., 1995).

Need based financial aid: Federal student financial aid based on the assets and income of the student and their family.

Persistence: The process of a student remaining enrolled at the same institution from semester to semester.

Physical activity: "Any bodily movement produced by skeletal muscles resulting in energy expenditure" (Casperson, Powell, \& Christenson, 1985, p. 126).

Second-year student: Students that began as first-time, full-time freshmen that persist to the second year of continuous enrollment. Second year enrollment is based on year of enrollment and not the number of credit hours completed. While most second year students would also be classified as a sophomore, some students could be starting their second-year at the institution with less than the 30 credits required to be classified a sophomore (University of Louisville, 2018).

Sophomores: This term is used interchangeably with second-year student. For this study, the term is used to describe first-time, full-time freshmen students who continued to their second year of enrollment at the same institution with greater than 30 credit hours but fewer than 60 credit hours (University of Louisville, 2018).

Student entry characteristics: The distinguishing characteristics and identifiable attributes of the student at the time of enrollment to the institution (Astin, 1993a). Student retention: For the purposes of this study, a student was classified as being 
retained if $\mathrm{s} / \mathrm{he}$ returned for the next fall semester following the previous fall semester enrollment. The university providing the data for the sample used the description for student retention in its university reports. 


\section{CHAPTER II}

\section{LITERATURE REVIEW}

The intent of this review is to provide the reader with an understanding of existing literature relevant to the presence physical education have at college and university campuses. The discipline of physical education has been a mainstay at higher education institutions in some capacity for nearly the last 200 years. Moore and Trekell (1981) found structured training programs in physical education began in the $1820 \mathrm{~s}$. After first providing a brief historical overview of the presence of physical education in the higher education, setting the review includes a discussion of the benefits associated with physical activity participation. Finally, this review concludes with a discussion of the literature pertaining to the study of student retention at the higher education level.

\section{History of Basic Instruction Programs}

A majority of college campuses offer a physical activity program (PAP) also referred to as a basic instruction program (BIP) or general education program (Fornia, 1959; Hensley, 2000; Trimble \& Hensley, 1984). The following section will provide an overview of how the dynamic of physical education has evolved in the higher education landscape. Just as the discipline of physical education experienced substantial changes in the K-12 landscape, universities have changed substantially over the last century in both structure and availability of physical education. Historically, basic instruction programs 
(BIPs) have offered a wide array of course offerings, which has increased the number of students enrolling in BIP courses for elective purposes (Miller, Dowell, and Pender, 1989). Two prominent goals of BIP's are to (a) have students become interested in participating in physical activity throughout their lifetime and (b) promote physical activity participation and healthy lifestyle choices (Miller et al., 1989). College students' exposure to physical education is often limited to their enrollment in BIP courses (Trimble \& Hensley, 1984). Davis (1993) explained university BIP's should be viewed as an essential component of the general education model, as they provide a setting for students to be educated physically, thus allowing for both mind and body development. Some higher education faculty from disciplines not grounded in movement theory, however, view physical education as nonessential and thus an unnecessary degree program with course offerings having no perceived value (Davis, 1993).

The National Association of Sport and Physical Education (NASPE) and the College and University Physical Education Council (CUPEC) adopted a unified stance in promoting the presence of BIP's at higher education institutions in the United States.

The two organizations advocated for the presence of a BIP at colleges and universities to address the growing health issues found in this nation (NASPE, 2007). Evaul and Hilsendager (1993) explained BIPs often become the likeness of higher education physical education programs by university officials and faculty from non-physical education disciplines because of the substantial number of students serviced by the program. As a result, it is imperative the campus community views university BIP's favorably (Evaul \& Hilsendager, 1993). 
Lumpkin and Jenkins (1993) explained how the main goal of BIPs on university campuses prior to the twentieth century was for the enrolled students to notice health gains. As an extension to the work of Lumpkin and Jenkins (1993), Johnson and Deshpande (2000) explained BIPs lead to physical development in college students. Johnson and Deshpande (2000) further stated a goal of these programs was to instill an interest in physical and sports activities during the college years, which students would continue after leaving campus. Each passing decade saw changes to both the structure and goals of the BIP. The original purpose of offering BIP courses to promote student health remains one of the reasons for offering BIP courses today. In addition, to health gains, BIP courses often create student interest in physical activity for an entire lifetime (Johnson \& Deshpande, 2000).

The programs originated prior to the twentieth century and have operated on college and university campuses in some capacity since their inception. Initially, the goal of these programs was to increase the overall health of students and enhance the academic quality of the student work. Throughout various historical periods the mission of these programs changed to include components such as educational objectives, competitive aspects, basic skill instruction, enjoyment/social purposes, and having gone full circle, currently comprises both health benefits and the development of life-long involvement in physical activities (Lumpkin \& Jenkins, 1993). In fact, researchers have found the majority of BIP course offerings fall under the classification of lifetime sports and fitness-based classes (Boyce, Lehr, \& Baumgartner, 1986; Oxendine, 1972; Oxendine \& Roberts, 1978). 
McCristal and Miller (1939) were the first to conduct research to determine the status of physical education requirements at higher education institutions. The findings of their work showed institutions of higher learning in the United States in the 1920s and 1930s were requiring $97 \%$ of the entire student body to complete physical education courses as a graduation requirement (McCristal \& Miller, 1939). Greene continued this line of research in 1955 , conducting a study to determine the extent universities included physical education courses as graduation requirements. Additionally, Greene looked at the number of institutions awarding academic credit for enrollment in physical education courses to see if the course factored into the student's GPA. The study included 253 institutions from the North Central Association of Colleges and Secondary Schools in nineteen different US states (Greene, 1955).

The data indicated $94.08 \%$ of the reporting institutions mandated physical education as a graduation requirement, while $75.88 \%$ assigned college credit to their service courses in physical education. Sixty-five percent of the institutions included physical education course grades in student GPA calculations. Finally, $56.13 \%$ of the institutions required four semester hours of physical education for graduation requirements (Greene, 1955). This study demonstrated the significance once placed on physical education being a component of the education process for the entire university student body. At the time of Greene's published work, including physical education as a graduation requirement was clearly the norm.

Six years later, Oxendine (1961) administered a similar survey to 265 chairs of physical education departments at higher education institutions in the US to determine the landscape of physical education programs. Specifically, the survey examined the 
requirements and typical practices of physical education service programs at US universities during the 1960-1961 academic year. Eighty-four percent of the participating institutions mandated physical education for all students as a graduation requirement. Of the institutions with physical education requirements, $68 \%$ required students to complete two years of physical education and $76 \%$ of the schools requiring physical education granted academic credit for the work completed. Additionally, there was no correlation between institutional size and the school mandating physical education as a degree requirement. It is important to note the recognizable decrease in the percentages, when comparing the Greene study in 1955 with the Oxendine study in 1961. This article demonstrated higher education institutions still placed a high degree of significance in physical education being a part of the degree requirements, but at decreased levels from the 1955 study conducted by Greene.

Oxendine and Roberts (1978) were the next researchers to examine the status of physical education as a requirement on university campuses. The sample was comprised of 667 chairs of physical education departments from universities across all geographical regions of the country. The data indicated $94 \%$ of the responding institutions offered physical education courses for all students, including those not majoring in physical education. The findings showed $57 \%$ of the institutions had physical education as a graduation requirement, with just over half of the reporting schools requiring one year of enrollment in physical education courses. Eighty-nine percent of the reporting institutions awarded academic credit. Finally, the participating chairs at institutions where physical education was not a degree requirement estimated that more than $33 \%$ of the student body enrolled in such courses. These findings documented the widespread 
practice of physical education being a component of the curriculum at higher education institutions, but again showed the pattern of significance decreasing as compared to the 1955 work by Greene.

Next, Trimble and Hensley (1984) conducted a study with 606 chairs of physical education departments to determine the status of BIPs on US campuses. The sample consisted of public and private schools from across the entire country. The analyzed data showed $94 \%$ of the responding schools offered BIP courses for non-physical education majors. Additionally, $60 \%$ of respondents reported enrollment in at least one BIP course offering was a graduation requirement. Eighty-eight percent of the schools awarded academic credit for enrollment in BIP courses. The data also showed $44 \%$ of the schools that required completion of a BIP course had over $20 \%$ of the student body enroll in more than the minimum BIP credit hour requirement (Trimble \& Hensley, 1984).

Miller et al. (1989) conducted a study to evaluate the status of BIPs at four-year higher education institutions with enrollments exceeding 5,000 students. The sample included 251 institutions with a BIP program and was representative of all geographical regions in the US. The findings showed $92 \%$ of the schools offered a BIP and $45 \%$ of the participating institutions had a physical education requirement for the general student who was not a physical education major (Miller et al., 1989). These findings demonstrated a decrease in the number of schools where physical education was included as a graduation requirement for all students from the previous studies.

In a follow-up study, Trimble and Hensley (1990) completed a review of the status and typical practices of physical education instruction programs at US higher education institutions. Chairs of physical education departments $(\mathrm{N}=682)$ at both public 
and private institutions completed the survey. The study findings showed $92 \%$ of the institutions offered physical education courses to the general student, either as a degree requirement or as an elective course offering. Of the participating institutions, $93 \%$, offered academic credit for the BIP courses (Trimble \& Hensley, 1990).

Most recently, Cardinal, Sorensen, and Cardinal (2012) conducted a study determining the present-day status of physical education graduation requirements at US higher education 4-year institutions. The researchers used a random sample of 354 institutions representing all geographical regions of the country. The data analysis showed $60.45 \%$ of the surveyed institutions did not have physical education as part of the graduation requirement for a baccalaureate degree (Cardinal et al., 2012). Thus, the higher education model of requiring physical education course(s) as a graduation requirement had gone from a high of $97 \%$ in the 1920 s and 1930 s to only $39.55 \%$ in 2010.

Physical education has had a presence on higher education campuses for over one hundred years, but during this period, the field has seen numerous changes. Historically, many higher education institutions offered physical education opportunities to their student body, even if there was no college major classified as physical education. Universities offered physical education course offerings referred to as basic instruction programs, physical activity programs, or part of the general education program. Even as recently as the early1960s, almost $90 \%$ of US higher education institutions required some component of physical education for graduation (Hensley, 2000). Unfortunately, for the field, the number of institutions requiring physical education for graduation quickly began to decrease across the country in the late 1960s and 1970s (Hensley, 2000). 
The decline continued over the 1980s and by 1998, the number of institutions requiring some form of physical education as a degree requirement was down to $63 \%$ (Hensley, 2000). The practice of requiring physical education for graduation had clearly shifted. This substantial decrease left the field of physical education on the defensive and attempting to find ways to demonstrate the program's worth in the US higher educational landscape (Hensley, 2000). It appears the field of physical education needs to find ways to promote the discipline more effectively. A logical way for physical educators to promote their field would be to promote the many gains associated with participation in physical activity. Thus, the next section of this literature review will provide an overview of benefits gained by participation in physical activity.

\section{Benefits of Physical Activity}

The previous section demonstrated how the status of physical education had changed in the US educational landscape through history. As documented, the composition of physical education in higher education has evolved to where more students enroll in physical education not as a degree requirement, but rather for elective purposes. The fact many university degree requirements do not include physical education courses necessitates the need to understand the personal benefits gained from enrollment in BIP courses. Next, this review will provide an overview of certain personal benefits gained from participation in physical activity. The first benefit discussed will be the physical benefits gained from participation in physical activity.

\section{Physical Benefits}

Participation in physical activity (PA) is critical to human health and wellness. Advanced technology, touting a more efficient life, often pulls individuals away from 
PA. As a result, people around the world are experiencing many health-related issues. The health consequences of inactivity are well documented (Daniels et al., 2005; Strauss \& Pollack, 2001). This section of the review includes a succinct discussion on the health consequences of inactivity. Additionally, this section contains the operational definitions for physical activity and moderate physical activity (MPA). Finally, this section will help frame the need for PA opportunities in educational settings.

Physical activity is "any bodily movement produced by skeletal muscles resulting in energy expenditure" (Casperson, Powell, \& Christenson, 1985, p. 126). The broad nature of the definition allows for a wide variety of activities to fall under the classification of PA. In addition to defining PA, it was necessary to quantify appropriate levels of PA. The Centers for Disease Control and Prevention (CDC) and the American College of Sports Medicine (ACSM) worked jointly in 1995 to establish the desired amount of time needed in participation of PA to produce health benefits. The two organizations determined a minimum of thirty minutes of daily MPA was essential to see health gains. MPA includes any activity that used three to six times more energy than those expended at rest (Pate et al., 1995).

Additionally, the U.S. Surgeon General's office expanded on the recommendations created by the CDC and the ACSM by suggesting the desired amount of PA fall between thirty and sixty minutes daily and occur nearly each day of the week (USDH, 1996). Furthermore, published research indicates school aged children should participate in a minimum of sixty minutes of MPA daily (Koplan, Liverman, \& Kraak, 2005; Malina, 1996). Even though the daily recommendations have been defined and reported by these various entities, confusion still exists on what types of activities 
constitute MPA as well as the recommended number of daily and weekly minutes of participation in MPA. This confusion, coupled with the fact many adolescents are having their PA opportunities greatly decreased, has resulted in an alarming trend.

Physical inactivity is a growing problem throughout the US and may be attributable to the decrease in PA opportunities in school settings. Physical inactivity leads to a variety of negative health related consequences, resulting in a dramatic increase in pediatric obesity (Daniels et al., 2005; Strauss \& Pollack, 2001). The increasing prevalence of pediatric obesity has many negative health consequences (Daniels et al., 2005; Strauss \& Pollack, 2001). The health landscape as well as the overall quality of health for youth in the US is drastically declining due in large part to the increased number of adolescents electing to adopt sedentary lifestyles and withdrawing from PA (Ogden, Flegal, Carroll, \& Johnson, 2002). This trend of removing PA opportunities in the school system creates an attitude that PA is not an integral component of the educational experience.

Additionally, Sparling (2003) explained the importance of college-aged students participating in physical education courses to effectively promote physical activity and address the ever-growing obesity epidemic in the U.S. Sparling further explained that there was a wonderful opportunity available across US higher education institutions to address the lack of physical activity participation by young adults. Sparling explained how beneficial, from a health perspective, it would be if more institutions would go back to earlier degree requirements, where physical education was typically a part of the general education curriculum and a graduation requirement for all students (Sparling, 2003). At this time, however, it appears more institutions are continuing to go further 
away from physical education being included as a degree requirement, except for those students majoring in select degrees grounded in the field of physical education. Unfortunately, it appears most university administrators overlook the positive gains associated with physical education and physical activity involvement, thus minimizing the potential health gains for the college-aged population (Sparling, 2003).

Ogden, Carroll, Kit, and Flegal (2014) examined the prevalence of this issue conducting a study to determine the status of obesity rates in the US. The researchers collected survey responses from 9,120 participants, using the 2011-2012 National Health and Nutrition Examination Survey (Ogden et al., 2014). Participants were classified as obese if their body mass index (BMI) was at or above the $95^{\text {th }}$ percentile and overweight if their BMI was between the $85^{\text {th }}$ and $95^{\text {th }}$ percentiles as defined by the CDC's BMI age specific charts (Kuczmarski et al., 2002). The overweight classification included 31.8\% of the participants in the age range of 2-19 and an additional $16.9 \%$ of the participants fell in the obese classification during the 2011-2012 data collection period (Ogden et al., 2014). Additionally, the researchers found $34.5 \%$ of the participants in the age range of 12-19 were overweight, while $20.5 \%$ were obese. Finally, the study results showed $34.9 \%$ of the adult participants were obese (Ogden et al., 2014).

The findings from the Ogden et al. (2014) study were consistent with an earlier research study Ogden, Carroll, Kit, and Flegal (2012) conducted to determine obesity rates in the U.S. The researchers used data collected using the 2009-2010 National Health and Nutrition Examination Survey from a sample of 4,111 participants ranging in age from birth through the age of nineteen. The study results for the participants ranging in age of 2-19 showed $29.8 \%$ were overweight and $16.9 \%$ were obese. Whereas, the 
results for the participants ranging in age of 12-19 showed 33.6\% were overweight and 18.4\% were obese (Ogden et al., 2012).

Early decisions to limit or remove oneself from PA often can lead to negative lifetime consequences. Overweight children are more likely to continue to age without adjusting their lack of activity and thus have a higher chance of maturing into obese adults (Ogden et al., 2002). Consequently, these ingrained attitudes resulted in a recognizable decrease in college-aged students participating in PA (Ogden et al., 2002). Physical education offerings, including BIPs, are often the last chance for individuals to develop a structured exercise and fitness routine before leaving the school setting (Leslie, Sparling, and Owen, 2001; Sparling \& Snow, 2002). Additional research demonstrated graduates from higher education institutions where physical education was a degree requirement were more likely to participate and live an active lifestyle post-graduation than graduates of schools lacking this requirement (Adams \& Brynteson, 1992; Brynteson \& Adams, 1993; Sparling \& Snow, 2002). Additionally, physical education offerings at the college level are often the last opportunity for individuals to receive education-based training dealing with exercise and fitness without having to pay at fitness centers or to employ specialized trainers (NASPE, 2007). There is a consistent negative correlation with age and participation in fitness. Participation levels in physical activity continue to decrease post high school and then decreases even further post college (Caspersen, Pereira, \& Curran, 2000; Sparling \& Snow, 2002).

To demonstrate the value and worth of BIP courses, Leenders et al. (2003) discussed the opportunity available to higher education institutions to promote healthy behaviors for students. More specifically, institutions can instill an interest in physical 
activity participation by promoting enrollment in BIP courses and structuring the courses in such a manner to either slow or prevent the occurrence of various health related disparities (Leenders et al., 2003). Previous research has shown enrollment in physical education activity courses provides a logical setting to educate college age students about lifestyle choices and health risk behaviors (Dale \& Corbin, 2000; Pearman et al., 1997).

Huang et al. (2003) administered a survey to a convenience sample of 736 University of Kansas students ranging in age from 18 to 27 . The participants completed a survey during the spring 2001 and spring 2002 academic semesters. The purpose of the study was to evaluate the activity and obesity levels of college students. The study findings showed $21.6 \%$ of the participants were overweight and $4.9 \%$ were obese, when using body mass index (BMI). The study found older students, those aged at least 20 years, had a greater likelihood to fall under the overweight classifications than the participants did aged 19 or younger (Huang et al., 2003). This demonstrates how it becomes more challenging to maintain a healthy weight through the aging process. Thus, the present study demonstrates the importance of higher education institutions offering interventions and programs to help curb this trend. A feasible way to get more students physically active is to promote physical education courses on university campuses. This section of the literature review demonstrated there are many physical benefits associated with participation in physical activity. The next section of the review will discuss how participation in physical activity is linked with mental health benefits.

\section{Mental Health Benefits}

The findings of decreased levels of PA in college-aged students are alarming. An effective coping mechanism for many individuals when confronted with stressful 
circumstances is participation in PA. The increased levels of stress brought on through their college experience compounds health issues for college students (Sax, 1997). Research has shown many stressful experiences occur during the college years, with the most academic stress coinciding with periods where exams and finals happen. Conflicting time constraints are a challenge most college students must deal with (Abouserie, 1994). In addition to academic stressors, the financial costs associated with attending school greatly impact college students (Goodman, 1993; LeRoy, 1987). Avery and Lumpkin (1987) surveyed 2,559 University of North Carolina at Chapel Hill students enrolled in physical education courses. The students completed a 24-item survey, which assessed their perceived enrollment gains in a physical education course. The results showed the most significant reasons for enrollment in the physical education courses were to have fun, participate in frequent exercise, and maintain overall good health. Additionally, Avery and Lumpkin (1987) completed a factor analysis on the possible motives, which resulted in four underlying factors comprising of self-worth, physiological parameters, social affiliation, and lifetime use. These four factors accounted for $60.6 \%$ of the total variance, with the greatest explained variance being an increase in the student's self-worth. These findings demonstrate participation in physical education courses offer more than an outlet for enjoyable experiences but are also a means to increase self-esteem (Avery \& Lumpkin, 1987).

Ragheb and McKinney (1993) examined how leisure activities and campus recreation impacted students perceived academic stress levels. The sample consisted of 343 students from one community college and 2 universities from the same U.S. city, and included freshmen through graduate students. Seven items from the Occupational Stress 
Inventory created by Osipow and Spokane (1987) evaluated academic stress.

Additionally, Beard and Ragheb's (1983) Leisure Satisfaction Measurement evaluated leisure satisfaction. The study findings showed the greater the frequency of participation in recreational activities, the less likely the students displayed academic stress.

Additionally, the greater the reported level of satisfaction with leisure activities resulted in lower levels of perceived stress (Ragheb \& McKinney, 1993).

Additionally, Savage (1998) examined the motives of college students enrolling in BIP courses for elective credit by administering a survey to 795 enrolled students in the physical education skills program at Purdue University. The study showed the top four reasons students enrolled in BIP courses were to achieve physical success, increase their feeling of self-worth, enjoyment, and improvement in self-confidence levels. The identified motives of enrollment demonstrated college students longed to participate in activities they found enjoyable and improve their emotional state. Additionally, the study showed $43 \%$ of the participating students enrolled in a second physical education skills program course as an elective, which demonstrates the continued appeal of BIP courses (Savage, 1998).

Misra and McKean (2000) examined the relationship among academic stress, anxiety, and leisure satisfaction. The researchers administered a written survey containing four previously validated questionnaires to 249 undergraduate students at a Midwestern University. The findings showed the female respondents gained physiological benefits from their involvement in leisure activities, in turn decreasing their levels of academic stress in the categories of change and frustration (Misra \& McKean, 2000). The male respondents did not demonstrate an association between participation in 
leisure activities and decreased stress levels. Additionally, the study found leisure satisfaction helped reduce both male and female reaction to stress, with females benefiting to a greater level (Misra \& McKean, 2000). Fleshner (2000) found participation in PA improved blood circulation throughout the body, including the brain, which may cause lower levels of stress, act as a mood enhancer, and result in increased levels of academic success. Thus, the findings from Misra and McKean (2000) and Fleshner (2000) demonstrate the importance of leisure activities in the overall mental health of college students.

The findings of Misra and McKean (2000) demonstrated the importance of participating in leisure activities due to the health gains. It is important to note wellness extends beyond physical health and includes mental health as well. As previously discussed, the college experience can be quite intimidating and stressful. In an effort to document the vast nature of this problem, the American College Health Association published an executive summary in 2013 on findings from a National College Health Assessment. The sample for the study consisted of 96,611 undergraduates at 153 higher education institutions. A portion of the study specifically asked questions dealing with the mental health of the students within the last twelve months (American College Health Association Executive Summary, 2013). The findings demonstrated the extreme amounts of pressure confronting students today. Alarmingly, $46.5 \%$ of the respondents felt life was hopeless, $84.3 \%$ felt overwhelmed by all the things they had to complete, $79.1 \%$ felt exhaustion that was caused by not participating in PA, $57 \%$ felt very lonely, $60.5 \%$ felt very sad, and $51.3 \%$ felt overwhelming levels of anxiety. Additionally, $12.4 \%$ of the respondents stated a healthcare provider had treated them for anxiety and $10.7 \%$ for 
depression (American College Health Association Executive Summary, 2013) had treated them. These findings help demonstrate that stress clearly is an issue for college students and institutions must provide appropriate opportunities for alleviating stress.

Collins, Valerius, King, and Graham (2001) conducted a study to determine if a relationship existed between college students' self-esteem and their frequency of participation in PA. Participants discussed their perceived importance of participating in leisure, sport, or recreation activities. Both full-time and part-time enrolled students $(\mathrm{N}=198)$ at a large public institution located thirty miles from a large metropolitan area completed the survey. The researchers examined the self-esteem scores across the levels of frequency and the levels of importance for leisure, sport, and recreation participation. The subjects who had the lowest levels of leisure, sport, and recreation participation also had the lowest self-esteem scores. As sport and recreation participation increased, so too did respondent self-esteem scores. In fact, the participants who participated in the most recreation settings also reported the highest self-esteem scores (Collins et al., 2001). These findings demonstrate participation in sport and recreation activities can positively impact overall emotional wellness and an individual who has elevated levels of selfesteem will be able to better cope with the challenges and stress encountered in an academic setting.

In addition to the health benefits, participating in PA also can produce significant social benefits. This is an extremely important finding, as previous student retention research demonstrated students had been retained a greater rate when they had established social network at the school. For example, Spady (1971) explained that social integration and the academic abilities of the student were critical factors in students 
staying enrolled at the institution. The structure of BIP courses places students on teams and/or groups, which allows students to communicate and interact with one another in a low stress academic environment. Thus, the next section of the literature review discusses the social benefits gained from physical activity.

\section{Social Benefits}

Research has also identified social benefits for college students related to physical activity. In an early study, Lamont (2010) sought to determine if a correlation existed between the centralized campus recreational sport facilities and undergraduate student retention at 30 different four-year U.S. institutions. First and second year students used the recreational facilities at a rate nearly three times greater than upper level students (Lamont, 2010). Lamont determined that new students had a greater need to establish a peer group and socially integrate with others. In a different study, Bryant and Bradley (1993) found participation in recreational sports programs increased social diversity levels in students. Additionally, the researchers noticed recreation sports programs typically attracted the largest number of students as compared with other student activities offered on campus. Finally, participation in recreational sports programs positively impacted student development. (Bryant \& Bradley, 1993).

Artinger et al. (2006) conducted a study to examine if any social benefits existed because of participating in intramural sports activities. The sample included 349 undergraduate students at a mid-sized US university. The researchers distributed a survey, which included questions discussing possible social benefits of intramural sports participation as well as demographic information. Specifically, the social benefits questions examined university integration, personal social benefits, cultural social 
benefits, and social group bonding. The findings showed students living on campus scored significantly higher in several areas as compared to those living off campus. The study showed no significant correlation between the number of sport activities completed by the student and their living situation. Participation in intramural sports improved the students' ability to work with a diverse group of students. Finally, first-year students demonstrated significantly higher social benefits from participating in intramural sports compared to fourth-year students (Artinger et al., 2006). This finding shows the importance recreational and intramural sports programs have on students new to the campus experience.

Melendez (2006) collected data from 207 undergraduate students enrolled at four universities in the U.S. The sample was comprised of first and second year studentathletes and non-athlete students, who completed the Student Adaption to College Questionnaire developed by Baker and Siryk in 1989. The student-athletes demonstrated significantly higher levels on a feeling of institutional attachment and academic adjustment. Thus, university student-athletes displayed an easier academic transition and felt more a part of the social framework of the institution (Melendez, 2006). These findings are consistent with Astin (1993a) who found student-athletes had greater levels of student satisfaction for their college experience and developed greater levels of interpersonal skills compared to non-athletes. Similarly, previous research has shown individuals who had participated in high school athletics adjusted to university life more effectively and had higher levels of self-esteem (Kiger \& Lorentzen, 1988; Marsh \& Kleitman, 2003). Students attending college experience numerous social benefits from 
participating in PA. Beyond this, these same students also experience academic benefits as well.

\section{Academic Benefits}

The previous section discussed positive results associated with physical activity as well as the negative consequences associated with physical inactivity. Additionally, the literature demonstrated how enrollment in BIP courses often established positive health habits in the college student population, thus increasing the likelihood of them continuing these practices post-graduation and/or during their association with the institution. Physical activity involvement and enrollment in physical education courses, such as BIP courses, offer more benefits than the previously discussed health gains. The next section of this review will provide an overview of how the literature has shown a positive relationship between involvement in physical activity and academic gains. Next, the literature review includes subsections on the areas of cognitive functions, standardized test assessments, core content assessments, and student health status.

Dwyer et al. (1983) analyzed the influence a daily physical activity program had on the academic success of ten-year-old students in South Australia. The researchers established two groups, with one group participating in an endurance fitness program for one hour and fifteen minutes per day for a fourteen-week period, while the second group received regular classroom instruction. The time spent completing the endurance fitness program resulted in the students receiving less daily academic instructional time than the other participating group. Although the students completing the endurance fitness program received less academic instruction, the results showed no evidence of a decrease in academic performance (Dwyer et al., 1983). 
Dwyer et al. (1983) found decreased academic instructional time to allow for participation in physical activity did not negatively affect academic success. Shephard (1997) found no negative academic impact on student success, because of more time allocated to physical activity participation in the school setting. A statistically significant correlation existed between physical activity participation in adolescents and academic success (Fejgin, 2001; Pate et al., 1996). All these findings show participation in physical activity and exercise does not hinder academic gains and thus refutes the common misconception in academia that instructional time allocated to physical education negatively impedes academic performance.

Shephard (1996) presented findings from data collected in both an urban and rural school in Quebec. The study examined if additional physical activity participation for children enrolled in grades one through six, impacted academic success as measured by grades recorded on report cards. The researcher placed students in either a control group or an experimental group, which consisted of students receiving an additional one hour per day of physical activity. The study included the analysis of 2,282 report cards. Students in the experimental group significantly scored better grades than the control group in grades 2, 3, 5, and 6. The MANOVA results demonstrated a significant interaction between gender and the physical activity experimental group, as females who participated in the additional daily physical activity demonstrated higher academic scores than their male peers in the experimental group (Shephard, 1996). Thus, this study demonstrated physical activity participation aids in academic success instead of being a deterrent. Trost (2007) found no negative consequences for students becoming more physically active in the school setting. In fact, in many instances the active students 
scored more favorably than their less active peers did. Thus, Trost (2007) concluded the practice of school districts reducing and/or eliminating physical education from the curriculum in an attempt to increase instructional time within the classroom was an unsuccessful intervention. Additionally, Trudeau and Shephard (2008) completed a review of the literature on the relationship between physical activity in the school setting and academic performance. The articles they reviewed revealed a positive association between involvement in physical activity and student academic success, even though PA participation decreased the amount of instructional time offered for the core academic subjects such as mathematics, reading, and science (Trudeau \& Shephard, 2008).

The Centers for Disease Control and Prevention (CDC) conducted a review of 50 research studies in 2010. The articles reviewed by the CDC included research studies whose purpose was to examine if there was an association between school PA exposure and student academic success. The studies included in the review analyzed the impact of PA in physical education course offerings, recess, PA conducted by the classroom teacher and extracurricular PA at the school setting (CDC, 2010). The examination revealed a possible 251 associations between PA and academic performance. The CDC determined $50.5 \%$ of the possible associations in the studies showed a positive link between PA levels of students and their overall academic performance. Additionally, only $1.5 \%$ of the possible associations had a negative link, while $48 \%$ of the possible associations were neutral (CDC, 2010). These findings demonstrate in many instances PA has positive associations with academic gains and helps to support the notion of negative associations with involvement in PA and academic gains. Thus, due to the extremely limited cases of identified negative associations between PA and academic success, it seems logical for 
schools, including higher education institutions, to place more value on PA opportunities. In addition to the academic gains associated with involvement in physical activity, research has shown an association between physical activities and increased cognitive functioning. Thus, the next section of this review will specifically examine how physical activity impacts cognitive functioning.

\section{Cognitive Functions}

A study conducted by Li (1995) examined the differences in intelligence levels among obese and average weight children and found the individuals classified as overweight displayed lower IQ test scores. Additionally, overweight individuals demonstrated lower levels of academic achievement (Taras \& Potts-Datema, 2005). Participation in exercise by children increased overall mental functioning, aiding in their overall cognitive development (Davis et al., 2007). The influx of obesity levels in adolescents may have a negative relationship with academic performance in US schools (Allegrante, 2004; Coe, Pivarnik, Womack, Reeves, \& Malina, 2006; Li, 1995; Taras \& Potts-Datema, 2005).

Caterino and Polak (1999) examined the impact participation in physical activity had on concentration levels of elementary students. The total sample $(n=177)$ consisted of 54 second grade students, 71 third grade students, and 52 fourth grade students. The researchers randomly assigned participants to either the group participating in classroom activity or the group participating in physical activity. The researchers provided the students in the classroom activity group with practice samples and directions, and then both groups of students completed a timed test of concentration. Before the physical

activity group completed the timed test of concentration, they first completed 15 minutes 
of stretching and aerobic walking. The participants from the second and third grade physical activity group scored as well on the concentration tests as the classroom group, with no significant differences between the classroom activity group and the physical education group. The fourth-grade participants who were a part of the physical activity group, however, had significantly higher concentration scores than the participants in the classroom activity group (Caterino \& Polak, 1999). These findings demonstrate physical activity participation does not hinder academic performance and with certain populations this participation significantly improving academic success.

Tomporowski (2003) reviewed 45 different research studies, which examined the impact exercise had on cognitive performance in adults. The findings demonstrated exposure to consistent exercise sessions helped improve the overall cognitive performance of the study participants. The studies reviewed showed exercise participation positively influenced both the speed and accuracy of cognition (Tomporowski, 2003). Children who participated in exercise training and PA exhibited a positive correlation with increased cognition (Carlson, 2005; Nelson, 1999; Sibley \& Etnier, 2003). PA seems to have positive cognitive benefits in children, since their central nervous system is still in the process of being developed (Cabeza, 2001). Additionally, participation in PA assisted the cognitive processing abilities of older adults (Colcombe \& Kramer, 2003). This finding was consistent with previously conducted research, which demonstrated the positive cognitive gains across the lifespan associated in participation in PA.

Kramer, Erickson, and Colcombe (2006) found participation in physical activity helped with the effectiveness and maintenance of the cognitive functioning process in 
older adults. Additionally, Rovio et al. (2005) determined participation in physical activity helped decrease the likelihood of Alzheimer's disease.

Vaynman and Gomez-Pinilla (2006) explained research conducted with animal subjects has shown for some time the association between exercise and neuronal growth. Exercise in animal subjects has positively affected the neural systems of the body linked to memory and the learning process. Thus, there is a positive correlation between participation in physical activity and cognitive functioning in the brain (Vaynman \& Gomez-Pinilla, 2006). Due to advancements in the neurological imaging process, similar research findings have started occurring in human subjects with findings showing exercise helps improve overall brain functioning (Booth \& Lees, 2006; Hillman, Erickson, \& Kramer, 2008). Additionally, research has shown a correlation between higher fitness levels and greater amounts of brain matter, which aids in overall brain performance (Colcombe et al., 2004; Colcombe et al., 2006).

Davis et al. (2007) examined the impact aerobic exercise training had on children aged 7-11 (N=94) from elementary schools in Augusta, GA. The children were placed in cohorts consisting of a low dose exercise intervention (20 minutes of aerobic exercise per session; high does exercise intervention - 40 minutes), or a control group that did not participate in any exercise. The intensity of exercise did not vary between the two groups, only the amount of time spent exercising. The exercise interventions occurred five days per week for a total of 15 weeks. The participants' cognitive levels were assessed pre and post intervention using a Cognitive Assessment System (CAS) standardized test. The researchers used analysis of variance and found a significant difference in the CAS planning scale. Students in the high exercise cohort demonstrated 
significantly higher planning scores than those in the control group (Davis et al., 2007). These findings show positive cognitive outcomes can result from participating in physical fitness and exercise and thus helps document the value of physical education in an academic setting.

Hillman, Buck, Themanson, Pontifex, and Castelli (2009) conducted a study on 38 adolescents ranging in age between 8 and 11 to determine if aerobic fitness levels influenced executive control. Executive control refers to the functioning of the brain dealing with perception and memory (Meyer \& Kieras, 1997). The participants first completed an aerobic capacity test as pre-assessment. Next, the researchers divided the participants into two equal size groups - higher-fit and lower-fit individuals. The participants completed a flanker test, which evaluated executive control functioning. The study findings demonstrated the higher-fit participants scored more favorably on the flanker test as compared to their lower-fit peers (Hillman et al., 2009). Thus, the findings demonstrated higher cognitive functioning of the brain resulted from involvement in physical fitness. An increase of blood flow to the brain following physical activity resulted in improvement in cognitive functioning (Shephard, 1997). Lindner (1999) stated physical activity participation tends to increase an individual's energy levels, which in turn could improve overall cognitive functioning. This section of the literature review showed how participation in physical activity can improve overall cognitive functioning. Individuals with increased levels of cognitive function may have a greater likelihood to score favorably on standardized tests. Thus, the next section of this review will demonstrate how physical activity participation impacts standardized test performance. 


\section{Standardized Test Assessment}

A research study conducted in 2001 by the California Department of Education examined if a relationship existed between the assessed physical fitness levels of students and their academic achievement. The research study used FitnessGram scores to determine fitness levels and Stanford Achievement Test scores to determine academic achievement. The sample consisted of 353,000 fifth graders, 322,000 seventh graders, and 279,000 ninth graders. The study findings showed a positive correlation between physical fitness levels of all three-grade levels and their Stanford Achievement Test scores. The students with higher fitness levels also scored higher on the achievement test (California Department of Education, 2001). Thus, the research study demonstrated the importance of physical fitness on overall academic success.

Wilkins et al. (2003) collected data from 547 elementary school principals in Virginia to determine if the amount of physical education instructional time offered had any association with the school-level passing rates on the Virginia Standards of Learning assessment. The data for the study consisted of surveys completed by principals, student information, and the official Virginia Department of Education passing rates for the mathematics, English, science, and social exams. The researchers used the passing rates for the four content areas to measure school achievement. The researchers used multiple regression analysis and after controlling for demographics, the results showed no statistically significant correlation between the amount of time allocated to physical education instruction by a specialist and school achievement. Although not statistically significant, the results also did not show an inverse relationship. The allocation of more 
time to physical education resulted in less instructional time for the core content areas, yet there was no negative impact on school achievement (Wilkins et al., 2003).

Grissom (2005) conducted a study to determine if a relationship existed between student physical fitness levels and academic achievement. The researcher used the FitnessGram assessment tool to determine the student's fitness levels. Additionally, the researcher classified the student's academic achievement levels based on their performance on the Stanford Achievement Test. The sample consisted of 884,715 students from California in grades five, seven and nine. The study results showed a significant positive correlation between the fitness levels of the students and their academic success. The data consistently showed as the subjects' fitness levels improved so did their performance on the Stanford Achievement Test. While significant for both boys and girls, the positive relationship was larger and showed greater strength for the female study participants. Additionally, students with higher (SES) demonstrated a stronger relationship between fitness levels and academic successes as compared with their peers in lower SES levels (Grissom, 2005).

Coe et al. (2006) conducted a study with 214 sixth grade students to determine the impact physical education instruction and involvement in physical activity had on the student's academic success. The researchers analyzed academic success by the students' grades in the core coursework as well as their score on a standardized test. The researchers split the sample so half of the study participants completed a physical education class during the fall semester and the other half during the spring semester. The semester in which students enrolled in the physical education course showed no effect on the grades of the students. Students participated in 19 minutes of moderate and 
vigorous physical activity (MVPA) per physical education class session, which did not meet the recommended daily guidelines as stated in Healthy People 2010. Some of the students, however, met MVPA guidelines outside of the physical education classroom. Thus, the students who met or surpassed the Healthy People 2010 guidelines displayed higher levels of academic success as compared to their less active peers in both the fall semester $(p=.006)$ and spring semester $(p=.049)$ (Coe et al., 2006). The study findings demonstrate the importance of physical activity, especially at the moderate and vigorous levels.

Ahamed et al. (2007) studied 287 fourth and fifth grade students in British Columbia to determine if participation in daily physical activity affected student academic success. The researchers placed the participants into two groups consisting of usual practice and intervention. Both groups received their regular physical education instruction, but the intervention group participated in an additional 15 minutes of daily PA within the regular academic classroom setting. The researchers used the Canadian Achievement Test to evaluate the students' academic success. The participants in the usual practice group had substantially higher baseline scores on the Canadian Achievement Test than those in the intervention group. There was no statistically significant difference between the attained scores on the Canadian Achievement Test between the two groups one-year post intervention (Ahamed et al., 2007). Thus, the study findings demonstrated time dedicated to physical activity did not hinder academic success.

Tremarche et al. (2007) conducted a study analyzing data from 311 fourth-grade students residing in two different Massachusetts communities to determine if physical 
education instruction influenced academic achievement, as defined by standardized scores on the Massachusetts Comprehensive Assessment System (MCAS). The amount of physical education instructional time at the two schools varied. The findings showed the students who received more physical education instructional time scored significantly higher on the English and language arts portion of the MCAS assessment. There were no significant differences between the two groups on the mathematics portion of the MCAS assessment (Tremarche et al., 2007). These findings demonstrated the importance of physical education instruction in the school setting. Additionally, the results showed how physical education instruction could lead to academic gains.

Castelli, Hillman, Buck, and Erwin (2007) examined if a relationship existed between the physical fitness levels of elementary students and their assessed academic achievement levels. The sample was comprised of 259 third and fifth graders in four different elementary schools in one Illinois school district. The researchers analyzed FitnessGram scores to determine student's fitness levels and examined student performance in two content areas of the Illinois Standards Achievement Test to determine academic achievement. A positive correlation existed between achievement test scores and three components of the FitnessGram (PACER, push-ups, and curl-up tests). Additionally, the study found the body mass index (BMI) levels of the participants to be negatively correlated with the academic achievement scores (Castelli et al., 2007). Thus, the study results demonstrate physical fitness levels impact overall academic success in elementary aged students.

A study conducted by Wittberg et al. (2009) examined if an association existed between socioeconomic status (SES), gender, body mass index (BMI), and FitnessGram 
levels with academic performance. The FitnessGram evaluated the students' levels of aerobic capacity, abdominal strength, upper body strength, flexibility, and trunk lift. The researchers used the student's levels of mathematics, science, social studies, and language arts to determine overall academic performance. The sample consisted of 741 fifth grade students in a rural school district in West Virginia. The researchers used one-way analysis of variance to determine if a statistical difference existed between the study participants in the Healthy Fitness Zone (HFZ) on the FitnessGram and the Needs Improvement (NI) classification. The results showed all four academic achievement tests were significantly higher in the subjects in the HFZ for both aerobic capacity and abdominal strength as compared to the NI group. Children in the HFZ group for upper body strength and flexibility produced significantly greater math scores than those in the NI group. Additionally, children in the HFZ group for flexibility had significantly higher science scores than the NI group. No statistical difference existed between academic performance and the trunk lift assessment. This study demonstrates a positive correlation between physical fitness and student academic achievement (Wittberg et al., 2009). Thus, these results help document the usefulness of physical education in the school setting.

Chomitz et al. (2009) conducted a study to determine if a relationship existed between student physical fitness levels and their academic achievement levels in a publicschool system in urban Massachusetts. Passing scores from the Massachusetts Comprehensive Assessment System (MCAS) content exams determined academic achievement. The number of physical fitness tests passed by the students enrolled in physical education classes determined physical fitness levels. The sample consisted of 
1,841 students from grades four, six, seven, and eight. The study results showed that as students passed more physical fitness exams they were also more likely to pass the mathematics and English portions of the MCAS (Chomitz et al., 2009). In this study, data from a large sample size across four different grade levels indicated a positively significant correlation between physical activity levels and academic success.

Eveland-Sayeers, Farley, Fuller, Morgan, and Caputo (2009) conducted a study with elementary school students $(\mathrm{N}=134)$ from two school districts in Tennessee to determine if a relationship existed between the students' assessed fitness levels and academic achievement. The sample was comprised of students in grades three, four, and five. Physical fitness levels were determined using BMI, curl-up, sit-and-reach, and onemile run scores from the students in the sample. The number of questions answered correctly on the mathematics and language arts sections of the TerraNova achievement test determined academic achievement. The researchers found a statistically significant negative correlation $(r=-.28)$ between the students' one-mile times and their evaluated mathematics scores. The students who completed the mile run faster also scored higher on the mathematics portion of the exam. Additionally, the study findings showed a significant positive correlation $(r=.20)$ between the students' muscular strength, determined by curl-up and sit-and-reach scores, and mathematics scores. When the sample was analyzed based on gender, the researchers found a significant negative relationship existed among the females' one mile run scores and language arts scores ( $r=-$ .31) and mathematics scores ( $r=-.36)$ (Eveland-Sayers et al., 2009). Thus, the data indicated greater levels of physical fitness were associated in females with higher 
academic scores, demonstrating the academic influence of physical education and physical fitness.

Welk et al. (2010) conducted a study to determine if an association existed between physical fitness levels and academic performance in adolescents. The researchers examined data from 19,948 elementary students, 8,916 middle school students, and 1,373 high school students, for a total sample size of 36,835 students. The sample comprised of data from 6,222 various schools in 1,052 various school districts in Texas. The FitnessGram test classified physical fitness levels. The number of students who met the age appropriate standards on the Texas Assessment of Knowledge and Skills (TAKS) assessment determined academic performance. The researchers used a mixedmodel analysis and controlled for the potential variables of school size, minority enrollment, and differences in SES. The study found a low to moderate correlation between the students' TAKS assessment scores and their cardiovascular fitness levels ( $r=.41)$. Additionally, the study found a smaller correlation between the students' BMI levels and their TAKS assessment scores ( $r=.24)$ (Welk et al., 2010).

Van Dusen, Kelder, Kohl, Ranjit, and Perry (2011) examined if an association existed between physical fitness levels of students and their mathematics and reading achievement scores. The researchers used existing data from thirteen different school districts from the state of Texas. The sample $(\mathrm{n}=254,743)$ included students in grades three to eleven. The Texas Essential Knowledge and Skills (TEKS) scores for each of the students in the included sample measured academic achievement. The six components of FitnessGram data collected by the school districts determined physical fitness levels. After grouping the data based on academic year in school and gender, the researchers 
analyzed the data with regression analysis. The findings revealed a positive linear association existed in the data set between physical fitness levels and academic performance with effect sizes ranging from .07 to .34 . Of the six tests conducted for the FitnessGram, only BMI did not produce a significant association. Cardiovascular fitness levels showed the greatest association, as individuals who had scored highest on the cardiovascular component of the FitnessGram also demonstrated the greatest levels of academic growth on the TEKS scores (Van Dusen et al., 2011). The findings from this extremely large sample demonstrate involvement in physical activity does not hinder academics and in fact seems to show a positive association between physical fitness and academic success. In addition to improved standardized test scores by more physically active students, research has also shown an increase in core content assessments. Thus, the next section will discuss how physical activity participation impacts core content assessments.

\section{Core Content Assessment}

Gabbard and Barton (1979) conducted a study with 106 sixth grade students to determine if participation in exercise affected mathematical computation effectiveness. The researchers assessed the participants before exercising for a baseline. Next, the researchers evaluated the participants after they had completed 20,30,40, and 50 minutes of vigorous physical activity. Participation in physical activity did not hinder the mathematical skills of the participants. In fact, students scored more favorably on mathematical assessments after having completed 50 minutes of vigorous physical activity. This finding demonstrated exercise was not an academic hindrance (Gabbard \& Barton, 1979). 
Additionally, McNaughten and Gabbard (1993) conducted a study with 120 sixth grade students to determine if mathematical computation speed and accuracy were impacted when students participated in walks of 20,30, and 40 minutes. The researchers also examined exercise impact at various times during the school day and determined participating in exercise during either the midday or afternoon resulted in higher academic performance on mathematical assessments. The researchers found the students' mathematical performance to be at higher levels the longer they participated in the walking activity. The findings from this study continue to support the premise that exercise does not negatively influence academic performance.

Field and Diego (2001) surveyed 89 high school seniors to determine if a correlation existed between an individual's exercise habits and academic success. The researchers specifically examined the number of occurrences of exercise participation and then calculated the mean number of occurrences for the sample. Once the mean was determined, the researchers divided the participants into either a high exercise group or a low group in relation to the group mean. The researchers used the student grade point average to measure academic success on a four-point scale. The subjects who participated in greater levels of exercise also had significantly higher-grade point averages than the subjects did in the low exercise group (Field, Diego, \& Sanders, 2001). These findings help demonstrate the positive academic gains associated with physical activity and exercise.

Nelson and Gordon-Larson (2006) conducted an extensive analysis of 11,597 adolescents from across the U.S. to determine if a correlation existed between participation in physical activity and academic success. The researchers controlled for 
demographics and socio-economic status (SES) (Nelson \& Gordon-Larson, 2006). The participants who had been involved with physical activity in school settings in physical education instruction or extracurricular team sports activities as well as students who participated in physical activity outside of school opportunities displayed greater levels of academic success. The physically active students had a $20 \%$ greater chance of earning the letter grade of an "A" in their mathematics and English courses as compared to their more sedentary peers (Nelson \& Gordon-Larson, 2006). These findings support the previous work of Lindner (2002), who examined middle to upper middle class high school seniors. Lindner (2002) found participants who were more physically active had higher GPAs than the less active participants did.

Stevens, To, Stevenson, and Lochbaum (2008) examined the impact participation in physical activity other than physical education courses in a school setting had on the overall academic performance of school aged children. Participants were individuals selected from a previous data set used for the Early Childhood Longitudinal StudyKindergarten, which consisted of a national sample of over 22,000 students who had entered kindergarten during the 1998-1999 academic year. For the present study, the researchers were interested in examining only students who had data collected for all grade levels from kindergarten through fifth grade. Thus, the total number of analyzed students was 6,482 for the mathematics assessment and 6,393 for the reading assessment. The parents of the participants reported the physical activity levels of their children. Activity levels included all aerobic activity lasting longer than 20 minutes. The data excluded physical activity in physical education classroom. The study demonstrated a positive significant relationship between student involvement in aerobic activities and 
academic achievement levels, as determined by a mathematics and reading assessment (Stevens et al., 2008). Thus, this study shows the importance of physical activity and academic success.

Carlson et al. (2008) used existing data collected from the Early Childhood Longitudinal Study of the kindergarten class of 1998-1999 to determine if the amount of time spent participating in physical education instruction led to higher levels of academic achievement. The longitudinal study monitored children from across the United States $(\mathrm{n}=5,316)$ from first through fifth grade. The researchers classified physical education participation levels based on the number of minutes of participation per week as low ( 0 35), medium (36-69), and high (70-300). The researchers used mathematics and reading tests from the item response theory scale (IRT) to determine academic achievement. The researchers used multivariate linear regression to analyze the collected data. The amount of time allocated for physical education had no correlation to academic achievement in the male participants. The girls in the low classification for physical education participation group throughout all the grade levels had the lowest IRT scores for mathematics and reading (Carlson et al., 2008)

The female students in the high physical education group had a small significant gain in academic achievement as compared with the low group, when controlling for demographic variables (Carlson et al., 2008). Female students in the high classification group scored 2.4 points higher on the IRT reading scale and 1.5 points higher on the IRT mathematics scale as compared with female students in the low physical education classification group (Carlson et al., 2008). Although the gains were small, the study did result in small increases in academic achievement, which helped demonstrate physical 
education participation does not hinder academic gains in students and can be a possible aid. This section demonstrated an association between participation in physical activity and academic success regarding core content areas. Research also indicates there is a relationship between participation in physical activity and overall student health, which will be addressed in the next section.

\section{Student Health Status}

Datar, Sturm, and Magnabosco (2004) conducted a two-year longitudinal study consisting of 11,000 kindergartners who transitioned to first grade to determine the impact of obesity on academic performance. The kindergartners classified as overweight had substantially lower math and reading scores compared to their non-overweight peers at entry into kindergarten and the differences remained consistent throughout the completion of the first grade. The study findings demonstrate differences in academic performance when comparing body weight and help show children being classified overweight may be a characteristic of low academic test scores (Datar et al., 2004).

Cottrell, Northrup, and Wittberg (2007) conducted a study with 968 fifth-grade students in West Virginia to determine if a relationship existed between the children's body weight status and their assessed academic performance. The researchers used BMI to classify the participants' body weight status and West Virginia Educational Standards Test (WESTEST) scores to determine academic performance. The participants classified as overweight based on their BMI score demonstrated lower scores on the WESTEST for language arts, mathematics, science, and social studies (Cottrell et al., 2007).

Burton and VanHeest (2007) explained one of the biggest challenges the U.S. educational system needs to address is the achievement gap between African American 
and Hispanic students with their Caucasian and Asian American peers. Past research has shown minority students have a higher rate of being overweight, 3-4\% greater for Hispanic and African American students as compared with Caucasian and Asian Americans (Ogden et al., 2006). Thus, it seems a possible intervention is to place more emphasis on movement, fitness, and physical education into the curriculum, as these could help combat the obesity epidemic and promote academic gains. While this intervention seemed viable, school districts continue to place more focus on language arts, mathematics, and science, while drastically reducing and/or eliminating physical education instructional time (King \& Zucker, 2005).

Shore et al. (2008) examined school records for 566 sixth and seventh grade students at a public middle school located in a suburb of Philadelphia, Pennsylvania. The researchers questioned if there was a difference between overweight students, measured by BMI, and non-overweight students, in academic success, attendance, and discipline. The sample consisted of 406 students classified as non-overweight, 85 at risk for being overweight, and 58 students as overweight. Analysis of variance findings showed the overweight students had lower grades. In fact, the overweight students had a 0.4 letter grade lower in GPA (on a 4.0 grading scale) than the non-overweight students. Additionally, overweight students scored $11 \%$ lower on national reading scores compared to students classified as non-overweight. Finally, students in the overweight classification were five times more likely to have served detention six or more times (Shore et al., 2008). The findings from the study demonstrate the correlation between overall physical fitness levels and academic success and thus help justify the inclusion of physical education in an academic setting. 
This section of the literature review has discussed how participation in PA can produce many benefits. One of the most obvious benefits of participating in PA are in the physical realm. Our nation is witnessing more and more individuals suffering from medical complications resulting from the prevalence of obesity across all ages. Ogden et al. (2002) found overweight children are more likely to continue to age without adjusting their lack of activity and thus have a higher chance of maturing into obese adults.

Additionally, Ogden et al. (2002) found as the number of overweight children increases there has also been a decrease in college-aged students participating in PA. This is a detrimental finding, as university physical education offerings, including BIPS, are often the last chance for individuals to develop a structured exercise and fitness routine before leaving the school setting (Leslie et al., 2001; Sparling \& Snow, 2002). Previous research has shown enrollment in physical education activity courses provides a logical setting to educate college age students about lifestyle choices and health risk behaviors (Dale \& Corbin, 2000; Pearman et al., 1997).

The college experience is often very stressful for individuals and can compound health issues for college students (Sax, 1997). Participation in PA can help combat increased stress levels. Avery and Lumpkin (1987) found participation in physical education courses increased self-esteem levels of students. Additionally, the researchers found many students mentioned participating in PA as an enjoyable source of entertainment and pleasure. Ragheb and McKinney (1993) found students with higher participation levels in recreational activities had lower levels of perceived academic stress. Fleshner (2000) found participation in PA improved blood circulation throughout 
the body, including the brain, which may cause lower levels of stress, act as a mood enhancer, and result in increased levels of academic success.

The transition to the university setting can be very stressful for students as they attempt to find their place socially. Spady (1971) explained the importance of social integration for students as a critical factor in academic success and student persistence. Artinger et al. (2006) found participation in intramural sports increased exposure to diverse groups of students and helped with the social integration process. Students seemed to find participation in sports and PA as a comfortable setting to establish friendships and peer networks.

There has been a substantial amount of research conducted in the K-12 setting regarding the role PA participation has on academic success. Dwyer et al. (1983) found decreased academic instructional time to allow for participation in physical activity did not negatively affect academic success. Shephard (1997) found no negative academic impact on student success, because of more time allocated to physical activity participation in the school setting. A statistically significant correlation existed between physical activity participation in adolescents and academic success (Fejgin, 2001; Pate et al., 1996). Trost (2007) found no negative consequences for students becoming more physically active in the school setting. In fact, in many instances the active students scored more favorably than their less active peers did.

Li (1995) examined the differences in intelligence levels among obese and average weight children and found the individuals classified as overweight displayed lower IQ test scores. In a similar study, Taras and Pott-Datema (2005) found overweight individuals demonstrated lower levels of academic achievement. Participation in 
exercise by children increased overall mental functioning, aiding in their overall cognitive development (Davis et al., 2007). The influx of obesity levels in adolescents may have a negative relationship with academic performance in US schools (Allegrante, 2004; Coe et al., 2006; Li, 1995; Taras \& Potts-Datema, 2005).

A research study conducted in 2001 by the California Department of Education found students with higher fitness levels scored higher on the achievement test. Grissom (2005) showed a significant positive correlation existed between the fitness levels of the students and their academic success. The data consistently showed as the subjects' fitness levels improved so did their performance on the standardized Stanford Achievement Test. Additionally, Chomitz et al. (2009) found as students passed more physical fitness exams they were also more likely to pass the mathematics and English portions of the standardized MCAS test.

McNaughten and Gabbard (1993) found students improved their ability in both speed and accuracy of mathematical computations when they participated in greater amounts of PA. Similarly, Field et al. (2001) found students who had participated in greater levels of exercise also had significantly higher-grade point averages than the students in the low exercise group. Additionally, Nelson and Gordon-Larson (2006) found physically active students had a $20 \%$ greater chance of earning the letter grade of an "A" in their mathematics and English courses as compared to their more sedentary peers. Datar et al. (2004) conducted a two-year longitudinal study consisting of 11,000 kindergartners and found those students classified as overweight had substantially lower math and reading scores compared to their non-overweight peers at entry into 
kindergarten and the differences remained consistent throughout the completion of the first grade.

The literature seems to demonstrate the significant role PA has on the overall academic success of students. In this era of increased academic accountability, administrators and key decision makers shouldn't ignore the importance of PA. As higher education institutions attempt to overcome decreased funding from state governments, decision makers continue to search for ways to increase other revenue sources. Revenue generated from student tuition is a substantial portion of the operating budget for the institution. Thus, schools are competing with one another in attracting students. The financial landscape in higher education has now forced institutions to prioritize student retention. A review of the student retention literature follows.

\section{Student Retention}

Over the last thirty years, universities have had to become more accountable to their constituents. In fact, higher education institutions were not required to report graduation data until 1985. That year the NCAA required member institutions to report graduation data as a way for the association to determine graduation rates of the student athletes and compare them to the rest of the campus community. Initially, this data was only available to the NCAA and there was no governmental oversight regarding higher education graduation rates (Cook \& Pullaro, 2010). The passage of the Federal Student Right-to-Know and Campus Security Act in 1990 required any higher education institution receiving Title IV funds to publicly report graduation rates to the U.S. Secretary of Education (Cook \& Pullaro, 2010). 
Because of the graduation data becoming public knowledge, institutions with favorable marks began using the information as part of their advertising campaigns, while those with unfavorable rates defended their worth to both prospective and current students (Astin, 1997). Thus, institutions with lower graduation rates had a perception they did not effectively address the educational needs of their student population. Obviously, no institution desires a high student dropout rate (Barefoot, 2004). Astin (1993a) explained institution graduation rates can be very misleading and may not be reflective of the student experience at the institution. Thus, it is important to discuss how higher education institutions started focusing on student retention rates. This section of the literature review will also provide an overview of the significance that student interaction and student involvement have on student persistence.

\section{Evolution of Student Retention Research}

The study of student persistence in higher education has been ongoing through the decades and is one of the most widely studied concepts in higher education (Astin, 1971; Astin, 1985; Barefoot, 2004; Bean, 1980; Spady, 1970; Spady, 1971; Tinto, 1993). The assumptions of these early analyses were that the demographics of the student population were the underlying driving force in student departure rates. These early researchers believed that individuals electing to leave the institution did so due to minimal levels of motivation and desire to excel in academic programs. Through these early analyses of student retention rates, all the justification and motives for departure rates was due to the failures of the students themselves (Chase, 1970; Sewell \& Shah 1967; Wegner \& Sewell, 1970). The work of Spady $(1970,1971)$ and Rootman (1972) are the first researchers in the field of student retention to examine the problem of student departure 
because of more than just identifiable student characteristics. Student retention research has since evolved to now examining possible attributes of the institution, which may lead to increased attrition rates.

Even though much research focused this problem in higher education, the percentage of students enrolled at four-year institutions who progress to graduation is less than favorable. In fact, the United States Department of Education National Center for Educational Statistics (2015) reported the six-year graduation rate for first-time, full-time undergraduate students, who began their academic pursuits of a bachelor's degree at a four-year institution in fall 2007 was 59.4\%. The six-year graduation data for the fall 2007 cohort only displayed an increase of $4 \%$ from the six-year graduation data for the fall 1996 cohort (U.S. Department of Education National Center for Educational Statistics, 2015).

While the recognized gains between the two cohorts are less than desirable, the findings are consistent with past data on graduation rates in the U.S. In fact, Swail (2004) reported the national undergraduate graduation rate in the U.S. consistently hovers around the fifty percent mark. Additionally, The National Center for Education Statistics (2005) reported student retention rates and graduation rates had shown minimal changes over the earlier decade. Thus, the problem of student retention and student degree completion has been present in the higher education landscape for a substantial period of history. Additionally, it is important to acknowledge the low graduation rate figures are a six-year average, while the common time is four years. The data for four-year graduation rates for the selected fall 1996 (33.7\%) and fall 2007 (39.4\%) cohorts demonstrated slightly better gains than the $4 \%$ increase for six-year graduation rates, but less than $40 \%$ 
of all beginning students graduated in four years (U.S. Department of Education National Center for Educational Statistics, 2015).

Additionally, it is necessary to address the existing limitation of the retention data obtained at U.S. institutions (Barefoot, 2004). Reported retention rates do not consider students who transfer to a different institution and finish their degree at the new institution. The first institution would report the student in the previous mentioned scenario as not retained. Another limitation to this method of retention data collection is students who stop attending school for a window of time, then return to the same institution, and complete their degree at their original institution are referred to as a shortterm stop out. Regarding reporting of data purposes, students labeled as short-term stop outs fell into the classification as not retained. This approach also does not consider some individuals attend higher education institutions to increase their knowledge base without ever aspiring of persisting towards a college degree (Barefoot, 2004).

Tinto (1990) explained higher education has a notion that most students who withdraw from an institution are suffering academically and as result remove themselves from the challenging situation. This is a misconception, as there are academically high performing students who elect to leave institutions out of boredom, lack of academic challenges, or feeling uncomfortable at the school (Tinto, 1990). Additionally, many students withdraw due to a lack of institutional fit with the campus climate or social networks (Barefoot, 2004). Thus, it is shortsighted to make broad assumptions that students are only leaving higher education institutions due to academic deficiencies.

Barefoot (2004) discussed most college-aged students have no strong affiliation with an institution and as a result are very willing to look for a different school. Choy 
(2002) conducted a national study indicating $47 \%$ of participating college students beginning at a baccalaureate institution will earn a degree from that institution within five years. Additionally, 29\% of the students had enrolled in coursework at a different institution or had graduated from a different institution (Choy, 2002). These findings demonstrate a major limitation in the process of reporting data.

As previously stated, research has been conducted on student retention for an extensive period. In fact, Berger and Lyon (2005) reported research on student undergraduate retention in the U.S. began in the 1930s, but at the time the terminology was referred to as student mortality, which is different than the present-day nomenclature of student retention, student persistence, and student attrition. While the wording on the terminology may be different from present research, the premise of the concept was consistent with its modern understandings. McNeely (1937) conducted a research study on student mortality using a method never examined previously. The study consisted of a large sample of higher education institutions. McNeely's study examined 25 institutions $(\mathrm{N}=15,535$ students), whereas the previous literature specifically only analyzed data from single institutions. The study examined student mortality rates at participating institutions during a four-year period. The findings from this groundbreaking piece are very consistent with modern data on student retention in that $31.6 \%$ of the participating students in the study graduated with a college degree in a four-year period (McNeely, 1937).

Astin (1968) conducted a study with 669 college students from 248 different US four-year higher education institutions to determine how the perceived status of the school influenced student success. In other words, did students enrolled at schools 
classified as higher quality by national polls display greater levels of academic success than students enrolled at schools lower in the national ranking polls. Astin found that students enrolled at the higher ranked schools scored more favorable in academic success than the participants enrolled at lower ranked schools. However, when controlling for various student input factors, the results of the study did little to distinguish noticeable differences between student performances at higher ranked schools as compared to lower ranked institutions (Astin, 1968). Thus, the researchers demonstrated the type of student and their characteristics affected academic success greatly in college.

Spady (1970) developed a conceptual model of dropout based on the previous sociological work of Durkheim (1951) who identified reasons why individuals elected to commit suicide. While at first glance most would not see an appropriate link between the studies of suicide and student persistence, Spady (1970) was able to demonstrate identifiable characteristics between the two concepts. Durkheim (1951) had found one of the biggest motivating factors was attributable to a lack of social integration. Spady (1970) theorized the same motives of a lack of social integration could help explain why students withdrew from higher education institutions.

Spady (1971) conducted a study to test the theoretical retention model, which he first introduced in his 1970 work. To test this model, Spady (1971) analyzed longitudinal data from 683 first-year students enrolled at the University of Chicago. Spady's model revolved around the premise each student began enrollment at the institution with certain educational aspirations as well as varying educational abilities, which greatly impacted the student's satisfaction with his/her experiences at the institution as well as the student's ability to effectively integrate socially with institutional peers. Spady was 
under the belief students' aspirations and educational abilities were greatly influenced by the family environment they were raised in as well as their previous educational exposure and environment. College students' social network directly affects the educational experience. Spady explained that social integration and the academic abilities of the student were critical factors in students staying enrolled at the institution (Spady, 1971). Additionally, Tinto (1993) supported this theory stating, "Egotistical suicide provides the analogue for our thinking about institutional departure from higher education" (Tinto, 1993, p. 100).

A different study completed by Astin (2005) discussed how retention rates at higher education institutions carry certain assumptions from both the campus community as well as the community at large. There are belief institutions with higher retention rates have implemented policies which have effectively combated student departure so students attending these institutions have a greater likelihood of experiencing academic success (Astin, 2005). As the study of student retention evolved, an area for more in depth examination and analysis was student involvement and student interaction.

\section{Student Involvement and Student Interaction}

Tinto (1975) examined how the environment and the individual interacted with one another. Tinto referred to the environment in this early work as both the academic and social systems of the institution. This early description of a campus community consisting of both an academic and a social component lead to the concept of student involvement. Tinto (1975) stated an individual's integration into both the academic and social systems of the institution were the most influential aspects in deterring dropout. Insufficient interaction with others in college and a lack of integration into the social 
system of the school would result in lower levels of commitment, in turn increasing the likelihood the individual would choose to part ways with the institution (Tinto, 1975).

Pascarella and Terenzini (1976) surveyed 379 freshmen enrolled in the College of Arts and Sciences at Syracuse University. The purpose of the study was to determine how informal interaction with faculty members influenced overall student satisfaction as well as student attrition rates at the institution. The researchers placed participants into one of three categories (low, medium, high), based on their overall informal interaction levels with faculty members. The study results found participants in the moderate and high interaction levels reported greater levels of satisfaction with their specific academic program and the institution. Additionally, the participants in the high interacting group attributed their academic success and personal development more because of the faculty compared to the low interacting study participants (Pascarella \& Terenzini, 1976).

Additionally, the study findings demonstrated a significant association between informal student interaction with faculty members and their rate of returning to the institution for their sophomore year. In fact, $90.6 \%$ of the participants from the high interaction category returned to the school for their sophomore year. This figure is substantially higher than for the individuals classified in the low interaction category that returned for a second year at a $72.9 \%$ rate (Pascarella \& Terenzini, 1976). Pascarella and Terenzini (1976) explained this finding may be attributable to the fact as students have more opportunities to interact informally with faculty members they simultaneously become more intertwined and comfortable with the school's social structure and academic systems. 
Terenzini and Pascarella (1978) conducted a study attempting to determine how student characteristics upon entering college influenced the student experience during the first year. They also tried to identify experiences occurring during the first year, which affected student retention. A random sample consisting of 766 incoming freshmen completed an initial survey. This group of students then received a second survey instrument during the second semester of their first year, which produced 536 usable responses. Student characteristics before attending the institution were not statistically significant. Academic integration variables including students' perceptions of their academic program, earned GPA, and perception of advancement in intellectual development explained six percent of the variance in student retention and were statistically significant (Terenzini \& Pascarella, 1978). Terenzini and Pascarella (1978) also found informal communication outside the classroom between students and faculty members was a significant predictor of student retention. These findings demonstrate successful student retention efforts by institutions must consider more than the incoming attributes of the student population.

Astin (1984) provided an operational definition for the term student involvement by stating, "Student involvement refers to the amount of physical and psychological energy that the student devotes to the academic experience" (Astin, 1984, p. 297). Student involvement comprises the experiences in and out of the classroom that occur on campus, including extracurricular activities (Astin, 1985). Astin (1985) further explained student involvement enhances the student learning experience by placing individuals in situations allowing them to experience new things, which leads to new knowledge acquisition. In other words, a highly involved student spends vast amounts of time on 
campus studying and becoming involved with other campus activities, while an uninvolved student comes to class and has very little other interactions. Astin further explained involvement consists of a behavioral component, in that the student's actions are more significant than his/her feelings or thoughts on the concept of involvement (Astin, 1985).

Pace (1984) discussed the significance of displayed effort on the part of the student in their coursework. The scholar explained students must demonstrate quality of effort. It was the premise of Pace the effort levels displayed by the student had an influence on student success in addition to student involvement. Pace stated,

"All learning and development requires an investment of time and effort by the student. Quality of experience and quality of effort are similar concepts, connected with one another in that the likelihood of having a high-quality experience depends on investing high-quality effort" (Pace, 1984, p. 7).

Both Pace and Astin had discussed the necessity of students investing time, energy, and effort into their academic pursuits. Additionally, Astin (1984) defined the components necessary for successful student involvement.

Astin (1984) identified five basic principles of involvement theory. First, involvement included the use of both physical and psychological energy. Second, involvement occurs on a continuum, meaning there are periods where a student is more or less involved in an activity than his/her peers. Third, involvement is quantitative in make-up, such as the number of hours spent studying (Astin, 1984). Involvement encompasses qualitative characteristics as well. For example, a student could demonstrate qualitative characteristics of student involvement through class discussions by displaying understanding of the course material. Fourth, the quality and quantity of student involvement influences student learning and personal development. Finally, the 
amount of student involvement can affect the overall effectiveness of educational policy (Astin, 1984).

Astin $(1984,1985)$ discussed how the theory of student involvement is based on understanding students have a finite amount of time. Thus, the academic component of student life competes with all the other experiences the student encounters. Family, work, social activities, and school all pull the time and attention of students. Student time is a critical resource in the overall success of the student learning experience and thus important when considering if a student will continue making progress towards degree completion. When students involve themselves in activities they find enjoyable and which result in positive outcomes for their educational experience, they are likely to invest more of their time in similar experiences. The reverse holds true for experiences leading to negative outcomes (Astin, 1984; Astin, 1985). University administrators must be cognizant of the significance student involvement has on the education success and the vast amount of competing demands students face.

Numerous research studies have identified involvement as one of the major reasons for student persistence (Astin, 1975, Astin, 1984, Astin, 1993b; Braxton, 2000; Pascarella, 1980; Pascarella \& Terenzini, 1991; Terenzini, Lorang, \& Pascarella, 1981; Upcraft, Gardner, \& Barefoot, 2005). These research findings demonstrated how involvement during the first year was critical in establishing student persistence. These findings persuaded many researchers to begin examining students' first year experiences. Upcraft, Gardner, and Associates (1989) discussed how many institutions began developing more in-depth orientations for new students, freshman seminars, and finding ways to involve students in more extracurricular activities. These changes in institutional 
policies were a direct reflection of a shift from explaining persistence using concepts derived from (and, therefore, blaming) students to one in which notable characteristics of colleges and universities were important.

Tinto (1990) discussed how retention programs used by higher education institutions might have varied in appearance at the surface, but a closer examination showed many similar underlying principles. The author discussed common retention strategies, which are often at the heart of most retention programs. First, a sense of community needs to be present at the institution, where students develop the attitude they are socially accepted (Tinto, 1990). Additionally, this culture provides an environment where faculty and staff have meaningful interactions with students outside of the confines of the classroom walls. "The research in this regard is quite clear, namely that the frequency and perceived worth of interaction with faculty, especially outside the classroom is the single strongest predictor of student voluntary departure" (Tinto, 1990, p. 36). Tinto (1990) reiterated this does not take away the value of quality instruction and interaction within the classroom. Students believe faculty who display substantial amounts of interaction within their course instruction are easier to communicate with outside the academic setting.

The second principle identified by Tinto (1990) was institutions must display a strong level of commitment to the overall student academic success. Universities with successful retention programs are student-driven first, meaning the success of the students is the focus instead of faculty gains and prestige. Institutions with success in minimizing student withdrawal rates have created a culture where the majority of faculty and staff have realized the academic success of the student is priority number one. 
Unfortunately, there are many institutions where staff members holding positions in student affairs are the only individuals who have adopted the student first mentality. It should come as no surprise then when these institutions have lower levels of student persistence compared to those displaying the student first mentality (Tinto, 1990).

Tinto (1990) explained the third principle of an effective retention program is for institutions to focus on the overall education of the student body and not their retention to the school. In other words, schools need to be concerned first with the development of the student both socially and intellectually and not solely focus on retaining the student. "The obligation of institutions to educate the students they admit springs from a more fundamental obligation of higher education generally. It derives from the social contract higher education has to serve the welfare of society by educating its members and thereby helping to ensure its preservation over time" (Tinto, 1990, p. 39). Tinto (1990) explained schools must determine what their educational mission is and realize that not all individuals will align with this mission. This realization increases the importance of properly screening applicants during the admission process. There will be instances, however, where student's alignment with the educational mission of the institution dwindles (Tinto, 1990).

Tinto (1990) explained this creates an interesting paradox for the institution. If the university is student driven there will be times when the best decision for the student is to withdraw from the school. Thus, the significance of a student first mentality overpowers the goal of student retention in situations like these. "Those institutions that are committed to the education of their students, and therefore willing to tell students when it is in their interests to leave, are also those institutions that are more likely to have 
students who are committed to the institution. Consequently, they will also retain more of their students to degree completion" (Tinto, 1990, p. 42). It will become apparent to students that the university mission of student success has greater value than the university goal of retaining students and producing many graduates.

Tinto (1990) explained it is useful for universities to frontload the student experience with many different activities and programs designed to maintain student persistence. This is a logical time to offer many of these programs, as an extremely considerable number of student departures occur in the first year of college (Tinto, 1990). The first year is one of major transitions for young adults, as often this is the first time they are living away from home and experiencing substantial amounts of freedom. This newfound freedom pulls the student's attention away from their academic pursuits. Tinto (1990) explained there is not one catch all program institutions can offer to prevent student withdrawal. "Rather than reflect any one type of effort, successful institution retention programs are the result of the correlation across the campus of a variety of diverse types of programs that seek, in differing ways, to integrate and support students and promote their becoming effective learners while in college" (Tinto, 1990, p. 44). Attinasi (1989) and Tinto $(1993,1997)$ demonstrated student academic success and persistence were impacted by the student's ability to become socially and academically integrated at the institution. Students who developed a social network felt more comfortable with the dynamics of the institution and were able to demonstrate greater levels of academic success. These social interactions do need to have positive outcomes associated with them, however. In other words, if a students' social network pulls his/her attention and time to a level that distracts from academics, then social 
integration is having a negative effect. Except for the previously stated caveat, the literature does demonstrate social interactions lead to positive academic gains.

Astin (1993b; 1993c) conducted research at more than 200 US four-year institutions with 25,000 students. The students completed surveys upon enrollment at the participating institutions and then completed a follow-up survey four years later. Astin used a series of multivariate analyses to help control for the student input characteristics of the freshman students. The results showed that as students became more involved in their educational experience, they displayed greater levels of student development and academic success. A significant positive correlation existed between the hours spent studying and the likelihood of the students' being retained, graduating with honors, and pursuing education beyond the bachelor's degree. The most influential finding from the study was that undergraduate student academic success was affected the most by the peer group the student associated with (Astin, 1993b, 1993c).

Additionally, Astin (1993b, 1993c) demonstrated peer involvement influenced almost every area of the student learning process as well as the student development process. The findings showed many undergraduate students establish peer networks in the form of friends and various groups of the same sex. Further, undergraduate students typically join social organizations typically comprised of individuals from their own race. Finally, the study found student interaction with faculty was a significant contributor to successful student development (Astin, 1993b; Astin, 1993c).

Terenzini et al. (1994) conducted focus group interviews with 132 incoming students at four different institutions of higher learning in the U.S. The four institutions varied in both characteristics and size to produce a sample with varying student 
characteristics. Reoccurring themes emerged from the interviews. First, it is critical the staff and faculty are aware of the differences among students and that not all students respond in the same manner to the transition process. Second, it is important for faculty and staff to help students believe they can be successful at college (Terenzini, et al., 1994). The interviews demonstrated students given validation early in their academic careers experienced greater academic success.

Additionally, Terenzini et al. (1994) demonstrated the importance of involving faculty in new student orientation programs. The students in the study conveyed faculty involvement demonstrated interest in the student's academic success. Additionally, the study found the significance of involving parents and/or spouses in the orientation process, as these individuals will serve as a support system for the student during this transition process. The overwhelming sentiment of the study participants was that it is critical for students to feel someone cares about their academic success. If the students believe someone cares about them and wants them to excel academically, they believe a support system is present (Terenzini, et al., 1994).

Nora, Cabrera, Hagedorn, and Pascarella (1996) found a significant predictor of college success was the ability of the student to interact with peers and develop close personal relationships. The common lecture style approach of education often hinders students from having the opportunity to develop close personal relationships with their peers (Nora et al., 1996). Tinto (1997) explained the structure of college classrooms often limits the amount of student interaction and involvement. Additionally, the structure of higher education coursework often presents coursework as individual units with limited connection from one course to the next. The nature of this style limits the 
amount of social interaction among students. Social interaction in a course is often present outside the classroom in the form of group work (Tinto, 1997).

The study of student persistence in higher education has been ongoing and is one of the most studied concepts in higher education (Astin, 1971; Astin, 1985; Barefoot, 2004; Bean, 1980; Spady, 1970; Spady, 1971; Tinto, 1993). The early studies on student retention placed all the blame on the failures of the students for departing from the school (Chase, 1970; Sewell \& Shah 1967; Wegner \& Sewell, 1970). However; the work of Spady $(1970,1971)$ and Rootman (1972) began to examine how student retention was impacted by more than just identifiable student characteristics. This change in thinking caused the student retention research to evolve to include both student characteristics and attributes of the institution.

Barefoot (2004) found most college-aged students have no strong affiliation with an institution and as a result are very willing to look for a different school. Thus, this signals an area higher education institutions need to address and emphasize more. Based on this finding from Barefoot (2004), schools must create a culture on their campus which instills a strong affiliation to that specific institution. Spady (1971) determined social integration of the students was a critical factor in students staying enrolled at the school. Tinto (1975) determined a student's integration into both the academic and social systems of the institution were influential aspects in deterring student dropout and increasing student retention.

Pascarella and Terenzini (1976) demonstrated a significant association between informal student interaction with faculty members and their rate of returning to the institution for their sophomore year. In fact, $90.6 \%$ of students who experienced high 
levels of faculty interaction returned to the school for their sophomore year. This finding demonstrates faculty have a significant role in retaining students. Additionally, the involvement levels of the student impacts student retention rates. A highly involved student spends more time on campus participating in both educational and social activities. As a result, the more involved student has a greater sense of belonging to the campus community and in turn are less likely to withdraw from the school. Numerous research studies have identified involvement as one of the major reasons for student persistence (Astin, 1975, Astin, 1984, Astin, 1993b; Pascarella, 1980; Pascarella \& Terenzini, 1991; Terenzini et al., 1981).

Tinto (1990) explained it is useful for universities to frontload the student experience with many different activities and programs designed to maintain student persistence. This is a logical time to offer many of these programs, as an extremely substantial number of student departures occur in the first year of college. It appears many higher education institutions have heeded this advice and placed a high priority on the first-year experience. An overarching theme for first-year programs is to help the student become socially connected. Attinasi (1989) and Tinto $(1993,1997)$ demonstrated student academic success and student retention were impacted by the student's ability to become socially and academically integrated at the institution.

\section{Utilizing Campus Recreation and Physical Activity for Retention}

The study of student retention has shown the importance of students being socially integrated and having a peer network. Sporting and recreational activities provide a logical setting for social integration to occur on college campuses. As a result, university administrators have continued to place an important level of significance on 
campus recreation facilities and their various programming opportunities. Campus recreation programs have had a presence at higher education institutions for quite some time now. Taylor, Canning, Brailsford, and Rokosz (2003) reported the University of Michigan was the first university to build a campus recreational facility, which occurred in 1928. The target audience for the facility was male students participating in intramural programs, physical education courses and club sports. Other institutions began building athletic facilities over the next three decades with the same users in mind. During the 1960s and 1970s, the athletic facilities built were multipurpose facilities to accommodate the academic piece of physical education (Taylor et al., 2003). The 1980s and 1990s saw great growth in the number of recreational sport facilities on university campuses. This growth was a result of the increase of women's involvement in sporting activities after the passage of Title IX. The recreational facilities built during these two decades differed greatly from previous facilities regarding appearance, offerings, and significantly greater costs (Taylor et al., 2003).

In recent years, higher education has experienced the construction of more elaborate campus recreation facilities. These new facilities still include the traditional sports and fitness offerings but now encompass large numbers of niche sports as well. Many similarities exist in programs offered by campus recreation facilities and physical education course offerings. Leslie et al. (2001) explained the purpose of campus recreation was to offer extracurricular fitness and sports opportunities for students. Compare that to the mission of physical education programs to offer physical activity and sport-based courses for academic credit. Thus, the distinguishing characteristic between the two was the physical activity contained an academic assessment component, which 
resulted in a course grade and had GPA and degree attainment repercussions (Leslie et al., 2001).

Churchill and Iwai (1981) examined if a relationship was present between student involvement in multiple campus services and student persistence in school. The study sample consisted of a total of 1,231 students who had maintained enrollment at Arizona State University, as well as students who had withdrawn. An important finding in the study was the individuals who had withdrawn from school had utilized campus facilities and services the least of all in the sample. When looking at study participants with a low GPA, those who persisted had, visited campus facilities at a higher rate than the subjects with low a GPA who had withdrawn (Churchill \& Iwai, 1981). A significant correlation existed between the use of campus facilities and the overall student persistence levels of students with low GPAs. Thus, university administrators must implement strategies to help increase student involvement in campus programs.

Because of the Churchill and Iwai (1981) study findings, university officials quickly started realizing the significance student involvement and the campus experience had on overall student satisfaction. Preo (1986) explained institutions began placing more attention to the non-academic experiences of its students. Both academic and nonacademic experiences affected student academic success. One such area on university campuses, which many from the student body frequent, is the campus recreation facility. University administrators realized the importance campus recreation facilities had on the overall student experience (Preo, 1986).

Numerous daily social interactions occur at campus recreation facilities. Additionally, these facilities provide programs and opportunities for students to grow 
emotionally, physically, and mentally. Historically, campus recreation personnel attempted to justify the significance of the programs their facilities were offering for the student body by citing facility usage numbers (Lewis, Barcelona, \& Jones, 2001). Facility usage numbers are an effective way to demonstrate student interest in access to the facility as well as the programs. Recreational personnel should consider other ways to demonstrate the value their department adds to the university campus. Lewis et al. (2001) discussed the importance of campus recreation officials documenting student satisfaction with their facility and program experiences. Student satisfaction with recreational experiences increases the likelihood the student has a positive overall experience at the institution, which in turn increases the likelihood of student persistence (Lewis et al., 2001).

Haines (2001) conducted a study to demonstrate university recreation programs are a positive influence on the overall undergraduate student experience. Undergraduate students at The Ohio State University completed 374 questionnaires. Male students made up $70 \%$ of the participants. Data were collected as students either entered or left the student recreation center. The study findings demonstrated the respondents felt the presence of recreational facilities was somewhat important to very important in their decision to continue their education at the institution. Finally, more than $90 \%$ of the survey respondents reported believing sports and fitness would be important aspects of their life even after graduation (Haines, 2001). Thus, the study findings continued to demonstrate how the presence of campus recreation facilities played in the student decision-making process to remain enrolled. The findings that students perceive sport and exercise as important components of their life after graduation demonstrates the need 
for these types of activities on college campuses and thus should be considered in policy making decisions.

Belch et al. (2001) conducted a study to evaluate if a relationship existed between student participation at a campus recreation facility and the overall persistence rate of freshmen students. The researchers analyzed data from 11,076 freshmen students enrolled at a large public university in the state of Arizona. The researchers used the operational definition of student persistence as first-time freshmen in a fall cohort, enrolled at the same institution during the next fall semester (Belch et al., 2001). Every time the students visited the recreation facility, a record of the visit occurred. The students were categorized into four distinct groups (1-4 visits; 5-19 visits; 20-49 visits; $50+$ visits) based on their level of involvement, as determined by the number of visits at the facility during the fall semester of their freshmen year (Belch et al., 2001).

Nearly $73 \%$ of the three-year cohort sample visited the recreational facility at some point during their first semester at school. African American students had the largest rate of facility admittance. Eighty percent of all African American students at the school had used the facility. Students classified as non-residents of Arizona visited the facility at a much higher rate than students did from Arizona ( $89 \%$ vs. $59 \%$ ). The results showed even though the student recreation participants had started at the institution with lower academic performance levels than the facility non-users, upon completion of the study they had higher GPAs during their first semester at as well as higher first year cumulative GPAs (Belch et al., 2001).

Additionally, student recreation users completed a larger number of academic credits during their first academic year than facility non-users. Persistence rates for 
facility users after the first academic year were higher than for non-users ( $71 \%$ vs. $64 \%)$. The study found as the number of visits to the facility increased during the first year, so too did the student GPA and persistence rates. In fact, the group of students with 50 or more visits during their first semester on campus had the highest persistence rates in the study. While no single variable can explain student persistence completely, this study helped demonstrate the significance participation in recreation sports has on student retention (Belch et al., 2001).

The study findings demonstrate participation in physical activity and recreation does not impede academic success, but rather can be one of the possible variables administrators can use to generate student academic success. Additionally, these findings help support the premise that involvement in physical activity and recreation students in a setting, which promotes student interaction, which increases overall student satisfaction. Students with higher levels of satisfaction with their academic experience and the institution are more likely to persist.

Kasim and Dzakiria (2001) conducted a study to determine if a relationship existed between student recreation involvement and the students' aspirations and academic achievement. Students enrolled $(\mathrm{n}=278)$ at the Universiti Utara Malaysia completed surveys. The researchers found the age of the respondents did not influence the frequency of participation at the recreation facility nor the types of recreational activities completed. Additionally, the duration of involvement in recreational activities had a significant correlation with student aspirations. Specifically, the longer the participants spent at the recreational facility, the greater the levels of educational aspirations (Kasim \& Dzakiria, 2001). 
Dalgarn (2001) examined the role a campus recreation facility in creating a feeling of a community among users. Dalgarn collected data at Vanderbilt University with students completing a survey examining their quality of life. Seventy-five percent of respondents reported weekly usage at the recreation center. Dalgarn (2001) found the recreation center was often the campus facility used by the most students and the facility that attracted a diverse clientele. Dalgarn (2001) discussed how students viewed student recreation centers as a social integrating environment. Forty-five percent of respondents reported the presence of the recreation center influenced their decision to continue enrollment. The results showed students viewed the recreation center allowed for informal faculty and student interaction in a non-classroom setting (Dalgarn, 2001). Dalgarn's (2001) findings are consistent to earlier research studies including Astin (1993c), and Pascarella \& Terenzini (1991). Thus, all the studies demonstrated the positive impact informal faculty and student interaction had on student persistence.

Downs (2003) conducted a study to determine the impact recreational sports had on the participants' lives. The sample included students from sixteen colleges of varying enrollment sizes, geographic locations, public/private, urban/rural, and four and two-year institutions. The researchers conducted interviews with 2,673 students. The results for the study showed respondents who participated in recreational sports programs and activities reported greater levels of satisfaction with their university experience and achieved greater levels of academic success. Additionally, the students' overall level of satisfaction with the institution and their student experience increased as the frequency of participation in recreational activities increased. The most frequent users of the campus recreational facilities and programs reported the greatest levels of satisfaction. The study 
results demonstrated involvement in recreation sports was rather consistent across all grade levels regarding overall importance. The one exception was freshmen male students, who displayed slightly greater significance levels. The study demonstrated the most frequent users of campus recreation also felt the most comfortable socially on campus. Finally, the study found high users of campus recreation also placed the same level of significance on their academic pursuits and were just as concerned about the quality of their educational experience as individuals who participated in campus recreation less frequently (Downs, 2003). This is an important finding as it demonstrates physical activity participation does not draw student attention and efforts away from the academic component of education. Rather, the findings show physical activity participation can be an effective component of a student's educational experience by increasing overall student satisfaction and leading to academic success.

Hall (2006) conducted a qualitative study at the University of the Pacific examining if student involvement in the campus recreation program increased the likelihood of a student's retention at the institution. The study demonstrated the importance of campus recreation at the institution in that $78 \%$ of students participated in a minimum of one activity offered by the campus recreation department during the previous calendar year. The sample for the study consisted of four men and four women and the emerging theme indicated participating in campus recreation programs created a sense of community for the participants. Through this sense of community, participants were able to interact and socialize with their fellow peers and in turn establish new friendships. Three of the eight study participants directly stated their involvement in campus recreation programs influenced their decision to stay enrolled (Hall, 2006). The 
findings from the study demonstrated the social benefits of campus recreation participation. Additionally, the study findings showed how creating a community environment had positive effects on student retention.

Lindsey and Sessoms (2006) conducted a study to assess the impact of campus recreational sports facilities and programs on student retention. The sample consisted of 244 undergraduate students ranging in age from 18-25 at a small southeastern U.S. university. The researchers analyzed the data using a chi-square test to determine any recognizable differences. The data showed $83 \%$ of the respondents participated in a recreational sports program or visited the recreation facility on a weekly basis, while $94 \%$ of the respondents stated their desire to participate in weekly recreational activities. Sixty-five percent of the African American respondents stated participation in sports and fitness activities would be an important part of their life beyond graduation (Lindsey \& Sessoms, 2006). The findings demonstrated the presence of a campus recreational facility and its programs influenced the students' decision to continue their educational pursuits at the institution at all grade levels. Additionally, the findings demonstrated students believed their participation in recreation sports programs decreased their stress levels, which in turn improved their overall satisfaction with the institution (Lindsey \& Sessoms, 2006). These findings further demonstrated how campus recreation programs and facilities improved overall student experience.

Huesman et al. (2007) examined how student participation at a campus recreation facility during the first semester of enrollment impacted the students' first term grade point average (GPA), first year persistence, and graduation rate upon completion of a fifth year. The study included 5,211 students enrolled at a large, public, Midwestern 
university, who were first time, full-time degree seeking freshmen. Thirty one percent of the freshmen cohort did not visit the student recreation center at all during their first semester of attendance at the institution, but for those students who attended at least once, the average number of visits during the semester were 14.4. Thus, when considering the entire sample, the average number of visits was 9.9. The students in the sample had an average first term GPA of 3.02, $85 \%$ of the sample were enrolled at the institution the following fall semester, and $57.9 \%$ graduated within five years. The study findings showed students who frequented the recreation center one standard deviation above the sample average of 9.9 had a predicted GPA that was 0.11 greater, a one percent greater likelihood of being retained, and a two percent higher graduation rate (Huesman et al., 2007). The study findings demonstrate the effectiveness of campus recreation participation as a tool to promote academic success. Campus recreation typically provides an environment, which promotes social integration and allows for interactions among students in an informal, non-stressful environment. Physical education activity courses also provide an environment for social integration and interaction amongst the students. Due to the similar structure of campus recreation offerings and physical education activity courses, the findings demonstrate the potential positive impact involvement in these programs has on the academic success of students.

Henchy (2011) conducted a study to determine if the presence of campus recreation facilities and programs positive influenced students. Additionally, the study looked at the impact campus recreation involvement had on student retention. Undergraduate and graduate/professional university students ranging in age from 18-66 $(\mathrm{N}=237)$ completed the survey. The data demonstrated a significant difference among 
participation levels when looking at year in school, as the freshmen respondents used the facility more than any other level (Henchy, 2011).

Thirty-one percent of the respondents stated that the presence of the campus recreation facility and its program offerings had a moderate to strong influence in their decision to maintain enrollment. Another significant finding was that $96 \%$ of respondents either agreed or strongly agreed the campus recreation facility positively affected overall student life experience at the institution. Henchy (2011) found $34 \%$ of the respondents stated their participation in campus recreation activities moderately or strongly improved their sense of belonging to the campus community. These study findings demonstrate campus recreation facilities and programs play a key role in student retention. Involvement in campus recreation has been shown to provide an outlet for social relationships with peers, which Tinto (1993) demonstrated as being critical in student persistence. Next, this review will include a discussion on some of the potential variables, which could influence overall student retention rates.

\section{Factors Influencing Student Retention}

Early researchers placed the blame for departure rates entirely on the students (Chase, 1970; Sewell \& Shah, 1967; Wegner \& Sewell, 1970). Researchers have since found many variables affect student persistence rates and total blame should not be placed on the students (Spady, 1970; 1971; Rootman, 1972). The process of students transitioning to college is very complex with numerous variables in play affecting the process and the likelihood of academic success. "The process is a highly interrelated, web-like series of family, interpersonal, academic, and organizational pulls and pushes that shape student learning and persistence" (Terenzini, et al., p. 61, 1994). Thus, this 
section will provide an overview of the literature on how previous academic preparation of the student, race, gender, and socioeconomic status all affect student retention.

College is a time for teenagers and young adults to formulate their own belief systems and is often their first opportunity to make daily decisions about their life experiences without guidance from their parents or caregivers. While the college years provide an opportunity for self-discovery, college students bring with them an historical foundation of beliefs and experiences that greatly influence their educational experience. Astin (1993a) classified student entry characteristics as identifiable attributes of the student as well as any previous experiences the students had encountered.

Astin (1993a) determined over 50\% of the variance in institutional retention rates was explained by the characteristics of the student upon admittance to the institution, rather than the experiences the student was exposed to at school. This finding is critical and demonstrates the importance of institutions understanding the significance of student attributes in the degree attainment process. Additionally, (Astin, 1993b, 1993c) found student characteristics upon enrollment at higher education institutions such as gender, race, and socioeconomic status SES contributed to student academic performance.

Astin and Oseguera (2005) analyzed retention data from 56,818 students attending 262 different institutions in the U.S., which produced two key findings. First, the characteristics of the students upon entering college played an extremely vital role in their overall retention rate. Additionally, the student characteristics at enrollment affected the differences between retention rates at the various participating institutions. Linear regression analyses demonstrated $70 \%$ of the explained variance between the participating institutions degree completion rates was due to the students' characteristics 
upon initial entry at the school (Astin \& Oseguera, 2005). Thus, this large-scale national study demonstrated student academic success was not a result of policy, practice, or instruction at the school, but rather a reflection of their respective recruitment strategies and the type of student attracted to the school.

Additional studies examined specific student entry characteristics. Some of these characteristics include previous academic preparation of the student, race, gender, and socioeconomic status. A succinct overview of each of these characteristics follows.

Previous academic preparation. One of the most common forms of measured ability for incoming college students is their high school GPA, which has been found to be a significant factor of student persistence in college (Astin, 1971, 1973a; Blanchfield, 1971; Chase, 1970; Coker, 1968; Jaffe \& Adams, 1970; Lavin, 1965; Lawhorn, 1971; Panos \& Astin, 1968; Smith, 1971; St. John et al., 2001; Taylor \& Hanson, 1970; Tross et al., 2000). In addition to the significance of high school GPA predicting future academic success, researchers also found the degree of difficulty of high school coursework to be a predictor of college academic success (Kuh, Kinzie, Buckley, Bridges, \& Hayek, 2006). Lee, Bryk, and Smith (1993) showed the academic quality of courses offered at high schools and the manner in which the courses challenged the students were also predictors to future student success in college.

Sewell and Shah (1967) found the measured ability of the student was nearly twice as important in determining student persistence as socioeconomic status. Astin (1971) found performance in high school as measured by GPA or class rank were important predictors of college success. Grade performance and class rank were better predictors of college success than standardized tests. Typically, previous educational 
experiences correspond more closely to the individual's ability to achieve academically and socially in an educational setting (Astin, 1972).

Additionally, Astin (1973a) conducted a four-year longitudinal study at over 200 higher education institutions. His sample included 25,455 students. The study looked at the percentage of students who were able to complete a baccalaureate degree in four years at any institution. The researcher classified transfer students whom completed their degree in four years as successful. Astin (1973a) found student-input characteristics (student attributes) impacted students' academic pursuits. Specifically, students who had a high school grade point average in the A range had a $70 \%$ chance of completing an undergraduate degree in four years. Students with a high school grade point average in the D range only had a $25 \%$ chance of degree completion in four years (Astin, 1973a). Additionally, the study findings demonstrated student standardized test scores upon entering college correlated with the rate of degree completion, in that students who scored favorable on standardized tests had a greater chance of graduating from college in four years. The study findings showed high school GPA to be a better predictor of college academic success compared to standardized test scores (Astin, 1973a). Thus, the present study demonstrated high school GPA was a significant predictor of college academic success.

Mathiasen (1984) conducted a review of sixty articles which examined variables previously evaluated as predictors for future academic success in college. Mathiasen (1984) concluded the two greatest predictors of academic success in college were high school GPA and ACT or SAT scores. These findings are consistent with other scholarly works, which have demonstrated high school grades and standardized test scores are 
significant predictors of academic success in college (Cabrera, Nora, \& Castaneda, 1993; Eimers \& Pike, 1997).

Pike and Saupe (2002) conducted a study on 8,764 freshman students at a research-oriented university located in the Midwest portion of the United States, who had enrolled at the school during fall semesters of 1996 through 1999. The sample consisted of students from 124 different high schools and various ethnic groups. The researchers attempted to determine the impact student entry characteristics related to academic preparation during high school had on predicting student grades during the first year at the university. The findings demonstrated high school academic performance, earned standardized test scores, and types of courses the students completed during their high school years accounted for $33 \%$ of the variance in the grades earned by first-year students (Pike \& Saupe, 2002).

Pike and Saupe's (2002) findings were consistent with previous research, which indicated high school academic success was a significant predictor for academic success in college (Mathiasen, 1984; Pascarella \& Terenzini, 1991). However, Adelman (1999) conducted a national study and found academic preparation of college students only accounted for $17 \%$ of the variance in college graduation rates. Thus, while important, academic preparation is not the sole predictor of academic success in higher education.

Race. A common variable examined in the retention literature is how race affects academic success and if disparities exist between different races regarding student academic preparation. Researchers have shown a large disparity in retention rates among different racial groups, specifically African-American students enrolled at predominantly white institutions (Harvey, 2001; Kroc, Woodard, Howard, \& Hull, 1995; National 
Collegiate Athletic Association, 2001; Porter, 1990). High rates of attrition among minority students at universities are an area of alarming concern (Bennett \& Okinaka, 1990). In fact, Bennett and Okinaka (1989) found the 1982 freshman cohort at Indiana University experienced attrition rates three and a half years later at $65 \%$ for African Americans, 52\% for Hispanics, $46 \%$ for American Indians, 27\% for Asians, but only $21 \%$ for Caucasians. Unfortunately, these alarming attrition rates experienced at Indiana University were representative of most institutions across the country and in fact, many institutions have not seen attrition rates decrease (Carey, 2005a, 2005b; NCES, 2005).

Skinner and Richardson (1988) determined the social atmosphere at predominantly white institutions was problematic for minority students, including those individuals with strong high school academic preparation. Tinto (1987) found the underlying factor in persistence rates in higher education between minorities and nonminority students was academic preparedness. Numerous studies have found minority students enrolling in college arrive with a weaker academic background, as compared to non-minority students (Hu \& St. John, 2001; Johnson, 1990; Mingle, 1987; Mow \& Nettles, 1990; Nettles, 1990).

Many researchers discuss the relationship between minority status and retention. The minority population may be lacking in academic preparedness due to deficiencies in the curriculum and educational opportunities available to them (Hu \& St. John, 2001; Mow \& Nettles, 1990; Nettles, 1990; Tinto, 1987). The retention literature demonstrates these disparities of academic preparation greatly influences student success and persistence rates (Astin, 1982, 1993a; Crosson, 1988; Fleming, 2002; Hu \& St. John, 
2001; Kennedy \& Sheckley, 1999; Mow \& Nettles, 1990; Noel, 1978; Opportunity for Postsecondary Education, 1996, 2000).

Research has shown socio-cultural factors impact the academic adjustment and achievement levels of minorities (Gibbs, 1975; Nettles, Theony, \& Gosman, 1986; Tracey \& Sedlacek, 1985). To move beyond the comparison of retention percentages for minority students, universities need to determine how various aspects of the campus environment affect students from different racial groups.

Mallinckrodt and Sedlacek (1987) administered a survey to a random sample of 207 second-semester freshmen at the University of Maryland to determine if student usage of campus facilities influenced student retention. The researchers used discriminant analysis to determine if facility usage statistically affected enrollment at the university the following fall semester. Hours spent using the campus recreation facility were found to be statistically significant for African American students, as those individuals with more time spent at the gym also demonstrated a higher likelihood of returning to the institution the next academic year. This significant finding did not hold true for other racial groups in the study (Mallinckrodt \& Sedlacek, 1987). The finding of African American students' academic success being impacted by non-academic variables are in line with previous research which demonstrated it is critical for African American students to address non-academic matters such as developing a feeling of a community and support system (Sedlacek \& Brooks, 1976; Tracey \& Sedlacek, 1984, 1985). The researchers believed this was attributable to the students' need for a sense of community and the environment of recreation centers and other campus facilities or conducive for informal student interactions (Mallinckrodt \& Sedlacek, 1987). University administrators 
should implement retention strategies promoting student usage at various campus facilities, including the campus recreation center.

Bradley, Phillipi, and Bryant (1992) conducted a study using the Quality and Importance of Recreational Services (QIRS) survey to determine the impact of campus recreation participation on student success for minority students. The researchers collected data from 2,000 students, 200 of whom identified as minority students. Minority students accessed recreation facilities quite frequently. In fact, $90 \%$ of the responding minority student participants reported they participated in recreation activities weekly. Most of them utilized the services of the recreational facility a minimum of three times weekly. Minority students cited the presence of campus recreation facilities and programs as significant factors in their decision to continue enrollment (Bradley et al., 1992).

Additionally, minority students reported involvement in recreation programs helped with their overall stress management by decreasing perceived stress levels while improving overall self-confidence. The researchers conducted an ANOVA analysis and determined the perceived benefits of participation in recreation programs was much greater for African American students as compared to Caucasian students. The study showed minority students viewed participation in recreation programs as a social asset by increasing the likelihood of interactions with faculty, staff, and university administrators. A chi-square analysis showed African-American respondents perceived having a greater opportunity to interact with campus administrators during their participation in recreation activities as well as significantly greater amounts of opportunities for interaction with faculty (Bradley et al., 1992). 
As an extension to the work of Bradley et al. (1992), Bryant, Banta, and Bradley (1995) also used the QIRS survey. The researchers administered the survey to 2,586 students at six institutions consisting of a private four-year school, a public two-year school, and four public four-year institutions. Ninety-five percent of the respondents reported they participated in recreational activities several times per week. Additionally, participants stated they were $20 \%$ more likely to participate in a recreational activity than any other type of campus-sponsored program. Thirty percent of respondents stated the presence of campus recreational facilities and programs was a motivating factor when deciding to stay at the school (Bryant et al., 1995).

Minority students in the sample placed a greater level of significance on the presence of campus recreation facilities and programs as compared to Caucasian respondents. African American male respondents ranked campus recreation facilities and programs the highest. The student participants cited campus recreation provided an opportunity for them to interact with faculty and administrators in an informal setting. The researchers determined social integration occurring within the confines of the campus recreation facility was a key factor in student persistence (Bryant et al., 1995). A significant contributor to student success is students' informal interaction with university personnel (Astin, 1975; Pascarella, 1980). The study findings demonstrate the significance campus recreation has on retention of minority students, which is an area of needed improvement for most institutions.

Green and Gonsoulin (1997) found recreation centers are used as a site for social connections among students. Kovac and Beck (1997) supported these findings. The researchers evaluated recreational program participation levels of women and minority 
students. The findings demonstrated the presence of recreational facilities and recreational programs impacted students' decisions to continue at the institution. Both the female and minority respondents cited their participation at the recreation center led to both physical and emotional benefits. Additionally, $67 \%$ of the minority respondents stated the presence of recreational facilities and programs influenced their decision to stay at the institution, as compared to $36 \%$ of the Caucasian respondents (Kovac \& Beck, 1997). These findings demonstrate the importance of recreational sports programs and facilities as a retention tool for the campus community.

It becomes clear from the previous discussed studies that there are differences in how race impacts the adjustment of the student to college, both academically and socially. Higher education institutions must better understand how race impacts student retention, as the student body will continue to increase in diversity (Keller, 2001; Terenzini \& Pascarella, 1998; Woodard, Love, \& Komives, 2000). Next, the role gender has on student retention is discussed.

Gender. In a large national study conducted at over 200 institutions, Astin (1973b) found that female students who were in serious relationships and felt there was a high chance of getting married during the four-year period of college, were far less likely to complete their degree. The findings from the study are most likely reflective to this time in history and thus it would be inaccurate to generalize to women's career aspirations in modern society. Mortenson (2003) showed in the 1970s a very large percentage of the number of students obtaining a bachelor's degree were male. These findings were reflective across the entire country and seem to be consistent with the expectations of women's roles in the workforce during this era in our nation's history. 
Clearly, the gender roles have changed since the early 1970's and as a result, more women are actively pursuing careers in the workforce. As a result, Mortenson (2003) showed the pendulum had shifted and graduation data in 2001 in the U.S. demonstrated more females were graduating with bachelor's degrees than males.

Buchmann and DiPrete (2006) supported the results of Mortenson (2003), in that the researchers reported women were attending higher education institutions at a greater rate than males as well as graduating at a higher rate. Additionally, the U.S. Department of Education National Center for Education Statistics reported in 2012 that from the academic year of 1999-2000 through the academic year 2009-2010 the percentage of female graduates obtaining a bachelor's degree was between 57 and 58 percent. A 2014 report prepared by the Council of Economic Advisors, part of the Executive Council for the President of the U.S., found women in the age range of 25-34 enrolled at American institutions were more than $20 \%$ more likely than male students to graduate from their respective higher education institution (Council of Economic Advisors, 2014).

In a study conducted by Dwyer, Hodson, and McCloud (2013) female students who elected to stop attending a higher education institution had a much bleaker future earning potential than their male counterparts, who elected to withdraw from higher education institutions. Dwyer et al. (2013) attributed this premise to the reality of the available jobs for individuals without college degrees was more trade focused, which historically are heavily male dominated professions. This finding could help explain why female students are now graduating at a higher rate than male students are. The bleak job market for females without college degrees could be enough motivation to keep more female students persisting towards a college degree (Dwyer et al., 2013). 
While there are identifiable differences in retention rates regarding gender, there are additional variables impacting student retention rates. One area that impacts student retention is the cost associated with obtaining a college degree. Thus, the review will include a discussion on how access to financial aid and the socioeconomic status of the student impacts overall student retention rates.

Financial and socioeconomic status. Many studies conducted in the field of student retention have included SES as a possible contributing factor to student retention. In a large national study conducted at over 200 institutions, Astin (1973a) found no direct correlation between the income levels of the student's parents and graduation rates in college. However, the study results found a significant positive relationship between students receiving scholarships and graduation rates. Students receiving scholarships had a $15 \%$ greater chance of completing a college degree as compared to those students in the study, who did not receive any type of scholarship funding (Astin, 1973a).

While the earlier work of Astin (1973a) found no direct correlation between the income levels of the student's parents and graduation rates, Astin (1993b, 1993c) found students who had come from high SES families displayed a greater likelihood to have positive experiences during their college experience, as compared to their low SES peers. Additionally, the work of St. John, Cabrera, Nora, and Asker (2000) showed the economic status of the student could impact student retention rates.

Kuh et al. (2006) found the SES levels of the students did influence their decision making regarding college. Students from higher SES levels were more likely to aspire of attending college, as well as more likely to follow through with completing the college application process. Institutions accepted applicants with higher SES levels at a greater 
frequency than students from lower SES levels (Kuh et al., 2006). Similarly, Swail, Cabrera, Lee, and Williams (2005) found SES to impact academic success. Specifically, Latino students included in the study from middle class SES families had a 17\% greater likelihood in obtaining a bachelor's degree as compared to the Latino students in the study from low SES families (Swail et al., 2005).

Thayer (2000) found minority students coming from a lower SES background were impacted negatively by their financial limitations. In fact, Cabrera, Burkum, and $\mathrm{La}$ Nasa (2005) showed students in lower SES classifications were more likely to attend a two-year institution over a four-year institution. The researchers even found this to hold true for lower SES students that had attended a K-12 facility, which offered similar academic services and opportunities as higher SES schools (Cabrera et al., 2005). Additionally, other research has shown students from lower SES classifications are less likely to decide to apply and attend more selective colleges and universities, even when they have experienced and been offered similar academic services and opportunities offered to higher SES students (Carnevale \& Rose, 2003; Bowen, Kurzweil, \& Tobin, 2005).

Choy (2002) acknowledged the rising cost of higher education was a factor for potential students in determining if they would pursue a college degree as well as the institution they would attend. The rising costs of education played a greater role in the decision to attend college for students in the low income and middle socioeconomic classes (Choy, 2002). Finally, Choy (2002) reported the availability of student financial aid for prospective students in the low and middle socioeconomic classes seemed to help 
offset some of the financial concerns for these prospective students and thus increased their likelihood of enrolling at the school.

While the availability of financial aid has proven to help address some of the enrollment concerns of prospective students in lower socioeconomic concerns, this shift in dependency of borrowing funds to finance a college degree has resulted in negative financial consequences post-graduation (Baum \& McPherson, 2008). More students are graduating or leaving higher education institutions with debt and will be required to spend many years in repayment of expenses incurred during their educational pursuits (Dwyer et al., 2013).

\section{Summary}

As documented in this literature review, student retention research is not new to higher education. Even though the study of student retention started many decades ago, this line of research is still pertinent in the present educational landscape. One could even argue student persistence is even more critical today for universities because of the financial strains placed on higher education institutions due to substantially decreased levels of financial assistance from both national and state levels. Universities have come to realize it is fiscally more responsible and affordable to retain existing students who are considering departing the institution than to allow them to walk away, which results in the school having to recruit new students. Thus, researchers continue to examine potential influencers to student academic success and overall student persistence rates at higher education institutions.

Through this historical work, researchers found many different variables shown to have an association with student persistence. While individual studies have shown these 
variables had a correlation with student persistence, this line of research has not been able to determine that the presence of one specific variable guarantees $100 \%$ student retention in all cases and at all institutions. Rather, student retention research demonstrated successful student retention programs encompassed many different variables. In other words, the academic success of the student and the continued persistence towards degree completion resulted from the presence of many different experiences and student attributes. Student academic success and persistence requires many different attributes to be present.

This literature review included a discussion on how student entry characteristics and student attributes influenced student's decision to maintain enrollment in school. Astin (1993a) determined over $50 \%$ of the explained variance in institutional retention rates was due to characteristics of the student upon admittance to the institution. One of the most common forms of measured ability for incoming college students is their high school GPA, which has been found to be a significant factor of student persistence in college (Astin, 1971, 1973a; Blanchfield, 1971; Chase, 1970; Coker, 1968; Jaffe \& Adams, 1970; Lavin, 1965; Lawhorn, 1971; Panos \& Astin, 1968; Smith, 1971; Taylor \& Hanson, 1970).

In addition to high school GPA, the literature review demonstrated that the student entry characteristic of high school class ranks also had a positive correlation with student persistence. The review of literature showed grade performance and class rank were better predictors of college success than standardized tests. Typically, previous educational experiences correspond more closely to the individual's ability to achieve academically and socially in an educational setting (Astin, 1972). Skinner and 
Richardson (1988) determined the social atmosphere at predominantly white institutions was problematic for minority students, including those individuals with strong high school academic preparation. Tinto (1987) found the underlying factor in persistence rates in higher education between minorities and non-minority students was academic preparedness. Numerous studies have found minority students enrolling in college arrive with a weaker academic background, as compared to non-minority students (Hu \& St. John, 2001; Johnson, 1990; Mingle, 1987; Mow \& Nettles, 1990; Nettles, 1990). Finally, the demographic factor of financial status of the students receiving scholarships had a $15 \%$ greater chance of completing a college degree as compared to those students in the study, who did not receive any type of scholarship funding (Astin, 1973a).

This literature review specifically discussed how participation in physical activity benefited individuals physically, mentally, socially, and academically. Throughout history, there has been substantial amounts of research conducted in the K-12 setting, which examined the benefits of physical activity participation. These findings have consistently shown participation in physical activity resulted in positive outcomes. Caterino and Polak (1999) found fourth grade students who were part of a physical activity intervention had significantly higher concentration scores than students who were part of the traditional classroom group and did not receive additional physical activity opportunities. Additionally, a different study found participation in exercise by children increased their overall mental functioning, which aided their overall cognitive development (Davis et al., 2007).

Grissom (2005) found as students' fitness levels improved so did their performance on the Stanford Academic Achievement Test. While the results were 
significant for both boys and girls, the positive relationship was larger and showed greater strength for the female study participants. Additionally, students with higher SES demonstrated a stronger relationship between fitness levels and academic success as compared to students in lower SES levels (Grissom, 2005). In a similar study conducted by Tremarche et al. (2007), the researchers examined the influence of increased instructional time in physical education towards obtained scores on academic assessments. The researchers found students who received more physical education instructional time scored significantly higher on the English and language arts portion of the MCAS assessment. Additionally, there were no significant differences between the two groups on the mathematics portion of the MCAS assessment (Tremarche et al., 2007).

Wittberg et al. (2009) found a positive correlation between the physical fitness levels of students and their academic achievement. Additionally, Lindner (2002) found high school students who were more physically active had higher GPAs than less physically active students did. Finally, Nelson and Gordon-Larson (2006) found physically active students had a $20 \%$ greater chance of earning an A letter grade in their mathematics and English courses as compared to their more sedentary peers.

In addition to increased levels of academic success, the review of literature demonstrated a direct positive link between participation in physical activity and overall health. Fleshner (2000) found participation in PA improved blood circulation throughout the body, including the brain, which may cause lower levels of stress, act as a mood enhancer, and result in increased levels of academic success. Physical inactivity in youth 
today has resulted in a dramatic increase in the prevalence of pediatric obesity, which has many negative health consequences (Daniels et al., 2005; Strauss \& Pollack, 2001). Additionally, Sparling (2003) explained the importance of college-aged students participating in physical education courses to effectively promote physical activity and address the ever-growing obesity epidemic in the U.S. Sparling discussed the opportunity for numerous health benefits gained from participation in physical education courses at the university setting. By both offering and requiring physical education courses in the higher education setting, institutions have the chance to address the lack of physical activity participation by young adults and help combat growing health concerns. Sparling explained how beneficial it would be if more institutions would go back to earlier degree requirements, where physical education was typically a part of the general education curriculum and a graduation requirement for all students (Sparling, 2003).

Leenders et al. (2003) discussed the opportunity available to colleges and universities to promote healthy behaviors for students to demonstrate the value and worth of physical education BIP courses at higher education institutions. More specifically, institutions can instill an interest in physical activity participation by promoting enrollment in physical education BIP courses and structuring the courses in such a manner to either slow or prevent the occurrence of various health related disparities (Leenders et al., 2003). Previous research has shown enrollment in physical education activity courses provides a logical setting to educate college age students about lifestyle choices and health risk behaviors (Dale \& Corbin, 2000; Pearman et al., 1997).

Participation levels in physical activity continue to decrease after high school and then decreases even further after college (Caspersen et al., 2000; Sparling \& Snow, 
2002). Physical education offerings at the college level are often the last opportunity for individuals to receive education-based training dealing with exercise and fitness without having to pay at fitness centers or to employ specialized trainers (NASPE, 2007). There is a consistent negative correlation with age and participation in fitness (Caspersen et al., 2000; Sparling \& Snow, 2002). Research has shown one approach to address the negative correlation between age and participation in fitness is to get more college aged students enrolled in physical education courses during their academic experience. In fact, graduates from higher education institutions where physical education was a degree requirement were more likely to participate and live an active lifestyle post-graduation than graduates of schools lacking this requirement (Adams \& Brynteson, 1992;

Brynteson \& Adams, 1993; Sparling \& Snow, 2002).

The national trend of decreasing the number of physical activity opportunities has long lasting consequences, including in mental health. Physical activity involvement helps to address stressful situations (Sax, 1997). Students, especially those in higher education, find the process of navigating the educational landscape quite stressful and daunting (Abouserie, 1994; Goodman, 1993; LeRoy, 1987). Avery and Lumpkin (1987) found enrollment in physical education courses at the higher education level linked with higher levels of self-esteem and greater levels of self-worth.

Social interactions and experiences with peers affect students' self-esteem and self-worth. Physical activity opportunities are often social in nature; thus, many people turn to these offerings to associate with peer groups. Participation in recreational sports programs positively impacted student development (Bryant \& Bradley, 1993). Lamont 
(2010) found new students at university campuses and colleges had a much greater need to establish a peer group and socially integrate with others.

Lamont (2010) found first and second year students at higher education institutions used recreational facilities at a rate nearly three times greater than upper level students. This finding shows students' need to find a social network during their early years at the institution. Additionally, a different study found first-year students demonstrated significantly higher social benefits from participating in intramural sports compared to fourth-year students (Artinger et al., 2006). Churchill and Iwai (1981) found a significant correlation existed between campus facility usage and the overall student persistence levels of students with low GPAs. In fact, the retained students with low GPAs at the institution had frequented campus facilities at a more frequent rate as compared to the students with low GPAs that withdrew from the school (Churchill \& Iwai, 1981).

In a different study conducted by Belch et al. (2001) the researchers found similar findings, in that student recreation users completed a larger number of academic credits during their first academic year than facility non-users. Persistence rates for facility users after the first academic year were higher than for non-users ( $71 \%$ vs. $64 \%)$. The researchers found as the number of visits to the facility increased during the first year, so too did the student GPA and persistence rates. In fact, the group of students with 50 or more visits during their first semester on campus had the highest persistence rates in the study.

Lindsey and Sessoms (2006) found that the presence of a campus recreation facility and its program offerings influenced the decision of the students to continue their 
educational pursuits at the institution. The study findings demonstrated a correlation between the overall student satisfaction levels of the students and their access to campus recreation facilities and programs. Additionally, a different study showed students, who frequented campus recreation centers at a frequency that was one standard deviation above the sample average had a predicted GPA that was 0.11 greater and had a $1 \%$ greater likelihood of being retained (Huesman et al., 2007). These findings demonstrate the considerable influence participation in fitness and sports in a campus recreational setting has on academic success of students.

The literature review showed a substantial amount of empirical studies conducted in the K-12 setting. Additionally, the existing studies conducted at the university level were in recreational settings, instead of the academic side. Thus, while the literature review presented numerous benefits of participation in physical activity, it became apparent one of the major gaps in the literature was the extremely limited amount of empirical evidence conducted on determining if academic gains were associated with physical education course enrollment during the college academic experience. One of the most pressing issues in the higher education landscape is addressing and determining effective strategies to increase student retention rates. Attinasi (1989) and Tinto (1993, 1997) demonstrated student academic success and persistence were impacted by the student's ability to become socially and academically integrated at the institution. Astin (1993b, 1993c) found student characteristics upon enrollment at higher education institutions such as gender, race, and socioeconomic status (SES) contributed to student academic performance. Additionally, the literature review provided further explanation how these student entry characteristics affected the academic success and likelihood of 
retention. Therefore, the purpose of this study was to determine how student entry characteristics along with enrollment in a university physical education activity course affected the overall undergraduate student retention rates at a metropolitan research institution located in the southern region of the U.S. 


\section{CHAPTER III}

\section{METHOD}

This chapter provides an overview of the methodological approach used in the current study. First, the section includes a discussion of the research purpose. Next, the section contains a discussion of the research questions and the research design. The chapter concludes with a discussion of the data collection procedures used, an overview of the study participants, the sampling methods used, and a discussion of the data analysis used.

\section{Research Purpose}

The higher education landscape has seen a shift in the significance placed on student retention (Tinto, 2006). Due to decreased state funding levels, institutions are aggressively seeking alternative funding sources. As a result, schools are in search of programs and initiatives which potentially could increase overall student retention rates. The purpose of this study, therefore, was to determine how enrollment in university physical education activity courses affected the overall undergraduate student retention rates at a metropolitan research institution located in the southern region of the United States. The university where the study was conducted does not include enrollment in a physical education course as part of the general education degree requirements. Undergraduate degrees offered by the Health and Sport Sciences Department, however, 
do include enrollment in two physical education activity courses as a degree requirement. The participating institution offers numerous types of physical activity courses each semester for elective purposes.

\section{Research Questions}

To examine the role enrollment in physical education activity courses had on academic success and overall student retention rates in a university setting, several research questions were formulated.

RQ1 - Who is enrolling in BIP courses and how do they differ from the rest of the student population?

RQ1a-Does a student's gender influence enrollment in BIP courses?

RQ1b-Does a student's race influence enrollment in BIP courses?

RQ1c- Does a student's high school GPA influence enrollment in BIP courses?

RQ1d- Does a student's ACT composite score influence enrollment in BIP courses?

RQ1e- Does a student's PELL eligibility status influence enrollment in BIP courses?

RQ1f- Does a student's declared college major influence enrollment in BIP courses?

RQ2 - How does the year of BIP enrollment and the number of BIP classes enrolled in influence student retention?

RQ3 - How is the relationship between enrollment in BIP courses and retention influenced by student characteristics? 
RQ3a-Does a student's gender influence the relationship between enrollment in BIP courses and retention?

RQ3b-Does a student's race influence the relationship between enrollment in BIP courses and retention?

RQ3c-Does a student's cumulative GPA at the end of their freshmen academic year influence the relationship between enrollment in BIP courses and retention? RQ3d-Does a student's high school GPA influence the relationship between enrollment in BIP courses and retention?

RQ3e-Does a student's combined ACT score evaluated during high school influence the relationship between enrollment in BIP courses and retention? RQ3f-Does enrollment in a Health and Sport Sciences (HSS) major (Health \& Human Performance and Sport Administration) influence the relationship between enrollment in BIP courses and retention?

RQ3g-Does a student's classification of PELL eligibility influence the relationship between enrollment in BIP courses and retention?

\section{Research Design}

The quantitative, ex post facto study design used existing historical data provided to the researcher by the Office of Institutional Research and Planning (IRP) at a metropolitan public research university located in the southern region of the United States. Vogt (2005) defines an ex post facto research design as, "Any investigation using existing data rather than new data gathered specifically for the study" (Vogt, 2005, p.

114). Analysis of historical data provided the researcher the opportunity to predict future outcomes based on the historical findings. The use of historical data was extremely 
useful for the study, since the stated purpose of the research study was to determine how enrollment in BIP courses affected student retention and persistence toward graduation. The office of IRP removed all personal identifiable information before the researcher gained access to the data set. To ensure confidentiality, the IRP office assigned each student with a unique project identification number. This number was not the student's university assigned ID number. This predictive study examined the relationship of students' entry characteristics and attributes of their college experience with retention rates at a public metropolitan university located in the southern region of the United States.

\section{Data Collection and Sampling Procedure}

The office of IRP at a metropolitan public research university provided the historical data set. As previously stated, the office of IRP removed all identifiable personal characteristics before the researcher was provided access to the data set. This historical data sample consisted of all first-time, full-time, baccalaureate degree-seeking freshmen at the selected institution over the two-year period of 2014-2015. The study consisted of a retrospective cohort design, which assessed the relationship between activity course participation and student retention. The freshmen cohorts had sample sizes of the following: 2014 cohort $(\mathrm{N}=2,830)$ and 2015 cohort $(\mathrm{N}=2,735)$. Thus, the total sample size for the study was $(\mathrm{N}=5,565)$. The vast size of the study sample was representative of the population, as the larger the size of the sample, the more reflective the results of the study were for the total population.

The university that provided the data set for the sample characterized student retention as a student who returned for the next fall semester following the previous fall 
semester enrollment. For example, students in the fall 2014 freshmen cohort were classified as retained after year one if they were enrolled at the same institution during the fall 2015 semester. Year two retention for the fall 2014 freshmen cohort was when the student was enrolled at the school at least in a part-time basis in the fall 2016 semester. Additionally, students in the fall 2015 freshmen cohort were classified as retained after year one if they were enrolled at the same institution during the fall 2016 semester. Year two retention for the fall 2015 freshmen cohort was when the student was enrolled at the school at least in a part-time basis in the fall 2017 semester. Thus, for this study student retention was defined as a student enrolled in classes at the same university the following fall semester on at least a part-time basis.

The IRP office analyzed student records and pulled data of academic readiness for college from each of the student application files. The application files provided information on high school GPA, which was used to demonstrate academic readiness for college. Additionally, the IRP office provided the researcher with combined ACT scores of the students from their application files. The obtained ACT scores were an additional way to demonstrate the student's academic readiness for college. The IRP office pulled the remaining information required for the data set from the student records of each student included in the sample.

\section{Study Participants}

The sample for the study consisted of all first-time, full-time, baccalaureate degree-seeking students enrolled at a metropolitan public research university located in the southern region of the United States during the years of 2014-2015. The criteria of first-time degree seeking students excluded all transfer students from the study sample, 
thus any students who previously attended a different institution were omitted. Students who had completed college level work during high school were included in the study sample.

It is important to understand the profile of the student at the institution used in the study. During the years 2007-2016, the university that provided the data set had an average of 2,630 first-time, full-time baccalaureate degree seeking freshmen students enrolled each year. The ten-year average high school GPA for incoming students was 3.54, on 4.0 scale. The average ACT score during the ten-year period for incoming freshmen was 24.9. Additionally, during this ten-year period, the institution averaged 896 incoming freshmen students scoring 27 or higher on the ACT test annually. This represented $33.9 \%$ of all first-time, full-time baccalaureate degree seeking students at the institution. Additionally, over the ten-year period, the university enrolled an average of 540 new minority freshmen students per year, which represented $20.2 \%$ of all first-time, full-time baccalaureate degree seeking students. Finally, $82.9 \%$ of all incoming firsttime, full-time baccalaureate degree seeking students over the ten-year period were classified as in-state residents and a total of $39 \%$ of the in-state students resided in the same county as the institution.

In addition to understanding the student profile at the participating institution, it is also important to understand the characteristics of the BIP. The program provides a variety of course offerings based in fitness, individual sports, team sports, dance, and aquatics for academic credit. During each fall and spring academic semesters, the program offers between 35-50 courses per semester. While a limited number of institutions still require enrollment in physical education activity courses as part of the 
general education requirement, the university used in the existing study does not have such a requirement for the general student population. However, the Health and Sport Sciences (HSS) Department, which is the home department of the BIP, does require all declared majors to complete two hours of academic credit in physical education activity courses.

\section{Variables}

The data set provided by the IRP office contained demographic information for the participants. The variables included in the study were gender, race, high school GPA, ACT composite test score, PELL eligibility, intended college major, number of BIP courses enrolled in, year of enrolled activity courses, and cumulative college GPA at the end of the freshmen academic year. Additionally, the data set included if the student had been retained, which was the dependent variable in the study. This dichotomous variable was coded as a " 1 " if the student was enrolled in courses at the participating institution the following fall semester and a " 0 " if the student was not retained at the school the following fall semester. As stated earlier, the IRP office categorized a student as retained if the student was enrolled in courses at the university the following fall semester. Thus, the students in the sample from the 2014 freshmen cohort were classified as retained if they were still enrolled at the same institution for classes at least on a part-time basis during the fall 2015 semester (year one) and during the fall 2016 semester (year two). Additionally, the students in the sample from the 2015 freshmen cohort were considered

retained if they were still enrolled at the same institution for classes at least on a part-time basis during the fall 2016 semester (year one) and during the fall 2017 semester (year two). Additional demographic information included: 
Gender: This nominal variable had two possible classifications $(1=$ female, $2=$ male). Gender information was obtained from the student's application records. Race: For this nominal variable, students in the data set were classified into one of two classifications $(0=$ Minorities; $1=$ White $)$.

High School GPA: This continuous interval variable on a 4.0 scale was obtained from the student's application records.

ACT test score: This continuous interval variable was obtained from the student's application records. The combined composite total score was used.

Financial Aid Status: Students were classified into one of two nominal classifications based on their need based financial aid status. ( $1=$ Yes, PELL eligible and $0=$ No, not PELL eligible).

College Major: Student's intended college major was obtained from their application records. The student's self-reported college major was included in the data set. Students were classified into one of two nominal classifications. ( $1=$ HSS major; $0=$ All other declared majors).

Number of BIP Courses: This continuous interval variable was obtained from student records and showed the number of BIP courses taken during the student's freshmen and sophomore academic years.

Academic Year of BIP Enrollment: Year of enrollment in BIP courses was obtained from student records. Students were classified into one of two nominal classifications.

Cumulative College GPA: This continuous interval variable on a 4.0 scale was obtained from student records. The cumulative GPA at the end of the first year 
was used.

\section{Analysis}

Descriptive statistics were used to address all the sub sections of RQ1.

Descriptive statistics were important to include as they provided a clearer description of the subjects. These descriptive statistics aided in describing the makeup of the two freshmen cohorts at the time of enrollment in their first academic year at the institution. This information included student gender, race, high school GPA, ACT combined test score, financial aid status, and intended college major. Information on the number of BIP courses enrolled in during the freshmen and sophomore academic years was included. Additionally, the semester in which enrollment in BIP courses occurred was included. Finally, an analysis of student cumulative freshmen GPA at the completion of the first academic year was included.

In addition to analyzing the descriptive statistics of the data set, Pearson's chisquare tests and independent samples $t$-test were used to analyze the variables. The use of a chi-square test was effective when attempting to determine if a relationship existed between two categorical variables (Field, 2013). The dependent variable of student retention was categorical in nature and was recorded as (1=Student was retained; $0=$ Student was not retained). A student was classified retained after year one if the student continued enrollment at the selected university in the fall semester following his/her first academic year at the institution. The student was classified retained after year two if the student continued enrollment at the selected university in the fall semester following his/her second academic year at the institution. The independent variables of gender, race, PELL eligibility, and declared college major were both dichotomous and 
categorical in nature and thus a chi-square analysis was appropriate. A contingency table, which displays frequencies of categorical variables, is produced when conducting chi-square tests (Vogt, 2005). This technique of analyzing the frequencies in a contingency table is also called cross tabulation (Vogt, 2005).

Two assumptions must be met before one can effectively use the chi-square statistical procedure. The first assumption was that the statistical test cannot be used in a repeated measures design. Thus, the student participants must only be classified into one category of the contingency table, which was the case for the existing study (Field, 2013). For example, regarding the variable of financial aid status, the PELL eligible students were classified in the contingency table as either retained or non-retained, but not in both categories. The second assumption was that the expected frequency in each of the columns of the contingency table needed to have a frequency greater than five (Field, 2013).

Logistic regression was used to address RQ2. The use of logistic regression provided the opportunity to predict the outcome of the discrete dependent variable (Tabachnick \& Fidell, 2001). Logistic regression analysis predicts the probability of an event occurring using an odds ratio (Field, 2013). In the present study, the dependent variable of a student being retained fits the criteria of being discrete in nature. Additionally, logistic regression works well in analyzing a single dichotomous (categorical) dependent variable. In the present study, student retention was dichotomous. In fact, Osborne (2015) touted logistic regression as the best statistical technique to use when the dependent variable was dichotomous or categorical. 
Meyers, Gamst, and Guarino (2006) explained the best practice for coding in logistic regression was to have the predicted event coded as the number one and the nonoccurrence outcome of the event coded as the number zero. Specifically, regarding the dependent variable of student retention, the researcher examined if an occurrence or nonoccurrence existed. If the student was enrolled in courses the following fall semester after his/her first or second year, s/he was classified as retained, and coded as a "1". If the student was no longer enrolled in courses the following fall semester after either their first or second year, he/she was coded a "0", and was perceived as a student who withdrew and didn't persist toward graduation at the specific institution used for data collection. As a point of clarification, one should not assume that all students who didn't maintain enrollment in classes at the institution used in the study ended their academic pursuits completely. The data provided by the IRP office at the institution did not consider students who withdrew but transferred to a different institution the following fall semester. Thus, the present study only examined the retention rates for the two freshmen cohorts at the specific institution.

The use of a dichotomous dependent variable prevented the researcher from using other regression techniques, as it would have violated the assumption that the outcome variables must be continuous. Additionally, there is an assumption of linearity in multiple regression, meaning there is a linear relationship between the independent variable and the dependent variable (Field, 2013). Logistic regression is nonlinear in nature because the statistical procedure gives the researcher the opportunity to take a categorical dependent variable and predict its outcome from the independent variables, which could be binary, categorical, or continuous in nature (Osborne, 2015). Logistic 
regression does not require an equality of variance assumption, such as found in other regression models and ANOVA.

Logistic regression can be used to analyze a problem with a single dependent variable and one or more independent variables. The logistic regression procedure allowed the researcher the opportunity to examine the effects of multiple independent variables on student retention, as well as assess the interaction effects between the independent variables. Additionally, this statistical procedure allowed the researcher the opportunity to distinguish which of the independent variables used in the study were the best predictors of student retention. Researchers examine the overall model fit of regression models by examining the multiple $R$ value and determining the overall amount of variance accounted for by the model with $\mathrm{R}^{2}$. However, logistic regression does not determine these statistics. Rather, logistic regression determines the concept of deviance, which shows the lack of fit from the observed data (Osborne, 2015).

Logistic regression allowed the researcher the opportunity to determine the probability an event would occur. Probability of an event was determined by taking the number of instances of the event divided by the total number of observations (Osborne, 2015). This determined probability value can be slightly misleading, however, as the probability value is not entirely representative of all subjects included in the study sample. Thus, logistic regression allows the researcher to determine conditional probability, which narrows the probability of an event occurring to a more specific condition (Osborne, 2015). Determining conditional probability gives the researcher the opportunity to effectively decide the attributes present in the subjects, when the outcome variable was met. Graphing the probability results from logistic regression analysis 
results in a logistic curve. "This curve, called a logistic curve (among other names), represents the conceptual underpinning of logistic regression-that the probability that something will happen can be predicted from other variables, that these relationships are usually curvilinear, and often asymptotic" (Osborne, 2015, p. 25). Interpretation of the logistic curve provides an opportunity for the researcher to analyze the ranges the independent variables helped to predict the outcome variable.

Conditional odds consider how other variables affect conditional probability (Vogt, 2005). "Conditional odds are the odds that an outcome (i.e., dropping out) will happen given a particular value of another variable (i.e., being below or above average in family income)" (Osborne, 2015, p. 27). Conditional probability is the term used to describe the chance an event will happen due to the fact another condition or event is also present (Vogt, 2005). Interpretation of conditional probability is often quite challenging to understand, however, since there is not a clear explanation of what the conditional probability figures are being compared with.

Thus, when using logistic regression to analyze data, a value known as the odds ratio is reported (Osborne, 2015). Odds ratio is defined as, "A ratio or one odds to another. The odds ratio is a measure of association, but unlike other measures of association, "1.0" means that there is no relationship between the variables" (Vogt, 2005, p. 219). The distance the odds ratio value is further away from the value of one, the greater the relationship. A positive relationship exists when the odds ratio value is greater than the value of one and a negative relationship exists when the odds ratio value is smaller than the value of one (Vogt, 2005). "In general, odds ratios are calculated as the change in odds for every 1.0 increase in the IV. In the case of binary IVs, it is the 
comparison of those in the "1" group to those in the "0" group" (Osborne, 2015, p. 27). When the IV is continuous in nature, the calculated odds ratio represents the change in odds for each one unit of change in the IV (Osborne, 2015).

Logistic regression analysis results in a logit. "A logistic regression analysis yields a probability of an event; that probability is transformed into an odds; the natural $\log$ of that odds is taken to get the logit" (Vogt, 2005, p. 180). Just as is the case when conducting linear regression, it is critical in logistic regression to determine the overall fit of the model regarding the data. In logistic regression, the overall fit of the model is determined using the Wald statistic. "The Wald statistic tells us whether the $b$-coefficient for that predictor is significantly different from zero. If the coefficient is significantly different from zero then we can assume that the predictor is making a significant contribution to the prediction of the outcome (Y)" (Field, 2005, p. 224).

To address Research Question 2, the influence of the number of BIP classes enrolled in on the relationship between semester/year of BIP course enrollment and retention, retention was entered as the dependent variable. The independent variables in the study included the number of enrolled BIP classes, the semester/year of enrollment in BIP courses, and an interaction term (Number of enrolled BIP classes x semester/year of enrollment in a BIP course) were entered as the independent variables. The data was analyzed using logistic regression.

Logistic regression was the statistical procedure used to address each of the sub questions to RQ3. To address Research Question 3a, the influence of gender on the relationship between enrollment in BIP courses and retention, retention was entered as 
the dependent variable. Gender, enrollment in a BIP course, and an interaction term (gender x enrollment in BIP course) were entered as the independent variables.

To address Research Question 3b, the influence of race on the relationship between enrollment in BIP courses and retention, retention was entered as the dependent variable. Race, enrollment in a BIP course, and an interaction term (race x enrollment in BIP course) were entered as the independent variables.

To address Research Question 3c, the influence of cumulative GPA on the relationship between enrollment in BIP courses and retention, retention was entered as the dependent variable. Cumulative GPA after the first academic year, enrollment in a BIP course, and an interaction term (cumulative GPA x enrollment in BIP course) were entered as the independent variables.

To address Research Question 3d, the influence of a student's high school GPA on the relationship between enrollment in BIP courses and retention, retention was entered as the dependent variable. The student's high school GPA, enrollment in a BIP course, and an interaction term (high school GPA x enrollment in a BIP course) were entered as the independent variables.

To address Research Question 3e, the influence of a student's combined ACT score on the relationship between enrollment in BIP courses and retention, retention was entered as the dependent variable. The combined ACT score of the students, enrollment in a BIP course, and an interaction term (ACT score $\mathrm{x}$ enrollment in a BIP course) were entered as the independent variables.

To address Research Question 3f, the influence of a college major on the relationship between enrollment in BIP courses and retention, retention was entered as 
the dependent variable. A HSS major (Health \& Human Performance and Sport Administration), enrollment in a BIP course, and an interaction term (HSS major $\mathrm{x}$ enrollment in a BIP course) were entered as the independent variables.

To address Research Question 3g, the influence of need based financial aid eligibility on the relationship between enrollment in BIP courses and retention, retention was entered as the dependent variable. Need based financial aid participation, enrollment in a BIP course, and an interaction term (Need based financial aid eligible $\mathrm{x}$ enrollment in a BIP course) were entered as the independent variables.

\section{Summary}

The higher education landscape has changed in many areas over the last two decades, but the most recognizable transformation has come because of limited financial resources. Fiscal pressures continue to intensify and drive the higher education model closer to the dynamics of a privatized corporation. The limited financial assistance colleges and universities are receiving from their respective state governments has forced university administrators to look for alternative methods to address the budget shortfall. As a result, higher education institutions have now placed a larger emphasis on keeping their currently enrolled students persisting toward graduation. This shift in significance placed on student retention has now magnified the importance of developing successful retention programs (Tinto, 2006).

As a result, university administrators are constantly searching for potential interventions, which would result in higher retention rates. Higher education institutions have realized it is far more economical to implement strategies, which will effectively retain existing students, than to attempt to recruit and attract a new group of students. 
This shift in reasoning has now placed the concept of student retention at the forefront of the higher education success model. Researchers and university administrators are now challenged with the task of finding effective strategies to increase student retention and ways to effectively implement these interventions to the campus community.

The shift in priorities assigned to student retention helped the researcher for the current study formulate the research questions. Additionally, it was obvious there was a need at the participating institution in this study to evaluate potential student retention interventions. A good deal of research conducted in the K-12 setting demonstrated student academic success was positively linked with participation in physical activity. Additionally, research conducted at the university setting has shown participation in fitness and sports activities in a campus recreation setting had a significant positive influence on the academic success of students. However, one of the major gaps in the literature was the limited number of studies conducted looking at if an association existed between university student retention rates and enrollment in physical education courses. This gap in the literature was problematic given the increased emphasis placed on student retention in higher education. 


\section{CHAPTER IV}

\section{RESULTS}

This chapter provides the results of the study and consists of three sections including: background information of the sample, examination of the results, and a summary of the chapter. Descriptive statistics, Pearson's chi square analysis, independent samples $t$-test, and logistic regression analyses were used to examine the research questions.

\section{Sample Description}

This study examined whether student entry characteristics and enrollment in physical education activity courses influenced student retention of all first-time, full-time, baccalaureate degree-seeking students enrolled at a metropolitan public research university located in the southern region of the United States during the years of 20142015. The criteria of first-time degree seeking students excluded all transfer students from the study sample, thus any students who previously attended a different institution were omitted. Students who had completed college level work during high school were included in the study sample.

The variables included in the study were gender, race, high school GPA, ACT standardized test score, student financial aid status, intended college major, number of BIP courses enrolled in, semester and year of enrolled activity courses, and cumulative 
college GPA at the end of the freshmen academic year. Additionally, the data set included whether the student had been retained, which was the dependent variable in the study. This dichotomous variable was coded as a " 1 " if the student was enrolled in courses at the participating institution the following fall semester and a " 0 " if the student was not retained at the school the following fall semester. As stated earlier, the IRP office categorized a student as retained if the student was enrolled in courses at the university the following fall semester. Thus, the students in the sample from the 2014 freshmen cohort were classified as retained if they were still enrolled at the same institution for classes at least on a part-time basis during the fall 2015 semester (first year retention) or the fall 2016 semester (second year retention). Additionally, the students in the sample from the 2015 freshmen cohort were considered retained if they were still enrolled at the same institution for classes at least on a part-time basis during the fall 2016 semester (first year retention) or the fall 2017 semester (second year retention).

Data were collected from a total of 5,565 first-time degree seeking students from the 2014 and 2015 cohorts. All first-time degree-seeking students from the 2014 and 2015 cohorts were included in the study sample.

Table 1

Frequency in the Cohorts

$2014 \quad 2015 \quad$ Total

Sample $\quad 2830(50.9 \%) \quad 2735(49.1 \%) \quad 5565(100 \%)$




\section{Statistical Procedures}

The data analyses were conducted using the Statistical Package for Social Sciences (SPSS), version 25.0. Chi square analyses and t-tests were used to analyze the first research question, which was to determine who was enrolling in BIP courses and how they differed from the rest of the student population regarding gender, race, high school GPA, ACT standardized test score, financial need status, and declared college major. Logistic regression was used to analyze the data for the both the second and third research questions as the outcome variable of student retention was dichotomous. The outcome variable was either scored a " 1 " if the student was retained or a " 0 " if the student was not retained.

\section{Student Characteristics and BIP Enrollment}

Many higher education institutions no longer require enrollment in a physical education course as part of a degree requirement. However, many institutions still offer BIP courses to the campus community. Thus, it is important for physical education programs and higher education institutions to identify the type of student who is choosing to enroll in physical education courses for elective purposes. The first research question addresses this need. Specifically, this question states:

RQ1 - Who is enrolling in BIP courses and how do they differ from the rest of the student population?

RQ1a-Does a student's gender influence enrollment in BIP courses?

RQ1b-Does a student's race influence enrollment in BIP courses?

RQ1c- Does a student's high school GPA influence enrollment in BIP courses? 
RQ1d- Does a student's ACT composite score influence enrollment in BIP courses?

RQ1e- Does a student's PELL eligibility status influence enrollment in BIP courses?

RQ1f- Does a student's declared college major influence enrollment in BIP courses?

\section{Gender}

Approximately $50.1 \%(n=2,789)$ of the sample was male and $49.9 \%(n=2,776)$ of the sample was female. There were zero cases in the overall sample $(n=5,565)$ in which the IRP office didn't have the student's reported gender. The gender breakdown of the two-year cohorts (2014 and 2015) used in the sample was very similar with reported university data in 2016.

Research question 1A examined who was enrolling in BIP courses and how they differed from the rest of the student population regarding gender. A chi-square test of independence was performed to examine the relationship between gender and BIP course enrollment. There was not a statistically significant difference $(t=0.67, p=.796)$ in the gender of students enrolled in BIP courses. Results indicated both male and female students enrolled in BIP courses at a similar rate.

Table 2

Frequency of BIP Enrollment by Gender

\begin{tabular}{lccc} 
& Female & Male & Total \\
\hline Sample & $2776(49.9 \%)$ & $2789(50.1 \%)$ & $5565(100 \%)$ \\
Enrolled in BIP & $460(50.3 \%)$ & $455(49.7 \%)$ & $915(100 \%)$
\end{tabular}


Race

The IRP office provided the race classification the student's reported on their university application. There were zero cases in the overall sample $(n=5,565)$ in which the IRP office didn't have the student's self-reported race. Approximately, 77.4\% $(n=4,307)$ of the sample was White and $22.6 \%(n=1,258)$ was Minority.

Research question 1B examined who was enrolling in BIP courses and how they differed from the rest of the student population regarding race. A chi-square test of independence was performed to examine the relationship between race and BIP course enrollment. There was a statistically significant difference $(t=20.90, p<.001)$ in the race of students enrolled in BIP courses. Results indicated minority students were more likely to enroll in BIP courses.

Table 3

Frequency of BIP Enrollment by Race

\begin{tabular}{lccc}
\hline & Not enrolled in BIP & Enrolled in BIP & Total \\
\hline White & $4311(86.8 \%)$ & $656(13.2 \%)$ & 4967 \\
Minority & $1254(82.9 \%)$ & $259(17.1 \%)$ & 1513
\end{tabular}

\section{High School GPA}

The IRP office provided the student's high school GPA, which was obtained during the university application process. There were 147 cases in the two-year cohort in which no high school GPA data was available. Thus, regarding specifically the high 
school GPA data the overall sample size was $(n=5,418)$. The IRP office provided a unique high school GPA score for all students included in the sample.

Research question 1C examined who was enrolling in BIP courses and how they differed from the rest of the student population regarding high school GPA. An independent samples $t$-test was conducted to compare the high school GPAs between those enrolled in BIP courses and those not enrolled in BIP courses. There was a significant difference $(t=-4.579, p<.001)$ in the GPAs for those enrolled in BIP courses $(M=3.53, S D=.425)$ and those not enrolled in BIP courses $(M=3.60, S D=.418)$. Results indicated students who had lower high school GPAs were more likely to be enrolled in BIP courses during their first or second year at the institution.

Table 4

Frequency of BIP Enrollment by High School GPA

\begin{tabular}{lccc}
\hline & Mean & $N$ & $S D$ \\
\hline No BIP Enrollment & 3.60 & 4523 & 0.42 \\
BIP Enrollment & 3.53 & 895 & 0.42 \\
\hline
\end{tabular}

\section{ACT Composite Score}

Research question 1D examined who was enrolling in BIP courses and how they differed from the rest of the student population regarding ACT composite score. The IRP office provided the student's composite ACT score, which was obtained during the university application process. There were 153 cases in the two-year cohort in which no ACT composite score was available. Thus, regarding specifically the ACT composite 
score data the overall sample size was $(n=5,412)$. The ACT composite scores from the two-year cohort ranged from a low score of 15 to a high score of 36. Approximately, $50.9 \%$ of all students included in the two-year cohort had an ACT composite score fall in the range of 21-26.

An independent samples $t$-test was conducted to compare the ACT composite scores between those enrolled in BIP courses and those not enrolled in BIP courses. There was a significant difference $(t=-9.825, p<.001)$ in the ACT composite scores for those enrolled in BIP courses $(M=24.36, S D=3.69)$ and those not enrolled in BIP courses $(M=25.71, S D=3.96)$. Results indicated students who had lower ACT composite scores were more likely to be enrolled in BIP courses during their first or second year at the institution.

Table 5

Frequency of BIP Enrollment by ACT

\begin{tabular}{lccc}
\hline & Mean & $N$ & $S D$ \\
& & & \\
\hline No BIP Enrollment & 25.71 & 4520 & 3.96 \\
BIP Enrollment & 24.36 & 892 & 3.69 \\
\hline
\end{tabular}

\section{Financial Need Status}

Research question 1E examined who was enrolling in BIP courses and how they differed from the rest of the student population regarding PELL eligibility. The IRP office provided the researcher with information on the eligibility status for PELL assistance for the entire sample. There were no missing cases, thus the total sample consisted of $(n=5,565)$ students. Approximately $62.6 \%(n=3,483)$ of the sample was not 
PELL eligible and $37.4 \% \%(n=2,082)$ of the sample was PELL eligible. A chi-square test of independence was performed to examine the relationship between race and BIP course enrollment. There was not a statistically significant difference $(t=20.90, p=.081)$ in the financial need status of students enrolled in BIP courses. Results indicated both PELL eligible and PELL ineligible students enrolled in BIP courses at approximately the same rate.

Table 6

Frequency of BIP Enrollment by PELL Eligibility

\begin{tabular}{lccc}
\hline & PELL Eligible & PELL Ineligible & Total \\
\hline Sample & $2082(37.4 \%)$ & $3483(62.6 \%)$ & $5565(100 \%)$ \\
Enrolled in BIP & $319(34.9 \%)$ & $596(65.1 \%)$ & $915(100 \%)$ \\
\hline
\end{tabular}

\section{Declared College Major}

Research question $1 \mathrm{~F}$ examined who was enrolling in BIP courses and how they differed from the rest of the student population regarding declared college major. The IRP office provided information on the declared college major for the entire sample. There were no missing cases, thus the total sample consisted of $(n=5,565)$ students. As discussed earlier in this paper, HSS majors are the only students required to enroll in a BIP course, thus the number of declared majors in the HSS Department was compared to all other majors at the institution. Undeclared majors were group into the all other majors' category. HSS majors consisted of students in the Health and Human Performance (HHP) degree and the Sport Administration (SPAD) degree. Approximately, $4.9 \%(n=272)$ of the sample was a declared HSS major and $95.1 \%$ 
$(n=5,293)$ of the sample was a non-HSS major. A chi-square test of independence was performed to examine the relationship between declared college major and BIP course enrollment. There was a statistically significant difference $(t=1007.97, p<.001)$ in the declared college major of students enrolled in BIP courses. Results indicated HSS majors were more likely to be enrolled in BIP courses during their first or second year.

Table 7

Frequency of BIP Enrollment by College Major

\begin{tabular}{lccc}
\hline & HSS Major & All Other Majors & Total \\
\hline Sample & $272(4.9 \%)$ & $5293(95.1 \%)$ & $5565(100 \%)$ \\
Enrolled in BIP & $234(25.6 \%)$ & $681(74.4 \%)$ & $915(100 \%)$ \\
\hline
\end{tabular}

This section addressed the findings for RQ1 which examined differences between students enrolling in BIP courses and those not enrolled. The findings for RQ1 demonstrated there were statistically significant differences between the two groups in race, declared college major, high school GPA, and composite ACT score. The findings for RQ1 showed no statistically significant difference between the two groups for gender and PELL eligibility.

\section{BIP Enrollment and Student Retention}

An overlooked area of the literature is if enrollment in BIP courses has any relationship to student retention. The present study examined if academic year of enrollment in BIP courses was influential to student persistence. Additionally, the study examined if the number of BIP courses enrolled in by undergraduate students influenced student retention. Specifically, the second research question stated: 
RQ2 - How does the year of BIP enrollment and the number of BIP classes enrolled in influence student retention?

Logistic regression was the statistical procedure used to address RQ2. Both Osborne (2015) and Field (2005) touted logistic regression as the best statistical technique to use when the dependent (criterion) variable was dichotomous or categorical. Students enrolled in courses the following fall semester after his/her first or second years, were classified as retained and coded as a "1". Students no longer enrolled in courses the following fall semester after his/her first or second years, were coded a "0" and were classified as students who withdrew and didn't persist toward graduation at the specific institution used for data collection.

To address the first portion of RQ2, the influence of the year BIP classes were enrolled in on the relationship between year one retention, retention was entered as the criterion variable. Year one BIP enrollment was entered as the predictor variable. A logistic regression analysis was conducted on the dichotomous criterion variable of student retention after the first year of enrollment. A non-statistically significant model for predicting first year retention was present, $x^{2}(1)=1.21, p=.271$. The results for the regression coefficients, Wald statistics, odds ratios, and the $95 \%$ confidence intervals for the odds ratios can be found in the table below. Year one BIP enrollment $(p=.276)$ was not a statistically significant predictor of first year retention. 
Table 8

Logistic Regression Analysis of First Year Retention by Year One BIP Enrollment

\begin{tabular}{lcccccccc}
\hline & & & & & & \multicolumn{2}{c}{$95 \%$ C.I. for Odds Ratio } \\
& B & S.E. & Wald & $p$ & Odds Ratio & Lower & Upper \\
\hline First Year BIP Enrollment & 0.13 & 0.12 & 1.19 & 0.276 & 1.13 & 0.90 & 1.42 \\
Constant & 1.35 & 0.04 & 1489.36 & $<.001$ & 3.84 & & \\
& & & & & & & & \\
\hline
\end{tabular}

$\vec{\infty}$ 
Next, a logistic regression analysis was conducted to determine the influence of BIP enrollment during year one on second year retention. Year one BIP enrollment was entered as the predictor variable and second year retention was entered as the criterion variable. A non-statistically significant model for predicting first year retention was present, $x^{2}(1)=.12, p=.733$. The results for the regression coefficients, Wald statistics, odds ratios, and the $95 \%$ confidence intervals for the odds ratios can be found in the table below. Year one BIP enrollment ( $p=.734)$ was not a statistically significant predictor of second year retention.

Table 9

Logistic Regression Analysis of Second Year Retention by Year One BIP Enrollment

\begin{tabular}{|c|c|c|c|c|c|c|c|}
\hline & \multirow[b]{3}{*}{ B } & \multirow[b]{3}{*}{ S.E. } & \multirow[b]{3}{*}{ Wald } & \multirow[b]{3}{*}{$p$} & \multirow[b]{3}{*}{ Odds Ratio } & \multirow{2}{*}{\multicolumn{2}{|c|}{$\begin{array}{l}\text { 95\% C.I. for } \\
\text { Odds Ratio }\end{array}$}} \\
\hline & & & & & & & \\
\hline & & & & & & Lower & Upper \\
\hline Year 1 BIP & 0.03 & 0.10 & 0.12 & 0.734 & 1.03 & 0.85 & 1.26 \\
\hline Constant & 0.85 & 0.03 & 756.25 & $<.001$ & 2.33 & & \\
\hline
\end{tabular}

Next, a logistic regression analysis was conducted to determine the influence of BIP enrollment during year one or year two on second year retention. All students who had enrolled in at least one BIP course during their first or second year at the school were coded a "1" and students who had not participated in any BIP courses during their first two years were coded a "0". A statistically significant model for predicting second year retention was present, $x^{2}(1)=35.80, p<.001$. The Nagelkerke $R^{2}$ was equal to .009 , indicating a weak effect. The results for the regression coefficients, Wald statistics, odds 
ratios, and the $95 \%$ confidence intervals for the odds ratios can be found in the table below. Enrollment in a BIP course during the first or second year at the institution $(p<.001)$ was a significant predictor of second year retention. Students who had enrolled in a BIP course during their first or second year at the school had 1.65 greater odds of being retained after the second year at the institution than students not enrolled in BIP courses.

Table 10

Logistic Regression Analysis of Second Year Retention by Year One or Two BIP Enrollment 95\% C.I. for Odds Ratio

\begin{tabular}{lccccccc} 
& B & S.E. & Wald & $p$ & Odds Ratio & Lower & Upper \\
\hline Year 1/2 BIP & 0.50 & 0.09 & 33.59 & $<.001$ & 1.65 & 1.39 & 1.95 \\
Constant & 0.78 & 0.03 & 603.85 & $<.001$ & 2.17 & & \\
\hline
\end{tabular}

Finally, a logistic regression analysis was conducted to determine the influence of BIP enrollment during the second year at the school on second year retention. A statistically significant model for predicting second year retention was present, $x^{2}(1)$ $=90.10, p<.001$. The Nagelkerke $R^{2}$ was equal to .023 , indicating a weak effect. The results for the regression coefficients, Wald statistics, odds ratios, and the $95 \%$ confidence intervals for the odds ratios can be found in the table below. Enrollment in a BIP course during the second year at the institution $(p<.001)$ was a significant predictor of second year retention. Students enrolling in a BIP course during their second year at the school had 3.22 greater odds of being retained after the second year at the institution than students not enrolled in BIP courses. 
Table 11

Logistic Regression Analysis of Second Year Retention by Year Two BIP Enrollment

\begin{tabular}{lccccccc}
\hline & & & & & & \multicolumn{2}{c}{$95 \%$ C.I. for Odds Ratio } \\
& B & S.E. & Wald & $p$ & Odds Ratio & Lower & Upper \\
\hline Year 2 BIP & 1.17 & 0.14 & 70.45 & $<.001$ & 3.22 & 2.45 & 4.22 \\
Constant & 0.77 & 0.03 & 652.08 & $<.001$ & 2.16 & & \\
\hline
\end{tabular}

To address the second portion of RQ2, the influence of the number of BIP classes enrolled in on the relationship between year two retention, retention was entered as the criterion variable. The total number of BIP classes enrolled in during the first and second year at the institution was entered as the predictor variable. A logistic regression analysis was conducted on the dichotomous criterion variable of student retention after the second year of enrollment. A statistically significant model for predicting second year retention was present, $x^{2}(1)=36.71, p<.001$. The Nagelkerke $R^{2}$ was equal to .009 , indicating an extremely weak effect.

The results for the regression coefficients, Wald statistics, odds ratios, and the $95 \%$ confidence intervals for the odds ratios can be found in the table below. The total number of BIP courses enrolled in during the first two years at the school $(p<.001)$ was a significant predictor of second year retention. As students increased the number of BIP courses enrolled, they had greater odds of being retained after the second year at the institution. For each additional BIP course enrolled in during the first two years at the school, students had 1.39 greater odds of being retained after the second year. This finding demonstrates the importance of BIP enrollment as a predictor of second year student retention. 
Table 12

Logistic Regression Analysis of Second Year Retention as a Function of Total \# of BIP Enrolled

95\% C.I. for

Odds Ratio

\begin{tabular}{lccccccc} 
& B & S.E. & Wald & $p$ & Odds Ratio & Lower & Upper \\
& & & & & & & \\
\hline \# of BIP Enrolled & 0.33 & 0.06 & 32.68 & $<.001$ & 1.39 & 1.24 & 1.56 \\
Constant & 0.78 & 0.03 & 628.20 & $<.001$ & 2.19 & & \\
& & & & & & & \\
\hline
\end{tabular}

A frequency table was created for the total number of BIP courses enrolled in by the included cohorts. Overall, $83.6 \%(n=4,650)$ of the students comprising the included cohorts had not enrolled in any BIP course during their first or second year at the school. Next, $11.0 \%(n=612)$ of the sample had enrolled in one BIP course during their first or second year at the school. There was 4.3\% $(n=240)$ of the sample, which had enrolled in two BIP courses during the first or second year at the school. Next, $0.9 \%(n=48)$ of the sample had enrolled in three BIP courses. Additionally, $0.2 \%(n=13)$ of the sample had enrolled in four BIP courses. Finally, less than $0.001 \%(n=2)$ of the sample had enrolled in five courses. The corresponding frequency table can be found below. 
Table 13

Frequency Table of Total \# of BIP Courses Enrolled

\begin{tabular}{|c|c|c|}
\hline Count & $n$ & $\%$ \\
\hline 0 & 4650 & 83.6 \\
\hline 1 & 612 & 11 \\
\hline 2 & 240 & 4.3 \\
\hline 3 & 48 & 0.9 \\
\hline 4 & 13 & 0.2 \\
\hline 5 & 2 & 0 \\
\hline Total & 5565 & 100 \\
\hline
\end{tabular}

RQ2 examined if enrollment in BIP courses influenced student retention. The findings for RQ2 showed BIP enrollment during the second year was a statistically significant predictor for second year retention. Students enrolled in BIP courses during the second year had 3.22 greater odds of being retained at the end of the second year as compared to students not enrolled in BIP courses during that same year.

Additionally, logistic regression analysis showed as the number of enrolled BIP courses increased, so did the odds of being retained. For each additional BIP course enrolled in during the first two years at the school, students had 1.39 greater odds of being retained after the second year.

\section{Student Characteristics and Student Retention}

RQ3 examined whether student characteristics influenced the relationship between BIP enrollment and retention. The student entry characteristics that were 
examined were: Gender, race, cumulative GPA at the end of the first academic year at the school, high school GPA, ACT composite score, declared college major, and PELL eligibility. BIP enrollment during the first year, first or second year at the school, and second year BIP enrollment were examined. The dependent variable of student retention after the first year as well as after the second year were included.

The first logistic regression analysis examined the previously mentioned seven student characteristics along with first year BIP enrollment. Additionally, the model examined if an interaction effect existed between first year BIP enrollment and each of the seven student characteristics. The student characteristics, first year BIP enrollment, and the interaction between first year BIP enrollment and each of the student characteristics were entered as the criterion variables. The dichotomous dependent variable was student retention after the first year of enrollment. A statistically significant model for predicting first year retention was present, $x^{2}(15)=1721.68, p<.001$. The Nagelkerke $R^{2}$ was equal to .428 , indicating a moderate effect.

The results for the regression coefficients, Wald statistics, odds ratios, and the $95 \%$ confidence intervals for the odds ratios can be found in the table below. There were no statistically significant interactions between the student characteristics and first year BIP enrollment. Race $(p<.001)$ and cumulative GPA after the first year at the school $(p<.001)$ were both statistically significant predictors for first year retention. White students had 0.62 less odds of being retained after the first year at the school as compared to minority students. For each unit increase in cumulative GPA after the first year at the school there was 4.85 greater odds of being retained after year one. Thus, students with 
higher cumulative GPAs at the end of the first year at the school had greater odds of being retained. 
Table 14

Logistic Regression Analysis of First Year Retention by First Year BIP Enrollment \& Student Characteristics

\begin{tabular}{lccccccc}
\hline & & & & & \multicolumn{3}{c}{$95 \%$ C.I. for Odds Ratio } \\
& B & S.E. & Wald & $p$ & Odds Ratio & Lower & Upper \\
\hline Year 1 BIP & -0.53 & 1.47 & 0.13 & 0.717 & 0.59 & 0.03 & 10.51 \\
Male & 0.13 & 0.09 & 1.95 & 0.163 & 1.14 & 0.95 & 1.37 \\
White & -0.48 & 0.12 & 17.36 & $<.001$ & 0.62 & 0.50 & 0.78 \\
HSS Major & -0.39 & 0.49 & 0.63 & 0.427 & 0.68 & 0.26 & 1.77 \\
High School GPA & -0.02 & 0.12 & 0.02 & 0.876 & 0.98 & 0.78 & 1.24 \\
ACT Composite & 0.02 & 0.01 & 1.63 & 0.202 & 1.02 & 0.99 & 1.05 \\
PELL Eligible & -0.14 & 0.09 & 2.47 & 0.116 & 0.87 & 0.72 & 1.04 \\
Cum. GPA after Year One & 1.58 & 0.06 & 807.75 & $<.001$ & 4.85 & 4.35 & 5.41 \\
1st Year BIP x Male & 0.09 & 0.31 & 0.09 & 0.760 & 1.10 & 0.60 & 2.00 \\
1st Year BIP x White & 0.04 & 0.34 & 0.01 & 0.905 & 1.04 & 0.53 & 2.04 \\
1st Year BIP x Cum. GPA & -0.09 & 0.18 & 0.27 & 0.604 & 0.91 & 0.65 & 1.29 \\
1st Year BIP x H.S. GPA & -0.05 & 0.39 & 0.02 & 0.899 & 0.95 & 0.45 & 2.04 \\
1st Year BIP x ACT Comp. & 0.05 & 0.05 & 0.84 & 0.360 & 1.05 & 0.95 & 1.16 \\
1st Year BIP x HSS Major & 0.42 & 0.57 & 0.54 & 0.463 & 1.52 & 0.50 & 4.62 \\
1st Year BIP x PELL Eligible & -0.05 & 0.32 & 0.02 & 0.888 & 0.96 & 0.51 & 1.78 \\
Constant & -2.57 & 0.41 & 40.43 & $<.001$ & 0.08 & &
\end{tabular}


The next logistic regression analysis used the same predictor variables from the previous model, but the dependent variable of second year retention replaced first year retention in the model. The student characteristics, first year BIP enrollment, and the interaction between first year BIP enrollment and each of the student characteristics were entered as the criterion variables. The dichotomous dependent variable was student retention after the second year of enrollment. A statistically significant model for predicting second year retention was present, $x^{2}(15)=2201.17, p<.001$. The Nagelkerke $R^{2}$ was equal to .474 , indicating a moderate effect.

The results for the regression coefficients, Wald statistics, odds ratios, and the $95 \%$ confidence intervals for the odds ratios can be found in the table below. There were no statistically significant interactions between the student characteristics and first year BIP enrollment. Race $(p<.001)$, gender $(p=.031)$, PELL eligibility $(p<.001)$, and cumulative GPA after the first year at the school $(p<.001)$ were all statistically significant predictors for first year retention. White students had 0.63 less odds of being retained after the first year at the school as compared to minority students. Male students had 1.20 greater odds of second year retention as compared to female students. Students who were PELL eligible had 0.75 less odds of second year retention as compared to students who were not PELL eligible. For each unit increase in cumulative GPA after the first year at the school there was 6.04 greater odds of being retained after year one. Thus, students with higher cumulative GPAs at the end of the first year at the school had greater odds of being retained. 
Table 15

Logistic Regression Analysis of Second Year Retention by First Year BIP Enrollment \& Student Characteristics

\begin{tabular}{|c|c|c|c|c|c|c|c|}
\hline & \multirow[b]{2}{*}{$\mathrm{B}$} & \multirow[b]{2}{*}{ S.E. } & \multirow[b]{2}{*}{ Wald } & \multirow[b]{2}{*}{$p$} & \multirow{2}{*}{$\begin{array}{l}\text { Odds } \\
\text { Ratio }\end{array}$} & \multicolumn{2}{|c|}{$\begin{array}{l}\text { 95\% C.I. for } \\
\text { Odds Ratio }\end{array}$} \\
\hline & & & & & & Lower & Upper \\
\hline Year 1 BIP & -0.08 & 1.29 & 0.00 & 0.954 & 0.93 & 0.07 & 11.65 \\
\hline Male & 0.18 & 0.08 & 4.67 & 0.031 & 1.20 & 1.02 & 1.42 \\
\hline White & -0.46 & 0.10 & 19.71 & $<.001$ & 0.63 & 0.52 & 0.77 \\
\hline HSS Major & -0.44 & 0.43 & 1.03 & 0.310 & 0.65 & 0.28 & 1.50 \\
\hline H.S. GPA & 0.16 & 0.11 & 1.92 & 0.166 & 1.17 & 0.94 & 1.46 \\
\hline ACT Composite & 0.02 & 0.01 & 1.77 & 0.183 & 1.02 & 0.99 & 1.04 \\
\hline PELL Eligible & -0.29 & 0.08 & 12.44 & $<.001$ & 0.75 & 0.63 & 0.88 \\
\hline Year 1 Cum. GPA & 1.80 & 0.06 & 840.23 & $<.001$ & 6.04 & 5.35 & 6.82 \\
\hline Year 1 BIP x Male & 0.05 & 0.27 & 0.04 & 0.848 & 1.05 & 0.62 & 1.78 \\
\hline Year 1 BIP x White & 0.22 & 0.30 & 0.56 & 0.456 & 1.25 & 0.69 & 2.26 \\
\hline Year 1 BIP x Cum. GPA & 0.01 & 0.20 & 0.00 & 0.954 & 1.01 & 0.68 & 1.51 \\
\hline Year 1 BIP x H.S. GPA & -0.47 & 0.36 & 1.70 & 0.192 & 0.63 & 0.31 & 1.26 \\
\hline Year 1 BIP x ACT Comp. & 0.07 & 0.05 & 2.14 & 0.144 & 1.07 & 0.98 & 1.17 \\
\hline 1st Year BIP x HSS Major & 0.74 & 0.50 & 2.16 & 0.142 & 2.10 & 0.78 & 5.63 \\
\hline Year 1 BIP x PELL Eligible & -0.13 & 0.28 & 0.20 & 0.651 & 0.88 & 0.51 & 1.53 \\
\hline Constant & -4.48 & 0.38 & 141.87 & $<.001$ & 0.01 & & \\
\hline
\end{tabular}

The third logistic regression analysis used the same student characteristics as the previous two models. However; enrollment in a BIP course during either year one or year two at the institution was used instead of BIP enrollment during year one. The student characteristics, first or second year BIP enrollment, and the interaction between 
first or second year BIP enrollment and each of the student characteristics were entered as the criterion variables. The dichotomous dependent variable was student retention after the second year of enrollment. A statistically significant model for predicting second year retention was present, $x^{2}(15)=2232.42, p<.001$. The Nagelkerke $R^{2}$ was equal to .480 , which indicates a moderate effect.

The results for the regression coefficients, Wald statistics, odds ratios, and the 95\% confidence intervals for the odds ratios can be found in the table below. There was a statistically significant interaction between the student characteristic of race and first or second year BIP enrollment. The interaction effect between White students and enrollment in a BIP course during the first or second year $(p=.030)$ was a statistically significant predictor of second year retention. White students who had enrolled in a BIP course during the first or second year at the school had 1.73 greater odds of being retained. Additionally, race $(p<.001)$, PELL eligibility $(p=.001)$, ACT composite score ( $p=.044)$, and cumulative GPA after the first year at the school $(p<.001)$ were all statistically significant predictors for second year retention. White students had 0.60 less odds of being retained after the second year at the school as compared to minority students. For each unit increase in ACT composite score there was 1.03 greater odds of being retained after year two. Students who were PELL eligible had 0.75 less odds of second year retention as compared to students who were not PELL eligible. For each unit increase in cumulative GPA after the first year at the school there was 6.01 greater odds of being retained after year two. 
Table 16

Logistic Regression Analysis of Second Year Retention by First or Second Year BIP Enrollment \& Student Characteristics

\begin{tabular}{|c|c|c|c|c|c|c|c|}
\hline & \multirow[b]{3}{*}{$\mathrm{B}$} & \multirow[b]{3}{*}{ S.E. } & \multirow[b]{3}{*}{ Wald } & \multirow[b]{3}{*}{$p$} & \multirow[b]{3}{*}{ Odds Ratio } & \multirow{2}{*}{\multicolumn{2}{|c|}{$\begin{array}{l}\text { 95\% C.I. for } \\
\text { Odds Ratio }\end{array}$}} \\
\hline & & & & & & & \\
\hline & & & & & & Lower & Upper \\
\hline YR 1/2 BIP & 0.55 & 1.02 & 0.29 & 0.588 & 1.74 & 0.24 & 12.89 \\
\hline Male & 0.15 & 0.09 & 3.07 & 0.080 & 1.17 & 0.98 & 1.38 \\
\hline White & -0.51 & 0.11 & 22.08 & $<.001$ & 0.60 & 0.49 & 0.75 \\
\hline HSS Major & -0.93 & 0.53 & 3.06 & 0.080 & 0.40 & 0.14 & 1.12 \\
\hline H.S. GPA & 0.15 & 0.12 & 1.58 & 0.209 & 1.16 & 0.92 & 1.45 \\
\hline ACT Composite & 0.03 & 0.01 & 4.04 & 0.044 & 1.03 & 1.00 & 1.05 \\
\hline PELL Eligible & -0.29 & 0.09 & 11.17 & 0.001 & 0.75 & 0.63 & 0.89 \\
\hline Year 1 Cum. GPA & 1.79 & 0.06 & 791.32 & $<.001$ & 6.01 & 5.31 & 6.81 \\
\hline YR 1/2 BIP x Male & 0.21 & 0.23 & 0.85 & 0.356 & 1.24 & 0.79 & 1.93 \\
\hline YR 1/2 BIP x White & 0.55 & 0.25 & 4.70 & 0.030 & 1.73 & 1.05 & 2.85 \\
\hline YR 1/2 BIP x Cum. GPA & -0.01 & 0.17 & 0.00 & 0.970 & 0.99 & 0.71 & 1.39 \\
\hline YR 1/2 BIP x H.S. GPA & -0.14 & 0.30 & 0.22 & 0.641 & 0.87 & 0.48 & 1.57 \\
\hline YR 1/2 BIP x ACT Comp. & 0.00 & 0.04 & 0.01 & 0.939 & 1.00 & 0.93 & 1.08 \\
\hline YR 1/2 BIP x HSS Major & 0.73 & 0.58 & 1.60 & 0.206 & 2.08 & 0.67 & 6.45 \\
\hline YR 1/2 BIP x PELL & -0.02 & 0.23 & 0.01 & 0.930 & 0.98 & 0.62 & 1.54 \\
\hline Constant & -4.69 & 0.39 & 143.21 & $<.001$ & 0.01 & & \\
\hline
\end{tabular}

The final logistic regression analysis used the same student characteristics as the previous three models. However; enrollment in a BIP course during the second year at 
the institution was used. The student characteristics, second year BIP enrollment, and the interaction between second year BIP enrollment and each of the student characteristics were entered as the criterion variables. The dichotomous dependent variable was student retention after the second year of enrollment. A statistically significant model for predicting second year retention was present, $x^{2}(15)=2259.45, p<.001$. The Nagelkerke $R^{2}$ was equal to .485 , which indicates a moderate effect.

The results for the regression coefficients, Wald statistics, odds ratios, and the $95 \%$ confidence intervals for the odds ratios can be found in the table below. There was a statistically significant interaction between the student characteristic of race and second year BIP enrollment. The interaction effect between White students and enrollment in a BIP course during the second year ( $p=.014)$ was a statistically significant predictor of second year retention. White students who had enrolled in a BIP course during the second year at the school had 2.48 greater odds of being retained. Additionally, race $(p<.001)$, PELL eligibility $(p=.001)$, ACT composite score $(p=.010)$, and cumulative GPA after the first year at the school $(p<.001)$ were all statistically significant predictors for second year retention. White students had 0.62 less odds of being retained after the second year at the school as compared to minority students. For each unit increase in ACT composite score there was 1.03 greater odds of being retained after year two. Students who were PELL eligible had 0.76 less odds of second year retention as compared to students who were not PELL eligible. For each unit increase in cumulative GPA after the first year at the school there was 6.01 greater odds of being retained after year two. 
Table 17

Logistic Regression Analysis of Second Year Retention by Second Year BIP Enrollment \& Student Characteristics

\begin{tabular}{lccccccc}
\hline & & & & & & \multicolumn{3}{c}{$95 \%$ C.I. for Odds Ratio } \\
& B & S.E. & Wald & $p$ & Odds Ratio & Lower & Upper \\
\hline Second Year BIP Enrollment & 1.89 & 1.41 & 1.79 & 0.182 & 6.60 & 0.41 & 105.19 \\
Male & 0.15 & 0.08 & 3.15 & 0.076 & 1.16 & 0.99 & 1.36 \\
White & -0.48 & 0.10 & 22.13 & $<.001$ & 0.62 & 0.51 & 0.76 \\
HSS Major & 0.09 & 0.22 & 0.18 & 0.672 & 1.10 & 0.71 & 1.69 \\
High School GPA & 0.11 & 0.11 & 1.04 & 0.307 & 1.12 & 0.90 & 1.39 \\
ACT Composite & 0.03 & 0.01 & 6.67 & 0.010 & 1.03 & 1.01 & 1.06 \\
PELL Eligible & -0.27 & 0.08 & 10.95 & 0.001 & 0.76 & 0.65 & 0.89 \\
Cum. GPA after Year One & 1.79 & 0.06 & 862.86 & $<.001$ & 6.01 & 5.33 & 6.78 \\
2nd Year BIP x Male & 0.58 & 0.35 & 2.71 & 0.100 & 1.78 & 0.90 & 3.53 \\
2nd Year BIP x White & 0.91 & 0.37 & 6.07 & 0.014 & 2.48 & 1.20 & 5.10 \\
2nd Year BIP x Cum. GPA & -0.02 & 0.28 & 0.01 & 0.935 & 0.98 & 0.57 & 1.69 \\
2nd Year BIP x H.S. GPA & 0.31 & 0.45 & 0.47 & 0.493 & 1.36 & 0.56 & 3.32 \\
2nd Year BIP x ACT Comp. & -0.11 & 0.06 & 3.76 & 0.053 & 0.90 & 0.81 & 1.00 \\
2nd Year BIP x HSS Major & -0.63 & 0.46 & 1.86 & 0.173 & 0.53 & 0.22 & 1.32 \\
2nd Year BIP x PELL & -0.17 & 0.35 & 0.24 & 0.622 & 0.84 & 0.43 & 1.66 \\
Constant & -4.75 & 0.38 & 159.93 & $<.001$ & 0.01 & & \\
\hline
\end{tabular}


RQ3 examined if student characteristics, BIP enrollment, and the interaction between the student characteristics and BIP enrollment were significant predictors of student retention. The student entry characteristics that were examined were: Gender, race, cumulative GPA at the end of the first academic year at the school, high school GPA, ACT composite score, declared college major, and PELL eligibility. There was a statistically significant interaction between the student characteristic of race and first or second year BIP enrollment. The interaction effect between White students and enrollment in a BIP course during the first or second year $(p=.030)$ was a statistically significant predictor of second year retention. White students who had enrolled in a BIP course during the first or second year at the school had 1.73 greater odds of being retained. Additionally, there was a statistically significant interaction between the student characteristic of race and second year BIP enrollment. The interaction effect between White students and enrollment in a BIP course during the second year $(p=.014)$ was a statistically significant predictor of second year retention. White students who had enrolled in a BIP course during the second year at the school had 2.48 greater odds of being retained.

\section{Summary}

This chapter provided an overview of the demographic information and statistical analyses of the provided data from the IRP office for the two-year cohort at the selected institution. This historical data sample consisted of all first-time, full-time, baccalaureate degree-seeking freshmen at the school over the two-year period of 2014-2015. The included 2014 freshmen cohort had a sample size of $(\mathrm{N}=2,830)$ and the 2015 freshmen 
cohort had a sample size of $(\mathrm{N}=2,735)$. Thus, the overall sample size between the two cohorts for the study was $(\mathrm{N}=5,565)$. Approximately, 50.1\% $(n=2,789)$ of the sample was male and $49.9 \%(n=2,776)$ of the sample was female.

RQ1 examined if there were differences between students who had enrolled in BIP courses and those not enrolled in BIP courses. The findings for RQ1 demonstrated there were statistically significant differences between the two groups in race, declared college major, high school GPA, and composite ACT score. The findings for RQ1 showed no statistically significant difference between the two groups for gender and PELL eligibility.

RQ2 examined if enrollment in BIP courses impacted student retention. Logistic regression analysis showed as the number of enrolled BIP courses increased, so did the odds of being retained. In fact, with each increase in the number of BIP courses students had 1.39 greater odds of being retained after the second year at the school. Additionally, the findings for RQ2 showed BIP enrollment during the second year was a statistically significant predictor for second year retention. Students enrolled in BIP courses during the second year had 3.22 greater odds of being retained at the end of the second year as compared to students not enrolled in BIP courses during that same year.

RQ3 examined if student characteristics, BIP enrollment, and the interaction between the student characteristics and BIP enrollment were significant predictors of student retention. There was a statistically significant interaction between the student characteristic of race and first or second year BIP enrollment. The interaction effect between White students and enrollment in a BIP course during the first or second year $(p=.030)$ was a statistically significant predictor of second year retention. White students 
who had enrolled in a BIP course during the first or second year at the school had 1.73 greater odds of being retained. Additionally, there was a statistically significant interaction between the student characteristic of race and second year BIP enrollment. The interaction effect between White students and enrollment in a BIP course during the second year $(p=.014)$ was a statistically significant predictor of second year retention. White students who had enrolled in a BIP course during the second year at the school had 2.48 greater odds of being retained. 
CHAPTER V

DISCUSSION

The higher education landscape has seen a shift in the importance placed on student retention (Webster \& Showers, 2011). As a result, schools are in search of programs and initiatives with potential to increase overall student retention rates (Jamelske, 2009). Thus, the primary purpose of this study was to determine how enrollment in a university Basic Instructional Program (BIP) course may affect overall undergraduate student retention rates at a metropolitan research institution located in the southern region of the United States. This study also sought to understand if certain student characteristics may interact with BIP enrollment to improve student retention rates at the institution. Finally, the study sought to determine the characteristics of students enrolled in BIP courses. The following research questions were developed to address the study's purpose.

RQ1 - Who is enrolling in BIP courses and how do they differ from the rest of the student population?

RQ1a-How does a student's gender influence enrollment in BIP courses?

RQ1b-How does a student's race influence enrollment in BIP courses?

RQ1c- How does a student's high school GPA influence enrollment in BIP courses? 
RQ1d- How does a student's ACT composite score influence enrollment in BIP courses?

RQ1e- How does a student's PELL eligibility status influence enrollment in BIP courses?

RQ1f- How does a student's declared college major influence enrollment in BIP courses?

RQ2 - How does the year of BIP enrollment and the number of BIP classes enrolled in influence student retention?

RQ3 - How is the relationship between enrollment in BIP courses and retention influenced by student characteristics?

RQ3a-How does a participant's gender influence the relationship between enrollment in BIP courses and retention?

RQ3b-How does a participant's race influence the relationship between enrollment in BIP courses and retention?

RQ3c-How does a participant's cumulative GPA at the end of his/her freshmen academic year influence the relationship between enrollment in BIP courses and retention?

RQ3d-How does a participant's high school GPA influence the relationship between enrollment in BIP courses and retention? RQ3e-How does a participant's combined ACT score evaluated during high school influence the relationship between enrollment in BIP courses and retention? 
RQ3f-How does enrollment in a Health and Sport Sciences (HSS) major (Health \& Human Performance and Sport Administration) influence the relationship between enrollment in BIP courses and retention? RQ3g-How does a participant's classification of PELL eligibility influence the relationship between enrollment in BIP courses and retention?

This chapter discusses the results presented in Chapter Four for each of the research questions. Additionally, major implications resulting from the study are discussed, followed by limitations of the study and potential future research.

\section{Student Characteristics and BIP Enrollment}

Research question one examined if demographic differences existed between students enrolling in BIP courses and the rest of the student population. The findings for research question one indicated four statistically significant differences in students enrolled in BIP courses and the rest of the students in the study sample.

Results indicated minority students were enrolled in BIP courses at a significantly greater percentage rate than white students, as the percentage of minority students enrolled in BIP courses was $5.8 \%$ greater than the percentage of minority students in the two-year cohort. These findings are similar to those from Belch et al. (2001) who found 85\% of all African American students at the participating institution had visited the campus recreation center, the greatest frequency of any racial group. Additionally, Lindsey and Sessoms (2006) found 65\% of all African American students had stated participation in sports and fitness activities was an important part of their college experience and would continue to be an important aspect of their life beyond college. 
This finding is of note considering prior research indicated minority youth were less likely to participate in physical activity (Basch, 2011). A result of decreased physical activity levels was the increased likelihood these students would experience negative academic achievement outcomes (Basch, 2011).

Statistically significant results indicated students who had lower high school GPAs were more likely to enroll in BIP courses during their first or second year at the institution. Similarly, students with lower ACT composite scores were statistically more likely to enroll in BIP courses during their first or second year at the school. High school GPA and ACT composite scores are both common criteria used to demonstrate academic aptitude and are used to predict academic success in college. Furthermore, higher high school GPAs are a significant factor in predicting college student persistence (Astin, 1971; Belfield \& Crosta, 2012; Fike \& Fike, 2008; Komarraju et al., 2013; Sawyer, 2013; St. John et al., 2001; Tross et al., 2000; Westrick et al, 2015). These findings show that slightly weaker academically prepared students were more likely to enroll in BIP courses. Students with lower academic aptitude may be drawn to enroll in BIP courses due to the perceived belief BIP courses are less academically challenging. Students potentially view BIP courses as a way to improve their cumulative GPA at college. While no empirical research has been conducted on grade distributions in BIP courses to know if BIP courses have higher than normal letter grades, earlier research by Hardin, Andrew, Koo, Bemiller (2009) showed $9.45 \%$ of the explained variance for student motivation for enrollment in BIP courses was for academic reasons. Specifically, the student respondents in the study indicated they enrolled in BIP classes to improve their college 
GPA and earn a high grade in the course. Thus, it seems quite plausible many students enrolled in BIP courses for elective purposes in the current study had similar motivations.

The previous three statistically significant findings regarding student characteristics of students enrolled in BIP courses have the potential for substantial implications and should not be overlooked. Students with a lower high school GPA and/or a lower ACT composite score are considered at risk populations. High school academic performance, measured by cumulative grade point average, has been shown to be positively related to graduation from college (Astin \& Oseguera, 2005; DeAngelo, Franke, Hurtado, Pryor, \& Tran, 2011; Nora, Barlow, \& Crisp, 2005; Pike, Hansen, \& Childress, 2014). Studies have also found that students' entering academic qualifications measured by ACT composite scores are positively related to graduation probability (Astin \& Oseguera, 2005; DeAngelo et al., 2011; Pike et al., 2014). Additionally, being a member of a historically underrepresented minority group has negative implications on degree attainment (Astin \& Oseguera, 2005; Cabrera et al., 2005; Carey, 2005a; DeAngelo et al., 2011; Pike et al., 2014). In fact, previous research has shown minority students, especially African American students, have much lower retention rates than their majority counterparts (Carey, 2005a, 2005b; Fleming, 2002; Harvey, 2001; Hu \& St. John, 2001; National Collegiate Athletic Association, 2001; NCES, 2005).

Since all three groups of students enrolling in BIP courses at a greater rate are considered at risk students, the findings from research question one demonstrates BIP courses provide a logical setting to target potential intervention programs with these students, who are at greater risk of not being retained. Since higher education institutions, including the participating institution in the study, are experiencing retention 
problems, it seems imperative for university officials to use an available opportunity to have many critical at-risk student groups in one setting. In addition to providing access to this highly valued subset of the student population, it appears BIP course offerings provide an opportunity to integrate these groups as well. BIP course offerings provide opportunities for social interactions between students and provide a setting for more personal interaction between the students and faculty members.

Finally, results from research question one showed a statistical difference in the declared college major of students enrolling in BIP courses, as HSS majors were more likely to enroll in BIP courses during their first or second year as compared to all other declared college majors. As discussed earlier in this paper, HSS majors are the only students required to enroll in a BIP course at the institution as part of a degree requirement. Since HSS majors are required to enroll in BIP courses for their degree, it is understandable HSS majors enrolled in BIP courses at a much higher rate. Students in non-HSS majors are enrolling in BIP courses as electives or for personal reasons. While this fourth finding from research question one demonstrates a distinguishing difference between students enrolled in BIP courses and the rest of the student population it does not expand the body of literature on BIP courses.

In sum, research question one found statistically significant differences in certain characteristics of students enrolling in BIP courses and the rest of the student population as minority students, students with lower high school GPAs, students with lower ACT composite scores, and HSS majors were more likely enroll in BIP courses. These findings have practical significance since weaker academic students and minority students are both critical groups in maintaining student persistence and progress towards degree 
completion. The next section discusses the study findings on how BIP course enrollment was a statistically significant predictor of student retention.

\section{BIP Enrollment and Student Retention}

One of the most pressing issues in the higher education landscape is addressing and determining effective strategies to increase student retention rates (Kahu \& Nelson, 2018). Higher education has seen a shift in the importance placed on student retention caused by the decrease in fiscal resources (Browne, 2010; Newman, Couturier, \& Scurry, 2010; Tinto, 2006). As a result, higher education administrators are aggressively searching for programs and interventions which could potentially increase overall student retention rates. An overlooked area in the student retention research at higher education institutions was if any positive association existed between enrollment in a university physical education course and student retention.

A plethora of previous research conducted in the K-12 setting has shown physical activity participation promotes physical, mental, social, and academic gains in adolescents (Davis et al., 2007; Donnelly et al., 2016; Grissom, 2005; Nelson \& GordonLarson, 2006; Rasberry et al., 2011; Tremarche et al., 2007; Wittberg et al., 2009). These earlier studies examined the broad concept of physical activity, but not physical activity associated with physical education involvement. Neither did these earlier studies examine if physical activity influenced student retention. Additionally, earlier research demonstrated participation in fitness and sports opportunities in a campus recreation setting was positively related to positive gains in overall individual academic success and institutional student retention rates (Belch et al., 2001; Henchy, 2011; Lindsey \& 
Sessoms, 2006; Miller, 2011). There appear to be similar characteristics between the programming offered by campus recreation departments and BIP programs. Both programs provide logical outlets for students to establish social interactions and develop peer groups (Miller, 2011). The course structure of BIP class offerings is conducive for interactions among students. Research indicates social interactions and experiences with peers positively affect students' self-esteem and self-worth (Sax, 1997). Student satisfaction with the student experience and the ability to create peer groups are critical aspects in student retention (Douglas et al., 2015). Additionally, students need to feel accepted and part of a peer social group early in their educational experience (Morrow \& Ackermann, 2012; O’Keeffe, 2013; Torres, 2003; Zurita, 2004).

Limited research exists on the benefits of physical activity participation in the college age population, however. Additionally, no studies have been located on how enrollment in university BIP courses influenced student retention before the present study. As a result, the findings from the current study could have implications for the perceived perception and worth of BIP courses. Historically, physical education professionals have touted the significance of the discipline due to the associated health gains from participation in physical activity (Bray \& Born, 2004; Carlson, 2015; Curry et al., 2015; Ebben \& Brudzynski, 2008; Johnson \& Deshpande, 2000), but there are more reasons to examine this issue. Therefore, research question two examined if the year of BIP enrollment as well as the number of enrolled BIP classes influenced student retention.

The present study examined if BIP enrollment during the first or second year at the school had any impact on student retention rates. Logistic regression analysis showed 
first year BIP enrollment was not a statistically significant predictor of first year or second year retention. However, logistic regression analysis did show enrollment in a BIP course during the second year at the institution was a significant predictor of second year retention. Students enrolling in a BIP course during their second year at the school had 3.22 greater odds of student retention after the second year at the institution than students not enrolled in BIP courses. Thus, the odds a student was retained after the second year at the school was over $200 \%$ greater when the student had enrolled in a BIP course during year two, than the odds of retention for students not enrolled in BIP courses during that same time.

The finding that student retention rates improved after the second year is important and adds to the body of student retention literature. Many institutions encounter a high number of their students withdrawing from the school after their sophomore year (Vuong, Brown-Welty, \& Tracz, 2010). In fact, student departure after the second year has been referred to as the sophomore slump for over 60 years (McBurnie, Campbell, \& West, 2012). Retention of sophomore students continues to be an area of research focus (Lee \& Leonard, 2009; McBurnie et al., 2012; Schaller, 2010; Tobolowsky, 2008; Vaughn \& Parry, 2013; Vuong et al., 2010). The sophomore year is often a period with high levels of stress for students because most schools require students to decide on and declare a major at this time (Tobolowsky, 2008).

Additionally, many higher education institutions invest a great deal of attention, resources, and retention themed programming during the first-year experience (Wang \& Kennedy-Phillips, 2013). While these initiatives help to decrease the number of students leaving the school after the first-year, students may perceive that administrators are only 
concerned about student academic success during year one. While it is important to offer many different retention programs during the students' first year, schools must understand many students elect to leave the institution after year two. As a result, schools must continue to research potential strategies to address student withdrawal during the sophomore year. Thus, the finding of research question two, that BIP course enrollment during year two at the school increases the odds of student retention, has the potential to help combat the number of student withdrawals.

The second portion of research question two looked at whether the number of BIP courses enrolled in by a student was a significant predictor of second year student retention. For each additional BIP course enrolled in during the first two years at the school, students had 1.39 greater odds of being retained after the second year. Thus, each additional BIP course enrolled in increases the likelihood of second year retention by $39 \%$. This finding demonstrates the importance of BIP enrollment as a predictor of second year student retention and demonstrates college students should be enrolling in multiple BIP courses during the first two years at the school.

The findings of the present study are similar to those from Belch et al., (2001) and Huesman et al., (2007), who found frequent users of student recreation centers had greater odds of being retained. As frequency of recreation center usage increased, so did student retention rates. Similarly, the findings in the present study showed as students enrolled in more BIP courses during the first two years at the institution their odds of second year retention also increased. As a result, the current study findings should be shared with academic advisors and university administrators at the participating institution. The results demonstrate enrollment in BIP courses may be an effective 
intervention to help address the departure of many students before degree completion. Additionally, the findings should be shared with other colleges and universities as a potential approach to assist their own student retention efforts.

\section{Student Characteristics and Student Retention}

Research question three examined whether student characteristics influenced the relationship between BIP enrollment and student retention. The concept of student characteristics influencing overall student retention rates has been examined quite frequently over the years, and researchers have shown student characteristics can affect overall retention rates at higher education institutions (Astin \& Oseguera, 2005; Belfield \& Crosta, 2012; Berger, 2001; Komarraju et al., 2013; Sawyer, 2013). For example, Astin and Oseguera (2005) found 70\% of the explained variance between the degree completion rates at institutions was due to the students' characteristics upon initial entry at the school. However, none of the earlier student retention research examined if student characteristics influenced the relationship between BIP enrollment and student retention. Therefore, the existing study looked to add to the student retention literature by examining if such an association existed. For this study, the student entry characteristics examined were gender, race, cumulative GPA at the end of the first academic year at the school, high school GPA, ACT composite score, declared college major, and PELL eligibility.

The present study showed there was a statistically significant interaction between the student characteristic of race and first or second year BIP enrollment. White students who had enrolled in a BIP course during the first or second year at the school had 1.73 greater odds of second year retention. Thus, White students who had enrolled in a BIP 
course during the first or second year at the school were $73 \%$ more likely to be retained after the second year. Additionally, there was a statistically significant interaction between the student characteristic of race and second year BIP enrollment, as White students who had enrolled in a BIP course during the second year at the school had 2.48 greater odds of second year retention. Thus, the odds of experiencing second year retention was $148 \%$ greater for White students enrolled in a BIP course during the second year.

A significant interaction effect between White students and enrollment in BIP courses does not imply minority students were not retained, but rather the findings from research question three demonstrated a stronger association was found amongst the White students and BIP course enrollment. The earlier results presented in this paper for research question one showed minority students enrolled in BIP courses at a higher rate than White students. Thus, the BIP program at the participating institution must determine why minority students were attracted to the program at a high rate, yet White students enrolled in BIP courses were retained at a higher rate than the minority students enrolled in BIP courses. Potential reasons for the differences in retention rates and the fact minority students experienced a weaker interaction effect with BIP course enrollment may be due to differences in academic and social experiences.

Previous research has shown students in historically underrepresented minority groups encounter negative experiences during the educational process, which can hinder progress toward degree attainment and decrease overall student retention rates (Astin \& Oseguera, 2005; Aud, Fox, \& KewalRamani, 2010; Baker \& Robnett, 2012; Cabrera et al., 2005; Carey, 2005a; Crisp, Taggart, \& Nora, 2014; DeAngelo et al., 2011; Farmer \& 
Hope, 2015; Ginder, Kelly-Reid, \& Mann, 2015; Pike et al., 2014). The lack of academic preparedness of minority students, especially African American students, is one of the biggest challenges for these students to overcome in higher education (Baker \& Robnett, 2012; Farmer \& Hope, 2015; Crisp et al., 2015; Simiyu, 2012). Additionally, the literature has shown minority students have an extremely challenging time developing a sense of identity, establishing a peer network, and becoming socially accepted at primarily White institutions (PWIs) (Fisher, 2007; Harper, 2009; Hudley \& Daoud, 2008; Johnson et al., 2007; Rankin \& Reason, 2005).

Based on these findings, it seems plausible to speculate that the findings for research question three in the present study may be related to minority students attempting to overcome their lower levels of academic preparedness. The findings for research question one in the present study showed students with a lower ACT composite score and a lower high school GPA enrolled in BIP courses with greater frequency. Students in these two categories are also considered members of at risk populations. Thus, based on the literature it seems very likely the minority students in the sample with a low high school GPA and a low ACT composite score would have had additional obstacles to overcome in their academic pursuits, since these individuals would have been classified as members of at risk populations based on three different attributes. As a result, while the intervention of BIP course enrollment does help minority student retention and progress toward degree completion, it appears the positive gains associated with BIP course enrollment are not sufficient on their own to overcome the lack of academic preparedness and social shortfalls for all minority students included in the sample. Thus, BIP course enrollment can be viewed as an effective possible student 
retention intervention. However, it is not as effective for this population as it is for White students. Thus, further investigation is needed to determine if BIP offerings and course content could be adjusted to further increase the strength of the relationship between minority student retention and BIP course enrollment.

\section{Practical Implications}

This study has important implications for the field of student retention, as it demonstrates a link between BIP course enrollment and student retention. The findings introduce a potential intervention to help increase the odds of more students successfully being retained at higher education institutions. Additionally, the findings demonstrate the importance of physical activity and the presence of physical education in the overall educational experience of college students. The findings promote the significance of whole-body education and illustrate how positive academic gains are associated with physical education experiences. The current findings will also strengthen the justification for the value of physical education in the academic setting.

These findings should provide physical educators another option to advocate for the discipline's value and worth, something which is desperately needed. Over the last century, many higher education institutions offered physical education courses for academic credit through a BIP program (Carlson, 2015; Hensley, 2000). As more emphasis has been placed on efforts to promote academic success and student retention efforts at higher education institutions, however, there has been a noticeable shift away from including physical education as a general education requirement. In fact, Cardinal et al. (2012) reported that $60.45 \%$ of universities and colleges included in their study no longer required any physical education course for graduation. 
This substantial decrease left the field of physical education on the defensive and attempting to find ways to demonstrate the program's worth in the US higher educational landscape (Hensley, 2000). As a result, the field of physical education elected to emphasize the positive health gains associated with participation in physical education. Thus, BIP programs emphasized the main goal of program offerings was to improve overall health and wellness and in turn help shape a healthy student population (Carlson, 2015; Curry et al., 2015). Physical activity involvement also helps address stressful situations and improves self-esteem levels (Joseph et al., 2014; Sax, 1997).

While it is true many health gains are associated with participation in physical education courses, this argument has not caused a shift in the priority placed on physical education in the higher education landscape. Advocating for the importance of physical education in the higher education structure because of potential health gains has not proven to be an effective approach in preventing the steady demise of the inclusion of physical education in degree requirements. Higher education institutions have continued to progress toward a degree model that excludes physical education. Thus, it has become imperative for physical educators to begin changing the narrative on why including physical education courses adds more to the student educational experience than positive health outcomes for the students. Since higher education administrators now place more emphasis on academic accountability, it seems critical that physical educators demonstrate how involvement in physical education can help improve academic success. The findings from the present study can successfully start to change the narrative.

BIP program administrators need to do a much better job with promoting the advantages of their programs. It is critical for survival of both BIP and physical education 
programs to begin to effectively demonstrate enrollment in BIP course offerings extends positive physical outcomes and can be linked with student academic success. Higher education institutions are searching for the appropriate mix of strategies and programming to effectively increase overall student retention rates (Bettinger, Boatman, \& Long, 2013; Carey, 2005a, 2005b; Chen, 2012; Tinto, 2006, 2010). Existing student retention research has demonstrated successful student retention programs encompass various factors and often differ from institution to institution (Bettinger et al., 2013; Tinto, 2006). Thus, the findings from the current study should be considered as a potential intervention in higher education student retention efforts.

In addition to adding to the study of student retention and providing a potentially stronger narrative for the field of physical education, the present study findings have the potential for significant implications for the university used in the study. The selected institution is dealing with a student retention issue. In fact, regarding the two-year cohort included in the study, $29.9 \%(n=1,666)$ of the original 5,565 students were not retained at the school after the second year. The National Center for Education Statistics (2018) found that the six-year graduation rate of undergraduate students who started college in fall 2010 was around $60 \%$. However, self-published data from the participating institution in the study showed the six-year graduation rate for the fall 2010 cohort was 52\% (University of Louisville IRP Office, 2018). This demonstrates the university still has work to accomplish in improving its retention efforts, since the institution is presently below the national average. University administration recently acknowledged its commitment to addressing this retention problem and as a result has allocated financial resources for new and innovative retention initiatives for the present academic year. The 
findings from this study could prove to be a beneficial source of information during the discussions over potential retention programming strategies. It seems imperative that the study findings should be shared with university administrators at the participating institution as they search for interventions to help increase the overall university retention rate.

The significant findings from the current study could result in possible programmatic changes for the BIP program at the participating institution. The BIP program is housed in the Health and Sport Sciences (HSS) Department and presently HSS requires students to complete two credit hours of BIP courses as a degree requirement. Currently, there is no stipulation by the Department on which academic year the BIP courses are completed. The current study results indicated students enrolled in BIP courses during the second year at the school had 3.22 greater odds of being retained after the second year than students not enrolled in BIP courses during the second year. Thus, HSS administration, faculty, and the academic advising staff need to strongly consider suggesting or even begin requiring HSS majors to enroll in at least one BIP course during year two at the school. This new approach of having HSS students enroll in a BIP course during their second year at the institution could be a logical tactic to greatly increase the odds that the HSS student population is retained after year two. The second-year retention rate for declared HSS majors in the sample was $70.96 \%$, which is consistent with the entire sample from the university of $70.0 \%$. This data demonstrates a need for strategies to help increase the student retention rates of HSS students as well as the rest of the campus community. The data from the present study demonstrates that mandating students enroll in a BIP course during year two at the school would be a 
successful student retention intervention and help to address the participating institutions retention issue.

An additional discussion item HSS must consider is the number of required BIP courses for each of its degree plans. The current study results indicated for each additional BIP course enrolled in during the first two years at the institution, students had 1.39 greater odds of being retained after the second year. These findings showed that enrolment in each additional BIP course increased the odds of the student being retained after the second year, therefore careful consideration on the appropriate number of required BIP courses in the degree plans is warranted. Presently, HSS majors are required to complete two BIP courses as a degree requirement. However, the current study findings seem to show increased value in requiring students to complete additional BIP courses as a degree requirement. Thus, HSS administration and faculty need to carefully consider the present study findings and evaluate if it would be feasible to increase the number of required BIP courses for degree attainment. Additionally, if the department determines increasing the number of required BIP courses in the degree plans is not feasible, the academic advising staff should still explain to students the benefits associated with enrollment, so students can consider enrolling in additional BIP courses for elective purposes.

Additionally, these findings should also be shared with the administration of the College of Education and Human Development (CEHD), where HSS is housed. After reviewing the study findings, CEHD administration should highly consider requiring all undergraduate degree plans housed in the College to include a minimum of one BIP course, preferably during the second year at the school. Teacher education programs are 
experiencing a national decrease in the number of prospective teachers enrolling in their programs (Sutcher, Darling-Hammond, \& Carver-Thomas, 2016). Additionally, Chen (2013) found that $20 \%$ of students who started college as a declared education major eventually dropped out of school completely. The teacher educator programs at the participating university have experienced a substantial decline in enrollments and as a result, it becomes even more critical to keep the students matriculating towards graduation. Thus, the administration of the CEHD should consider requiring enrollment in a BIP course for all teacher candidates as well as all undergraduate degrees as a strategy to increase overall retention rates.

In addition to discussing the findings from the current study with CEHD administration, the BIP program director and HSS administration must also have a discussion with CEHD administration regarding the way the BIP program is presently funded. Presently, the BIP program is self-funded with no allocation of financial resources from either the department or CEHD. Students are assessed a $\$ 50$ fee for each BIP course in which they enrolled. The present funding model limits both the number and type of BIP courses offered. If a different funding model existed, the program would have the opportunity to offer a wider variety of BIP courses, which could then potentially appeal to a larger number of students. Increasing both the number and variety of BIP courses might in turn cause a growth in the number of students electing to enroll in BIP courses. Since BIP enrollment during the second year was a significant predictor of second year retention it would be advantageous for administration to view BIP course enrollment as a possible student retention initiative and consider eliminating the assessed student fee. Now that the current study has shown BIP enrollment was a significant 
predictor of second year retention, it seems counterproductive to require students to pay an additional fee.

Additionally, the findings from the current study should also be disseminated with central administration at the participating institution, including the Associate Provost for Undergraduate Education, the Vice Provost for Strategic Enrollment Management and Student Success, and the Office of Enrollment Management. As previously mentioned, this is an area of research that has not been examined in the retention literature, thus the significant findings in the current study warrant that university administration, especially the three previously mentioned offices, should investigate the findings further to determine if BIP course enrollment should be used as a potential retention intervention. Central administration should evaluate the effectiveness of BIP course enrollment as a predictor of student retention and consider including BIP courses as part of the general education requirement at the school for undergraduate students. Additionally, based on the study findings it would be advantageous to encourage and or require students to enroll in a BIP course during their second year at the school.

While most of the previously listed implications are specific to the participating institution, the findings may have significance for other schools as well. Thus, the findings from the current study should be discussed with physical educators and university administrators at other institutions which presently offer BIP courses. The BIP program director should discuss the current study findings with other BIP program directors across the country. Additionally, the study findings should be discussed with other potential allies for physical education, fitness, recreation, and wellness. The study findings would be of interest to the Society of Health and Physical Educators, whose 
mission is to promote the fields of physical education and physical activity. Another potential ally would be NIRSA: Leaders in Collegiate Recreation, whose mission is to promote and advocate for recreation, sport, and wellness in the higher education setting. Other national organizations such as the National Association on Kinesiology in Higher Education (NAKHE) would be good outlets for this information as well. Sharing the current study findings with other institutions and national organizations has the potential for research to stem from these conversations. The next section of this paper addresses the limitations of the study.

\section{Limitations of the Study}

A limitation of this study was that only the two freshmen fall cohorts of 2014 and 2015 were examined at a single institution. It is unknown if the data set was representative of all freshmen cohorts at the selected institution over an extended period or just illustrative for the specific years of the study. Since the study used data from a single institution, extreme caution should be used before generalizing the findings to other schools. An additional limitation of the study was the omission of students who initiated enrollment during the spring and summer semesters. An added limitation of the study was the use of a pre-existing data set, which prevented the researcher from acquiring further information from the participants. Each freshman cohort has its own

unique make-up. These distinguishing characteristics can vary from year to year, thus making it difficult to make accurate comparisons from one cohort to the next. These identified limitations from the current study should be addressed in future research studies. 


\section{Future Research}

This study represented the first step in understanding how enrollment in BIP courses affected student retention. The study findings showed enrollment in BIP courses during the second year at an institution was a significant predictor for second year retention. Since the results from this initial study produced significant findings, future research on the topic is necessary. One possible extension to this study would be to expand beyond first and second year BIP enrollment. An examination of BIP enrollment during the third year at the institution may prove to be valuable in explaining student retention as well. This proposed future study would be consistent with earlier research by Allen, Robbins, Casillas, and Oh (2008) who found the third year of college as a critical variable to be studied in student retention research.

In addition to examining BIP course enrollment during the third year, future research could examine if the type of BIP course offerings affected student retention. Presently, the participating institution offers BIP courses in fitness, dance, individual sports, and team sports. Thus, a future study could examine how enrollment in these varying BIP course types predicts student retention. It may also result in suggestions for new types of course offerings. These future findings could have programmatic implications and help define specific courses that are more beneficial to increasing the overall student retention rate.

Other potential future studies could be completed at the participating institution. One future study could examine how an interaction between BIP course enrollment and first-generation college students predicted student retention rates. Research by DeAngelo 
et al. (2011) found first-generation college students have four and six-year graduation rates that are $14 \%$ lower than students whose families had college experience. A published 2017-2018 report from the participating institution showed that $17.3 \%$ of the first-time, full-time, baccalaureate degree-seeking students in the summer/fall 2017 cohort were first generation college students (University of Louisville IRP Office, 2018). Thus, it would be beneficial to conduct a future study to see if enrollment in BIP course by first-generation college students could be a significant predictor of student retention.

One of the student characteristics examined in the present study was declared college major. Specifically, the researcher looked at the interaction between declared HSS majors and enrollment in BIP courses. All other college majors were placed in one large group, since none of the non-HSS majors required BIP courses as a degree requirement. A future study could examine other declared majors besides HSS to determine if student retention could be significantly predicted by an interaction between declared major and BIP course enrollment. One potential focus could examine students who had declared a degree in science, technology, engineering, and mathematics (STEM). Chen (2009) found around 50\% of students who enter college with a declared major in STEM elect to switch to a different degree in a field that is not STEM related or leave higher education. Since there is a high need for graduates in the fields of STEM, helping keep students in school and pursuing STEM related degrees is vitally important.

All the previous future research recommendations could be implemented at the participating institution of the current study. However, this type of research is not limited to just one university. The data set used for this study came from only one participating institution. As a result, future research could include replicating the study methodology 
at additional universities. This would provide a clearer understanding if the present study findings are generalizable to other schools or if the current findings were only representative to the participating institution.

\section{Conclusion}

Existing student retention research has demonstrated successful student retention programs encompassed various factors and often differ from institution to institution (Bettinger et al., 2013; Tinto, 2006). Student academic success and student retention are the results of the presence of many different experiences and student characteristics (Berger, 2001; Tinto, 2010). While individual studies have shown student characteristics correlate with student persistence, this line of research has not been able to determine that the presence of one specific variable guarantees $100 \%$ student retention in all cases and at all institutions (Demetriou \& Schmitz-Sciborski, 2011). While the field of student retention has been widely studied, there continues to be areas in higher education that require further research (Tinto, 2006). While some institutions have successfully implemented student retention programs, many schools are still searching for the appropriate mix of strategies and programming (Bettinger et al., 2013; Carey, 2005a, 2005b; Chen, 2012; Tinto, 2006, 2010).

This last statement holds very true for the participating institution in the current study, which has acknowledged a commitment to improving current retention rates. To examine a potential strategy for improving student retention the current study examined whether student entry characteristics and enrollment in physical education activity courses influenced student retention of all first-time, full-time, baccalaureate degree 
seeking students enrolled at a metropolitan public research university located in the southern region of the United States during the years of 2014-2015. Enrollment in BIP courses during the second year at the institution was found to be a statistically significant predictor of second year retention. Students enrolled in a BIP course during their second year at the school had 3.22 greater odds of being retained after the second year at the institution than students not enrolled in BIP courses.

Additionally, the study results indicated that for each additional BIP course enrolled in during the first two years at the institution, students had 1.39 greater odds of being retained after the second year. Finally, the study found an interaction effect between White students and enrollment in a BIP course during the second year was a statistically significant predictor of second year retention. White students who had enrolled in a BIP course during the second year at the school had 2.48 greater odds of being retained. This connection between BIP course enrollment and increased odds of student retention had never been examined before in the field of student retention. These findings add to the student retention literature by demonstrating a significant association between BIP course enrollment and student retention. 


\section{REFERENCES}

Abouserie, R. (1994). Sources and levels of stress in relation to locus of control and self esteem in university students. Educational Psychology, 14(3), 323-330.

Adams, T. M., \& Brynteson, P. (1992). A comparison of attitudes and exercise habits of alumni from colleges with varying degrees of physical education activity programs. Research Quarterly for Exercise and Sport,63(2), 148-152.

Adelman, C. (1999). Answers in the toolbox: Academic intensity, attendance patterns, and bachelor's degree attainment. Washington, D.C.: U.S. Department of Education, Office of Educational Research and Improvement.

Ahamed, Y., Macdonald, H., Reed, K., Naylor, P. J., Liu-Ambrose, T., \& Mckay, H. (2007). School-based physical activity does not compromise children's academic performance. Medicine and Science in Sports and Exercise, 39(2), 371-376.

Allegrante, J. P. (2004). Unfit to learn. Education Week, 24, 38.

Allen, J., Robbins, S. B., Casillas, A., \& Oh, I. S. (2008). Third-year college retention and transfer: Effects of academic performance, motivation, and social connectedness. Research in Higher Education, 49(7), 647-664.

American College Health Association. (2013). National College Health Assessment II: Reference Group Executive Summary Fall 2012. Hanover, MD: American College Health Association.

American College Testing. (2018) Information retrieved from http://www.act.org/content/act/en/products-and-services/the-act/help.html

Artinger, L., Clapham, L., Hunt, C., Meigs, M., Milord, N., Sampson, B., \& Forrester, S. A. (2006). The social benefits of intramural sports. NASPA Journal, 43(1), 69-86.

Astin, A. W. (1968). Undergraduate achievement and institutional excellence. Science, $161,661-668$.

Astin, A.W. (1971, Winter). New evidence on campus unrest, 1969-70. Educational Record, pp. 41-46.

Astin, A.W. (1972). College dropouts: A national profile. ACE Research Reports, 7, Washington, D.C.: American Council on Education. 
Astin, A. W. (1973a). The impact of dormitory living on students. Educational Record, 54, 2014-210.

Astin, A. W. (1973b). Student persistence: Some stay, some don't-why. College and University, 48(4), 298-306.

Astin, A.W. (1975). Preventing students from dropping out. San Francisco: Jossey-Bass.

Astin, A.W. (1982). Minorities in American higher education: Recent trends, current prospects and recommendations. San Francisco: Jossey-Bass Inc., Publishing.

Astin, A.W. (1984). Student involvement: A developmental theory for higher education. Journal of College Student Personnel, 25(4), 297-308.

Astin, A. W. (1985). Involvement the cornerstone of excellence. Change, 17(4), 35-39.

Astin, A. W. (1991). The changing American college student: Implications for educational policy and practice. Higher Education, 22(2), 129-143.

Astin, A.W. (1993a). College retention rates are often misleading. The Chronicle of Higher Education, September 22, p. A48.

Astin, A.W. (1993b). What matters in college? Four critical years revisited. San Francisco: Jossey-Bass Inc., Publishing.

Astin, A. W. (1993c). What matters in college. Liberal Education, 79(4), 4-15.

Astin, A.W. (1997). How "good" is your institution's retention rate? Research in Higher Education, 38(6), 647-658.

Astin, A.W. (2005). Making sense out of degree completion rates. Journal of College Student Retention, 7(1-2), 5-17.

Astin, A.W., \& Oseguera, L. (2005). Degree attainment rates at American colleges and universities: Revised edition. Higher Education Research Institution, University of California Los Angeles.

Attinasi, L. C. (1989). Getting in: Mexican Americans' perceptions of university attendance and the implications for freshman year persistence. The Journal of Higher Education, 60(3), 247-277.

Aud, S., Fox, M. A., \& KewalRamani, A. (2010). Status and trends in the education of racial and ethnic groups. NCES 2010-015. Washington, DC: National Center for Education Statistics. 
Avery, M., \& Lumpkin, A. (1987). Students' perceptions of physical education objectives. Journal of Teaching in Physical Education, 7, 5-11.

Baghurst, T., \& Kelley, B. C. (2014). An examination of stress in college students over the course of a semester. Health Promotion Practice, 15(3), 438-447.

Baker, C. N., \& Robnett, B. (2012). Race, social support and college student retention: A case study. Journal of College Student Development, 53(2), 325-335.

Baker, R. W., \& Siryk, B. (1989). Student adaptation to college questionnaire: Manual. Western Psychological Services.

Barefoot, B. O. (2004). Higher education's revolving door: Confronting the problem of student drop out in US colleges and universities. Open Learning, 19(1), 9-18.

Basch, C. E. (2011). Physical activity and the achievement gap among urban minority youth. Journal of School Health, 81(10), 626-634.

Baum, S. \& McPherson, M. (2008). Introduction. In The Effectiveness of Student Aid Policies: What the Research Tells Us, edited by Baum, S., McPherson, M. \& Steele, P. New York: The College Board.

Bean, J. P. (1980). Dropouts and turnover: The synthesis and test of a causal model of student attrition. Research in Higher Education, 12(2), 155-187.

Beard, J. G., \& Ragheb, M. G. (1983). Measuring leisure motivation. Journal of Leisure Research, 15(3), 219-228.

Belch, H. A., Gebel, M., \& Maas, G. M. (2001). Relationship between student recreation complex use, academic performance, and persistence of first-time freshmen. Journal of Student Affairs Research and Practice, 38(2), 254-268.

Belfield, C. R., \& Crosta, P. M. (2012). Predicting Success in College: The Importance of Placement Tests and High School Transcripts. CCRC Working Paper No. 42. Community College Research Center, Columbia University.

Bennett, C., \& Okinaka, A. M. (1989, March). Factors related to persistence among Asian, Black, Hispanic, and White undergraduates at a predominantly White university: Comparison between first and fourth year cohorts. Paper presented at the annual meeting of the American Educational Research Association, San Francisco, CA.

Bennett, C., \& Okinaka, A. M. (1990). Factors related to persistence among Asian, Black, Hispanic, and White undergraduates at a predominantly White university: Comparison between first and fourth year cohorts. The Urban Review, 22(1), 3360 . 
Berger, J. B. (2001). Understanding the organizational nature of student persistence: Empirically-based recommendations for practice. Journal of College Student Retention: Research, Theory \& Practice, 3(1), 3-21.

Berger, J. B., \& Lyon, S. C. (2005). Past to present: A historical look at retention. In A. Seidman (Ed.), College student retention: Formula for student success (pp. 1-30). Westport, CT: Praeger Publishers.

Bettinger, E. P., Boatman, A., \& Long, B. T. (2013). Student supports: Developmental education and other academic programs. The Future of Children, 23(1), 93-115.

Bettinger, E. P., Evans, B. J., \& Pope, D. G. (2013). Improving college performance and retention the easy way: Unpacking the ACT exam. American Economic Journal: Economic Policy, 5(2), 26-52.

Blanchfield, W.C. (1971). College dropout identification: A case study. Journal of Experimental Education, 40, 1-4.

Booth, F. W., \& Lees, S. J. (2006). Physically active subjects should be the control group. Medicine and Science in Sports and Exercise, 38(3), 405-406.

Bowen, W.G., Kurzweil, M.A., \& Tobin, E.M. (2005). Equity and excellence in American higher education. Charlottesville: University of Virginia Press.

Boyce, B. A., Lehr, C. \& Baumgartner, T. (1986). Outcomes of selected physical education activity courses as perceived by university students. Journal of Teaching in Physical Education, 7(1), 280-292.

Bradley, J. Phillipi, R., \& Bryant, J. (1992). Minorities benefit from their association with campus recreation programs. NIRSA Journal, 46-49.

Braxton, J. M. (Ed.). (2000). Reworking the student departure puzzle. Nashville, TN: Vanderbilt University Press.

Bray, S. R., \& Born, H. A. (2004). Transition to university and vigorous physical activity: Implications for health and psychological well-being. Journal of American College Health, 52(4), 181-188.

Browne, J. (2010). Securing a sustainable future for higher education: an independent review of higher education funding and student finance.

Bryant, J. A., \& Bradley, J. L. (1993). Enhancing academic productivity, student development and employment potential. NIRSA Journal, 18(1), 42-47. 
Bryant, J. A., Banta, T. W., \& Bradley, J. L. (1995). Assessment provides insight into the impact and effectiveness of campus recreation programs. NASPA Journal, 32(2), 153-161.

Brynteson, P., \& Adams, T. M. (1993). The effects of conceptually based physical education programs on attitudes and exercise habits of college alumni after 2 to 11 years of follow-up. Research Quarterly for Exercise and Sport, 64(2), 208212.

Buchmann, C., \& DiPrete, T. A. (2006). The growing female advantage in college completion: The role of family background and academic achievement. American Sociological Review, 71(4), 515-541.

Burton, L. J., \& VanHeest, J. L. (2007). The importance of physical activity in closing the achievement gap. Quest, 59(2), 212-218.

Cabeza, R. (2001). Functional neuroimaging of cognitive aging. Handbook of Functional Neuroimaging of Cognition, 331-377.

Cabrera, A.F., Burkum, K.R., \& La Nasa, S.M. (2005). Pathways to a four-year degree: Determinants of transfer and degree completion. In A. Seidman (Ed.). College student retention: A formula for student success. Westport, CT: ACE/Praeger.

Cabrera, A. F., Nora, A., \& Castaneda, M. B. (1993). College persistence: Structural equations modeling test of an integrated model of student retention. Journal of Higher Education, 64(2), 123-139.

California Department of Education (CDE). (2001). California physical fitness test: Report to the governor and legislature. Sacramento, CA: California Department of Education Standards and Assessment Division.

Cardinal, B. J., Sorensen, S. D., \& Cardinal, M. K. (2012). Historical perspective and current status of the physical education graduation requirement at American 4year colleges and universities. Research Quarterly for Exercise and Sport, 83(4), 503-512.

Carey, K. (2005a). One step from the finish line: Higher college graduation rates are within our reach. New York: The Education Trust.

Carey, K. (2005b). Choosing to improve: Voices from colleges and universities with better graduation rates. New York: The Education Trust.

Carlson, S.A. (2015, January 12). When colleges abandon phys ed, what else is lost? The Chronicle of Higher Education. Retrieved from https://www.chronicle.com/article/When-Colleges-Abandon-Phys-Ed/151109 
Carlson, S. A., Fulton, J. E., Lee, S. M., Maynard, L. M., Brown, D. R., Kohl III, H. W., \& Dietz, W. H. (2008). Physical education and academic achievement in elementary school: Data from the early childhood longitudinal study. American Journal of Public Health, 98(4), 721-727.

Carlson, S. M. (2005). Developmentally sensitive measures of executive function in preschool children. Developmental Neuropsychology, 28(2), 595-616.

Carnevale, A.P., \& Rose, S.J. (2003). Socioeconomic status, race/ethnicity and selective college admissions. New York: The Education Trust.

Caspersen, C. J., Pereira, M. A., \& Curran, K. M. (2000). Changes in physical activity patterns in the United States, by sex and cross-sectional age. Medicine and Science in Sports and Exercise, 32(9), 1601-1609.

Caspersen, C. J., Powell, K. E., \& Christenson, G. M. (1985). Physical activity, exercise, and physical fitness: definitions and distinctions for health-related research. Public Health Reports, 100(2), 126.

Castelli, D. M., Hillman, C. H., Buck, S. M., \& Erwin, H. E. (2007). Physical fitness and academic achievement in third-and fifth-grade students. Journal of Sport and Exercise Psychology, 29(2), 239-252.

Caterino, M. C., \& Polak, E. D. (1999). Effects of two types of activity on the performance of second-, third-, and fourth-grade students on a test of concentration. Perceptual and Motor Skills, 89(1), 245-248.

Centers for Disease Control and Prevention. (2010). The association between school based physical activity, including physical education, and academic performance. Atlanta, GA: U.S. Department of Health and Human Services.

Chase, C. I. (1970). The college dropout; His high-school prologue. Bulletin of the National Association of Secondary School Principals, 54, 66-71.

Chen, R. (2012). Institutional characteristics and college student dropout risks: A multilevel event history analysis. Research in Higher Education, 53(5), 487-505.

Chen, X. (2009). Students who study science, technology, engineering, and mathematics (STEM) in postsecondary education. Stats in Brief. NCES 2009-161. National Center for Education Statistics.

Chen, X. (2013). STEM attrition: College students' paths into and out of STEM fields. NCES 2014-001. Washington, D.C.: National Center for Education Statistics.

Chomitz, V. R., Slining, M. M., McGowan, R. J., Mitchell, S. E., Dawson, G. F., \& Hacker, K. A. (2009). Is there a relationship between physical fitness and 
academic achievement? Positive results from public school children in the northeastern United States. Journal of School Health, 79(1), 30-37.

Choy, S. P. (2002). Access \& Persistence: Findings from 10 Years of Longitudinal Research on Students. Washington, DC, American Council on Education.

Churchill, W. D., \& Iwai, S. I. (1981). College attrition, student use of campus facilities, and a consideration of self-reported personal problems. Research in Higher Education, 14(4), 353-365.

Coe, D. P., Pivarnik, J. M., Womack, C. J., Reeves, M. J., \& Malina, R. M. (2006). Effect of physical education and activity levels on academic achievement in children. Medicine and Science in Sports and Exercise, 38(8), 1515-.1519

Coker, D. (1968). Diversity of intellective and non-intellective characteristics between persisting students and non-persisting students among campuses. Washington, D.C.: Office of Education Report.

Colcombe, S. J., Erickson, K. I., Scalf, P. E., Kim, J. S., Prakash, R., McAuley, E., \& Kramer, A. F. (2006). Aerobic exercise training increases brain volume in aging humans. The Journals of Gerontology Series A: Biological Sciences and Medical Sciences, 61(11), 1166-1170.

Colcombe, S. J., Kramer, A. F., Erickson, K. I., Scalf, P., McAuley, E., Cohen, N. J., \& Elavsky, S. (2004). Cardiovascular fitness, cortical plasticity, and aging. Proceedings of the National Academy of Sciences of the United States of America, 101(9), 3316-3321.

Colcombe, S., \& Kramer, A. F. (2003). Fitness effects on the cognitive function of older adults a meta-analytic study. Psychological Science, 14(2), 125-130.

Collins, J. R., Valerius, L., King, T., \& Graham, A. (2001). The relationship between college students' self-esteem and the frequency and importance of their participation in recreational activities. NIRSA Journal, 25 (2), 38-47.

Cook, B., \& Pullaro, N. (2010). College graduation rates: Behind the numbers. American Council on Education.

Cottrell, L. A., Northrup, K., \& Wittberg, R. (2007). The extended relationship between child cardiovascular risks and academic performance measures. Obesity, 15(12), 3170-3177.

Council of Economic Advisors for the Office of the U.S. President. (2014) Women's participation in education and the workforce. Document obtained April 12, 2016 from: 
https://s3.amazonaws.com/s3.documentcloud.org/documents/1350163/women_ed ucation_workforce.pdf.

Crisp, G., Taggart, A., \& Nora, A. (2015). Undergraduate Latina/o students: A systematic review of research identifying factors contributing to academic success outcomes. Review of Educational Research, 85(2), 249-274.

Crosson, P.H. (1988). Four-year college and university environments for minority degree achievement. The Review of Higher Education, 11, 365-382.

Curry, J., Jenkins, J. M., \& Weatherford, J. (2015). Focus on freshman: Basic instruction programs enhancing physical activity. Physical Educator, 72(4), 621-639.

Dale, D., \& Corbin, C. B. (2000). Physical activity participation of high school graduates following exposure to conceptual or traditional physical education. Research Quarterly for Exercise and Sport, 71(1), 61-68.

Dalgarn, M. K. (2001). The role of the campus recreation center in creating a community. NIRSA Journal, 25(1), 66-72.

Daniels, S. R., Arnett, D. K., Eckel, R. H., Gidding, S. S., Hayman, L. L., Kumanyika, S., \& Williams, C. L. (2005). Overweight in children and adolescents pathophysiology, consequences, prevention, and treatment. Circulation, 111(15), 1999-2012.

Datar, A., Sturm, R., \& Magnabosco, J. L. (2004). Childhood overweight and academic performance: national study of kindergartners and first-graders. Obesity Research, $12(1), 58-68$.

Davis, C. L., Tomporowski, P. D., Boyle, C. A., Waller, J. L., Miller, P. H., Naglieri, J. A., \& Gregoski, M. (2007). Effects of aerobic exercise on overweight children's cognitive functioning: a randomized controlled trial. Research Quarterly for Exercise and Sport, 78(5), 510-519.

Davis, K. L. (1993). Basic instruction programs in physical education: A foundation for an active tomorrow. Journal of Physical Education, Recreation \& Dance, 64(6), 29-32.

DeAngelo, L., Franke, R., Hurtado, S., Pryor, J. H., \& Tran, S. (2011). Completing college: Assessing graduation rates at four-year institutions. Los Angeles: Higher Education Research Institute, UCLA.

Demetriou, C. \& Schmitz-Sciborski, A. (2011). Integration, motivation, strengths and optimism: Retention theories past, present and future. In R. Hayes (Ed.), Proceedings of the 7th National Symposium on Student Retention, 2011, Charleston. (pp. 300-312). Norman, OK: The University of Oklahoma. 
Donnelly, J. E., Hillman, C. H., Castelli, D., Etnier, J. L., Lee, S., Tomporowski, P., \& Szabo-Reed, A. N. (2016). Physical activity, fitness, cognitive function, and academic achievement in children: a systematic review. Medicine and Science in Sports and Exercise, 48(6), 1197.

Douglas, J. A., Douglas, A., McClelland, R. J., \& Davies, J. (2015). Understanding student satisfaction and dissatisfaction: An interpretive study in the UK higher education context. Studies in Higher Education, 40(2), 329-349.

Downs, P. E. (2003). Value of recreational sports on college campuses. Recreational Sports Journal, 27(1), 5-64.

Durkheim, E. (1951). Suicide. New York: The Free Press.

Dwyer, R. E., Hodson, R., \& McCloud, L. (2013). Gender, debt, and dropping out of college. Gender \& Society, 27(1), 30-55.

Dwyer, T., Coonan, W. E., Leitch, D. R., Hetzel, B. S., \& Baghurst, R. A. (1983). An investigation of the effects of daily physical activity on the health of primary school students in South Australia. International Journal of Epidemiology, 12(3), 308-313.

Ebben, W., \& Brudzynski, L. (2008). Motivations and barriers to exercise among college students. Journal of Exercise Physiology Online, 11(5), 1-11.

Egli, T., Bland, H. W., Melton, B. F., \& Czech, D. R. (2011). Influence of age, sex, and race on college students' exercise motivation of physical activity. Journal of American College Health, 59(5), 399-406.

Eime, R. M., Young, J. A., Harvey, J. T., Charity, M. J., \& Payne, W. R. (2013). A systematic review of the psychological and social benefits of participation in sport for children and adolescents: informing development of a conceptual model of health through sport. International Journal of Behavioral Nutrition and Physical Activity, 10(1), 98.

Eimers, M. T., \& Pike, G. R. (1997). Minority and nonminority adjustment to college: Differences or similarities? Research in Higher Education, 38(1), 77-97.

Elkins, D. J., Forrester, S. A., \& Noel-Elkins, A. V. (2011). The contribution of campus recreational sports participation to perceived sense of campus community. Recreational Sports Journal, 35(1), 24-34.

Evaul, T., \& Hilsendager, D. (1993). Basic instruction programs: Issues and answers. Journal of Physical Education, Recreation \& Dance, 64(6), 37-58. 
Eveland-Sayers, B. M., Farley, R. S., Fuller, D. K., Morgan, D. W., \& Caputo, J. L. (2009). Physical fitness and academic achievement in elementary school children. Journal of Physical Activity \& Health, 6(1), 99-104.

Farmer, E. D., \& Hope, W. C. (2015). Factors that influence African American male retention and graduation: The case of gateway university, a historically black college and university. Journal of College Student Retention: Research, Theory \& Practice, 17(1), 2-17.

Fejgin, N. (2001). Participation in high school competitive sports: A subversion of school mission or contribution to academic goals. Contemporary Issues in Sociology of Sport, 95-108.

Field, A. (2005). Discovering statistics using SPSS. London: SAGE Publications Ltd.

Field, A. (2013). Discovering statistics using SPSS. London: SAGE Publications Ltd.

Field, T., Diego, M., \& Sanders, C. E. (2001). Exercise is positively related to adolescents' relationships and academics. Adolescence, 36(141), 105-110.

Fike, D. S., \& Fike, R. (2008). Predictors of first-year student retention in the community college. Community College Review, 36(2), 68-88.

Fischer, E. M. J. (2007). Settling into campus life: Differences by race/ethnicity in college involvement and outcomes. The Journal of Higher Education, 78(2), 125161.

Fleming, J. (2002). Who will succeed in college? When the SAT predicts Black students' performance. The Review of Higher Education, 25(3), 281-296.

Fleshner, M. (2000). Exercise and neuroendocrine regulation of antibody production: protective effect of physical activity on stress-induced suppression of the specific antibody response. International Journal of Sports Medicine, 21, S14-9.

Fornia, D. L. (1959). Coeducational physical education in institutions of higher learning. Research Quarterly, 30(4), 423-429.

Forrester, S. (2014). The benefits of campus recreation. Corvallis, OR: NIRSA.

Gabbard, C., \& Barton, J. (1979). Effects of physical activity on mathematical computation among young children. Journal of Psychology, 103, 287-288.

Gibbs, J. T. (1975). Use of mental health services by black students at a predominantly white university: A three-year study. American Journal of Orthopsychiatry 45:518-522. 
Ginder, S. A., Kelly-Reid, J. E., \& Mann, F. B. (2015). Postsecondary Institutions and Cost of Attendance in 2014-15; Degrees and Other Awards Conferred, 2013-14; and 12-Month Enrollment, 2013-14. First Look (Preliminary Data). NCES 2015097. Washington, DC: National Center for Education Statistics.

Goodman, E. D. (1993). How to handle the stress of being a student. Imprint, 40(2), 43.

Green, T.G., \& Gonsoulin, S. (1997). The economic impact of a multipurpose recreational sports complex on a university community. NIRSA Journal, 22, 4852.

Greene, M.M. (1955). Physical education as a college graduation requirement. Journal of Health, Physical Education, and Recreation, 27, 25-26.

Grissom, J. B. (2005). Physical fitness and academic achievement. Journal of Exercise Physiology Online, 8(1), 11-25.

Haines, D. J. (2001). Undergraduate student benefits from university recreation. NIRSA Journal, 25(1), 25-33.

Hall, D. (2006). Participation in a campus recreation program and its effect on retention. Recreational Sports Journal, 30, 40-45.

Hardin, R., Andrew, D. P., Koo, G. Y., \& Bemiller, J. (2009). Motivational factors for participating in basic instruction programs. Physical Educator, 66(2), 71-84.

Harper, S. R. (2009). Niggers no more: A critical race counternarrative on Black male student achievement at predominantly White colleges and universities. International Journal of Qualitative Studies in Education, 22(6), 697-712.

Harvey, W. B. (2001). Minorities in higher education 2000-2001: Eighteenth annual status report. Washington D. C.: American Council on Education.

Henchy, A. (2011). The influence of campus recreation beyond the gym. Recreational Sports Journal, 35(2), 174-181.

Hensley, L. (2000). Current status of basic instruction programs in physical education at American colleges and universities. Journal of Physical Education, Recreation \& Dance, 71(9), 30-36.

Hillman, C. H., Buck, S. M., Themanson, J. R., Pontifex, M. B., \& Castelli, D. M. (2009). Aerobic fitness and cognitive development: Event-related brain potential and task performance indices of executive control in preadolescent children. Developmental Psychology, 45(1), 114-129. 
Hillman, C. H., Erickson, K. I., \& Kramer, A. F. (2008). Be smart, exercise your heart: Exercise effects on brain and cognition. Nature Reviews Neuroscience, 9(1), 5865.

Hillman, S. J., \& Corkery, M. G. (2010). University infrastructural needs and decisions in moving towards online delivery programs. Journal of Higher Education Policy and Management, 32(5), 467-474.

Hu, S., \& St. John, E. P. (2001). Student persistence in a public higher education system: Understanding racial and ethnic differences. The Journal of Higher Education, 72(3), 265-286.

Huang, T. T. K., Harris, K. J., Lee, R. E., Nazir, N., Born, W., \& Kaur, H. (2003). Assessing overweight, obesity, diet, and physical activity in college students. Journal of American College Health, 52(2), 83-86.

Hudley, C., \& Daoud, A. M. (2008). Cultures in contrast: Understanding the influence of school culture on student engagement. In C. Hudley \& A.E. Gottfried (Edss), Academic motivation and the culture of school in childhood and adolescence, 187-215. New York, NY: Oxford University Press.

Huesman, R., Brown, A., Lee, G., Kellogg, J., \& Radcliffe, P. (2007, September). Modeling student academic success: Does usage of campus recreation facilities make a difference. In National Symposium of Student Retention, Milwaukee.

Jaffe, A., \& Adams, W. (1970). Academic and socio-economic factors related to entrance and retention at two-and four-year colleges in the late 1960's. Proceedings of the American Statistical Association, Social Statistics Section.

Jamelske, E. (2009). Measuring the impact of a university first-year experience program on student GPA and retention. Higher Education, 57(3), 373-391.

Johnson, D. R., Soldner, M., Leonard, J. B., Alvarez, P., Inkelas, K. K., Rowan-Kenyon, H. T., \& Longerbeam, S. D. (2007). Examining sense of belonging among firstyear undergraduates from different racial/ethnic groups. Journal of College Student Development, 48(5), 525-542.

Johnson, J. (1990). How prepared are our minority students for college-level mathematics? In M. T. Nettles (Ed.). The effect of assessment on minority student participation, no. 65: New directions for institutional research (pp. 8397). San Francisco: Jossey-Bass Inc., Publishers.

Johnson, J. \& Deshpande, C. (2000). Health education and physical education: Disciplines preparing students as productive, healthy citizens for the challenges of the $21^{\text {st }}$ century. Journal of School Health, 70(2), 66-68. 
Joseph, R. P., Royse, K. E., Benitez, T. J., \& Pekmezi, D. W. (2014). Physical activity and quality of life among university students: exploring self-efficacy, self-esteem, and affect as potential mediators. Quality of Life Research, 23(2), 659-667.

Kahu, E. R., \& Nelson, K. (2018). Student engagement in the educational interface: understanding the mechanisms of student success. Higher Education Research \& Development, 37(1), 58-71.

Kasim, A., \& Dzakiria, H. (2001). Influence of recreation on education aspiration. Asia Pacific Journal of Tourism Research, 6(2), 53-64.

Keller, G. (2001). The new demographics of higher education. The Review of Higher Education, 24, 219-236.

Kennedy, P., \& Sheckley, B.G. (1999). Attrition and persistence in higher education: A review of the literature. Paper presented at the North East Association for Institutional Research annual meeting, November, Cincinnati, $\mathrm{OH}$.

Kiger, G., \& Lorentzen, D. (1988). The effects of athletic participation on university academic performance: A comparison of athletes and the general student population. College Student Journal, 22, 287-293.

King, K. V. \& Zucker, S. (2005). Curriculum narrowing. Harcourt Policy Report. Harcourt Assessment, Inc.

Komarraju, M., Ramsey, A., \& Rinella, V. (2013). Cognitive and non-cognitive predictors of college readiness and performance: Role of academic discipline. Learning and Individual Differences, 24, 103-109.

Koplan, J., Liverman, C. T., \& Kraak, V. I. (Eds.). (2005). Preventing childhood obesity: health in the balance. Washington, DC: The National Academies Press.

Kovac, D.C., \& Beck, J.E. (1997). A comparison of student perceptions, satisfaction and patterns of participation in recreational sports. NIRSA Journal, 22, 10-12.

Kramer, A. F., Erickson, K. I., \& Colcombe, S. J. (2006). Exercise, cognition, and the aging brain. Journal of Applied Physiology, 101(4), 1237-1242.

Kroc, R., Woodard, D., Howard, R., \& Hull, P. (1995, May). Predicting graduation rates: A study of land grant, research I and AAU universities. Paper presented at the annual meeting of the Association for Institutional Research Forum, Boston MA.

Kuczmarski, R. J., Ogden, C. L., Guo, S. S., Grummer-Strawn, L. M., Flegal, K. M., Mei, Z., Wei, R., Curtain, L.R., Roche, A.F., \& Johnson, C. L. (2002). 2000 CDC 
Growth Charts for the United States: Methods and development. Vital and Health Statistics. Series 11, Data from the National Health Survey, (246), 1-190.

Kuh, G. D., Kinzie, J., Buckley, J. A., Bridges, B. K., \& Hayek, J. C. (2006). What Matters to Student Success: A review of the Literature. A commissioned report for the National Symposium on Postsecondary Student Success. National Postsecondary Education Cooperative.

Lamont, D. A. (2010). Undergraduate student recruitment and retention and the centralized on-campus recreational sports facility. NIRSA Journal, 16(1), 3-7.

Lavin, D. (1965). The prediction of academic performance. New York: Russell Sage Foundation.

Lawhorn, J.A. (1971). A study of persisters and dropouts in the secretarial science program at The University of Miami.

Lee, V. E., Bryk, A. S., \& Smith, J. B. (1993). The organization of effective secondary schools. Review of Research in Education, 19, 171-267.

Lee, K., \& Leonard, R. (2009). Destination unknown: Addressing the sophomore slump. NACE Journal, 70(2), 27-31.

Leenders, N. Y., Sherman, W. M., \& Ward, P. (2003). College physical activity courses: Why do students enroll, and what are their health behaviors? Research Quarterly for Exercise and Sport, 74(3), 313-318.

LeRoy, A. (1987). How to survive as a nontraditional nursing student. Imprint, 35(2), 734.

Leslie, E., Sparling, P. B., \& Owen, N. (2001). University campus settings and the promotion of physical activity in young adults: Lessons from research in Australia and the USA. Health Education, 101(3), 116-125.

Lewis, J. B., Barcelona, R., \& Jones, T. (2001). Leisure satisfaction and quality of life: Issues for the justification of campus recreation. NIRSA Journal, 25(2), 57-63.

Li, X. (1995). A study of intelligence and personality in children with simple obesity. International Journal of Obesity and Related Metabolic Disorders, 19(5), 355357.

Lindner, K. J. (1999). Sport participation and perceived academic performance of school children and youth. Pediatric Exercise Science, 11, 129-143. 
Lindner, K. J. (2002). The physical activity participation-academic performance relationship revisited: Perceived and actual performance and the effect of banding (academic tracking). Pediatric Exercise Science, 14(2), 155-169.

Lindsey, R., \& Sessoms, E. (2006). Assessment of a campus recreation program on student recruitment, retention, and frequency of participation across certain demographic variables. Recreational Sports Journal, 30(1), 30-39.

Lumpkin, A. \& Jenkins, J. (1993). Basic instruction programs continue to exist because they meet the needs of the students served. Journal of Physical Education, Recreation \& Dance, 64 (6), 32-36.

Malina, R. M. (1996). Tracking of physical activity and physical fitness across the lifespan. Research Quarterly for Exercise and Sport, 67, 48-57.

Mallinckrodt, B., \& Sedlacek, W. E. (2009). Student retention and the use of campus facilities by race. NASPA Journal, 46(4), 566-572.

Mallinckrodt, B., \& Sedlacek, W. E. (1987). Student retention and the use of campus facilities by race. NASPA Journal, 24(3), 28-32.

Marsh, H. W., \& Kleitman, S. (2003). School athletic participation: Mostly gain with little pain. Journal of sport and Exercise Psychology, 25(2), 205-228.

Mathiasen, R. E. (1984). Predicting college academic achievement: A research review. College Student Journal, 18(4), 380-386.

McBurnie, J. E., Campbell, M., \& West, J. (2012). Avoiding the second year slump: A transition framework for students progressing through university. International Journal of Innovation in Science and Mathematics Education, 20(2), 14-24.

McCristal, K.J. \& Miller, E.A. (1939). A brief survey of the present status of the health and physical education requirement for men students in colleges and universities. Research Quarterly,10(4), 70-80.

McNaughten, D., \& Gabbard, C. (1993). Physical exertion and immediate mental performance of sixth-grade children. Perceptual and Motor Skills, 77, 1155-1159.

McNeely, J.H. (1937). The disposition of institutional receipts. The Journal of Higher Education, 8(4), 201-207.

Melendez, M. C. (2006). The influence of athletic participation on the college adjustment of freshmen and sophomore student athletes. Journal of College Student Retention: Research, Theory \& Practice, 8(1), 39-55. 
Meyer, D. E., \& Kieras, D. E. (1997). A computational theory of executive cognitive processes and multiple-task performance: Part I. Basic mechanisms. Psychological Review, 104(1), 3-65.

Meyers, L. S., Gamst, G., \& Guarino, A. J. (2006). Applied multivariate research: Design and interpretation. Sage.

Miller, G. A., Dowell, L. J., \& Pender, R. H. (1989). Physical activity programs in colleges and universities: A status report. Journal of Physical Education, Recreation \& Dance, 60(6), 20-23.

Miller, J. J. (2011). Impact of a university recreation center on social belonging and student retention. Recreational Sports Journal, 35(2), 117-129.

Mingle, J. (1987). Trends in higher education participation and success. Denver, CO: Education Commission of the States and State Higher Education Executive Officers.

Misra, R., \& McKean, M. (2000). College students' academic stress and its relation to their anxiety, time management, and leisure satisfaction. American Journal of Health Studies, 16(1), 41-51.

Moore, A. C., \& Trekell, M. (1981). Encyclopedia of physical education, fitness, and sports-sponsored by AAHPERD. Salt Lake City: Brighton Publishing Co.

Morrow, J., \& Ackermann, M. (2012). Intention to persist and retention of first-year students: The importance of motivation and sense of belonging. College Student Journal, 46(3), 483-491.

Mortenson, T. G. (2003). Fact sheet: What's wrong with the guys. Postsecondary Education Opportunity, 125, 1-4.

Mow, S. L., \& Nettles, M. T. (1990). Minority student access to, and persistence and performance in, college: A review of the trends and research literature. In J. C. Smart (Ed.). Higher education: Handbook of Theory and Research (Vol. VI, pp. 35-105). New York: Agathon Press.

National Association of Sport and Physical Education. (2007). College and university physical activity programs: A critical piece in the education of young adults. Reston, VA: National Association for Sport and Physical Education.

National Center for Education Statistics (2005). College persistence on the rise? Changes in 5-year degree completion and post-secondary persistence rates between 1994 and 2000. Washington, DC: U.S. Department of Education, Office of Educational Research and Improvement. 
National Center for Education Statistics (2018). Undergraduate retention and graduation rates. Retrieved from: https://nces.ed.gov/programs/coe/indicator_ctr.asp .

National Collegiate Athletic Association (2001). 2001 NCAA Division I graduation-rates report. Indianapolis, IN: The National Collegiate Athletic Association.

Nelson, C. A. (1999). Neural plasticity and human development. Current Directions in Psychological Science, 8(2), 42-45.

Nelson, M. C., \& Gordon-Larsen, P. (2006). Physical activity and sedentary behavior patterns are associated with selected adolescent health risk behaviors. Pediatrics, 117(4), 1281-1290.

Nettles, M.T. (1990). Editor's notes. In M.T. Nettles (Ed), The effect of assessment on minority student participation, no. 65: New directions for institutional research (pp. 1-6). San Francisco: Jossey-Bass Inc., Publishers.

Nettles, M.T., Thoeny, A.R., Gosman, E.J. (1986). Comparative and predictive analyses of black and white students' college achievement and experiences. The Journal of Higher Education, 57(3), 289-318.

Newman, F., Couturier, L., \& Scurry, J. (2010). The future of higher education: Rhetoric, reality, and the risks of the market. John Wiley \& Sons.

Noel, L. (1978). Reducing the Dropout Rate: New Directions for Student Services. San Francisco: Jossey-Bass Inc., Publishers.

Nora, A., Barlow, E., Crisp, G. (2005). Student persistence and degree attainment beyond the first year in college. A Seidman (ed) College Student Retention: Formula for Student Success. 129-153.

Nora, A., Cabrera, A., Hagedorn, L.S., \& Pascarella, E. (1996). Differential impacts of academic and social experiences on college-related behavioral outcomes across different ethnic and gender groups at four-year institutions. Research in Higher Education, 37(4), 427-451.

Ogden, C. L., Carroll, M. D., Kit, B. K., \& Flegal, K. M. (2012). Prevalence of obesity and trends in body mass index among US children and adolescents, 1999-2010. The Journal of the American Medical Association, 307(5), 483-490.

Ogden, C. L., Carroll, M. D., Kit, B. K., \& Flegal, K. M. (2014). Prevalence of childhood and adult obesity in the United States, 2011-2012. The Journal of the American Medical Association, 311(8), 806-814. 
Ogden, C. L., Carroll, M. D., Curtin, L. R., McDowell, M. A., Tabak, C. J., \& Flegal, K. M. (2006). Prevalence of overweight and obesity in the United States, 1999-2004. Jama, 295(13), 1549-1555.

Ogden, C. L., Flegal, K. M., Carroll, M. D., \& Johnson, C. L. (2002). Prevalence and trends in overweight among US children and adolescents, 1999-2000. Jama, $288(14), 1728-1732$.

O'Keeffe, P. (2013). A sense of belonging: Improving student retention. College Student Journal, 47(4), 605-613.

Opportunity for Postsecondary Education (1996, December). Institutional graduation rates by pre-college academic records. Postsecondary Education Opportunity: The Mortenson Research Seminar on Public Policy Analysis of Opportunity for Post-Secondary Education, 54, 1-4.

Opportunity for Postsecondary Education (2000, February). Academic preparation for college by gender, race, and family income, 1983 to 1999. Postsecondary Education Opportunity: The Mortenson Research Seminar on Public Policy Analysis of Opportunity for Post-Secondary Education, 92.

Osborne, J. W. (2015). Best practices in logistic regression. SAGE Publications.

Osipow, S. H., \& Spokane, A. R. (1987). Manual for the Occupational Stress InventoryResearch version. Odessa, FL: Psychological Assessment Resources.

Oxendine, J. B. (1961). The service program in 1960-61. Journal of Health, Physical Education, Recreation, 32(6), 37-38.

Oxendine, J.B. (1972). Status of general instruction programs of physical education in four-year colleges and universities: 1971-1972. Journal of Health, Physical Education, \& Recreation, 43(3), 26-28.

Oxendine, J., \& Roberts, J. (1978). The general instruction program in physical education programs at four-year colleges and universities in the United States: 1977. Journal of Physical Education, Recreation, \& Dance, 49(1), 21-23.

Pace, C. R. (1984). Measuring the Quality of College Student Experiences. Los Angeles: University of California, Graduate School of Education, Higher Education Research Institute.

Panos, R., \& Astin, A. (1968). Attrition among college students. American Educational Research Journal, 5, 57-72.

Pascarella, E. (1980). Student-faculty informal contact and college outcomes. Review of Educational Research, 50, 545-595. 
Pascarella, E. T., \& Terenzini, P. T. (1976). Informal interaction with faculty and freshman ratings of academic and non-academic experience of college. The Journal of Educational Research, 70(1), 35-41.

Pascarella, E. T., \& Terenzini, P. T. (1991). How college affects students. Findings and Insights from Twenty Years of Research. San Francisco: Jossey-Bass.

Pate, R. R., Heath, G. W., Dowda, M., \& Trost, S. G. (1996). Associations between physical activity and other health behaviors in a representative sample of US adolescents. American Journal of Public Health, 86(11), 1577-1581.

Pate, R. R., Pratt, M., Blair, S. N., Haskell, W. L., Macera, C. A., Bouchard, C., Buchner, D., Ettinger, W., Heath, G., King, A., Kriska, A., Leon, A., Marcus, B., Morris, J., Paffenbarger, R., Patrick, K., Pollock, M., Rippe, J., Sallis, J., \& Wilmore, J. (1995). Physical activity and public health: a recommendation from the Centers for Disease Control and Prevention and the American College of Sports Medicine. Jama, 273(5), 402-407.

Pearman III, S. N., Valois, R. F., Sargent, R. G., Saunders, R. P., Drane, J. W., \& Macera, C. A. (1997). The impact of a required college health and physical education course on the health status of alumni. Journal of American College Health, 46(2), 77-85.

Pelletier, S.G. (2012). Rethinking Revenue. Public Purpose. Retrieved from http://www.aascu.org/WorkArea/DownloadAsset.aspx?id=5569

Physical Activity Council (2018). 2018 PAC report press release. Retrieved from: http://physicalactivitycouncil.com/PressRelease/.

Pike, G. R., Hansen, M. J., \& Childress, J. E. (2014). The influence of students' precollege characteristics, high school experiences, college expectations, and initial enrollment characteristics on degree attainment. Journal of College Student Retention: Research, Theory \& Practice, 16(1), 1-23.

Pike, G. R., \& Saupe, J. L. (2002). Does high school matter? An analysis of three methods of predicting first-year grades. Research in Higher Education, 43(2), 187-207.

Porter, O.F. (1990). Undergraduate completion and persistence at four-year colleges and universities. Washington, DC: The National Institute of Independent Colleges and Universities.

Preo, L. (1986). College rec's future is now. Athletic Business, 10, 12-17. 
Ragheb, M. G., \& McKinney, J. (1993). Campus recreation and perceived academic stress. Journal of College Student Development, 34(1), 5-10.

Rankin, S. R., \& Reason, R. D. (2005). Differing perceptions: How students of color and White students perceive campus climate for underrepresented groups. Journal of College Student Development, 46(1), 43-61.

Rasberry, C. N., Lee, S. M., Robin, L., Laris, B. A., Russell, L. A., Coyle, K. K., \& Nihiser, A. J. (2011). The association between school-based physical activity, including physical education, and academic performance: a systematic review of the literature. Preventive Medicine, 52, S10-S20.

Rootman, I. (1972). Voluntary withdrawal from a total adult socialization organization: A model. Sociology of Education, 45, 258-270.

Rovio, S., Kåreholt, I., Helkala, E. L., Viitanen, M., Winblad, B., Tuomilehto, J., \& Kivipelto, M. (2005). Leisure-time physical activity at midlife and the risk of dementia and Alzheimer's disease. The Lancet Neurology, 4(11), 705-711.

Saklofske, D. H., Austin, E. J., Mastoras, S. M., Beaton, L., \& Osborne, S. E. (2012). Relationships of personality, affect, emotional intelligence and coping with student stress and academic success: Different patterns of association for stress and success. Learning and Individual Differences, 22(2), 251-257.

Savage, M. P. (1998). University students' motivation for participation in a basic instruction program. College Student Journal, 32, 58-65.

Sawyer, R. (2013). Beyond correlations: Usefulness of high school GPA and test scores in making college admissions decisions. Applied Measurement in Education, 26(2), 89-112.

Sax, L.J. (1997). Health trends among college freshman. Journal of American College Health, 45(6), 252-262.

Schaller, M.A. (2010). College sophomores: The journey into self. In Hunter, M. S. et al. (Eds). Helping Sophomores Succeed: Understanding and Improving the Second Year Experience (pp. 66-79). San Francisco: Jossey-Bass.

Sedlacek, W.E. \& Brooks, G.C. (1976). Racism in American education: A model for change. Chicago: Nelson-Hall.

Sewell, W., \& Shah, V. (1967). Socio-economic status, intelligence, and the attainment of higher education. Sociology of Education, 40, 1-23.

Shephard, R. J. (1996). Habitual physical activity and academic performance. Nutrition Reviews, 54(4), S32-S36. 
Shephard, R. J. (1997). Curricular physical activity and academic performance. Pediatric Exercise Science, 9, 113-126.

Sheridan, R. (2011). General revenue: 47 ideas for raising funds for your college from unusual sources. University Business. Retrieved from http://www.universitybusiness. com/article/general-revenue

Shore, S. M., Sachs, M. L., Lidicker, J. R., Brett, S. N., Wright, A. R., \& Libonati, J. R. (2008). Decreased scholastic achievement in overweight middle school students. Obesity, 16(7), 1535-1538.

Sibley, B. A., \& Etnier, J. L. (2003). The relationship between physical activity and cognition in children: a meta-analysis. Pediatric Exercise Science, 15(3).

Simiyu, N.W.W. (2012). Challenges of being a black student athlete on U.S. college campuses. Journal of Issues in Intercollegiate Athletics, 5, 40-63.

Skinner, E., \& Richardson, R. (May-June, 1988). Making it in a majority university. Change, 20, 34-42.

Smith, J. (1971). A multivariate combination of academic and non-academic factors related to student attrition. Unpublished doctoral dissertation, University of Pittsburgh.

Spady, W. (1970). Dropouts from higher education: An interdisciplinary review and synthesis. Interchange, 1, 64-85.

Spady, W. (1971). Dropouts from higher education: Toward an empirical model. Interchange 2, 38-62.

Sparling, P. B. (2003). College physical education: An unrecognized agent of change in combating inactivity-related diseases. Perspectives in Biology and Medicine, 46(4), 579-587.

Sparling, P. B., \& Snow, T. K. (2002). Physical activity patterns in recent college alumni. Research Quarterly for Exercise and Sport, 73(2), 200-205.

Stevens, T. A., To, Y., Stevenson, S. J., \& Lochbaum, M. R. (2008). The importance of physical activity and physical education in the prediction of academic achievement. Journal of Sport Behavior, 31(4), 368-388.

St. John, E. P., Cabrera, A. F., Nora, A., \& Asker, E. H. (2000). Economic influences on persistence reconsidered: How can finance research inform the reconceptualization of persistence models? In J. Braxton (Ed.). Reworking the student departure puzzle, 29-47. Nashville: Vanderbilt University Press. 
St. John, E. P., Hu, S., Simmons, A. B., \& Musoba, G. D. (2001). Aptitude vs. merit: What matters in persistence. The Review of Higher Education, 24(2), 131-152.

Strauss, R. S., \& Pollack, H. A. (2001). Epidemic increase in childhood overweight, 1986-1998. Jama, 286(22), 2845-2848.

Sue, D.W. (2006). Overcoming our racism: The journey to liberation. San Francisco: Josey-Bass.

Sutcher, L., Darling-Hammond, L., \& Carver-Thomas, D. (2016). A coming crisis in teaching? Teacher supply, demand, and shortages in the US. Learning Policy Institute. Retrieved from https://learningpolicyinstitute. org/product/comingcrisis-teaching.

Swail, W. S. (2004). The art of student retention: A handbook for practioners and administrators. Austin, TX: Educational Policy Institute.

Swail, W. S., Cabrera, A. F., Lee, C., \& Williams, A. (2005). Latino students and the educational pipeline: Pathways to the bachelor's degree for Latino students. Stafford, VA: Educational Policy Institute.

Sweeney, M. M. (2011). Initiating and strengthening: College and University instructional physical activity programs. Journal of Physical Education, Recreation \& Dance, 82(4), 17-21.

Tabachnick, B. G., Fidell, L. S., \& Osterlind, S. J. (2001). Using multivariate statistics.

Taras, H., \& Potts-Datema, W. (2005). Obesity and student performance at school. Journal of School Health, 75(8), 291-295.

Taylor, H., Canning, W. F., Brailsford, P., \& Rokosz, F. (2003). Financial issues in campus recreation. New Directions for Student Services, (103), 73-86.

Taylor, R., \& Hanson, G. (1970). Interest and persistence. Journal of Counseling Psychology, 17, 506-509.

Terenzini, P. T., \& Pascarella, E. T. (1978). The relation of students' precollege characteristics and freshman year experience to voluntary attrition. Research in Higher Education, 9(4), 347-366.

Terenzini, P. T., \& Pascarella, E. T. (1998). Studying college students in the 21st century: Meeting new challenges. The Review of Higher Education, 21(2), 151-165.

Terenzini, P., Lorang, W., \& Pascarella, E. (1981). Predicting freshman persistence and voluntary decisions: A replication. Research in Higher Education, 15, 109-127. 
Terenzini, P. T., Rendon, L. I., Upcraft, M. L., Millar, S. B., Allison, K. W., Gregg, P. L., \& Jalomo, R. (1994). The transition to college: Diverse students, diverse stories. Research in Higher Education, 35(1), 57-73.

Thayer, P. B. (2000). Retention of students from first-generation and low-income backgrounds. The Journal of the Council for Opportunity in Education, Washington, DC.

Tinto, V. (1975). Dropouts from higher education: A theoretical synthesis of recent research. Review of Educational Research, 45, 89-125.

Tinto, V. (1987). Leaving college: Rethinking the causes and cures of student attrition. Chicago: University of Chicago Press.

Tinto, V. (1990). Principles of effective retention. Journal of The First-Year Experience \& Students in Transition, 2(1), 35-48.

Tinto, V. (1993). Building community. Liberal Education, 79(4), 16-21.

Tinto, V. (1997). Colleges as communities: Taking research on student persistence seriously. The Review of Higher Education, 21(2), 167-177.

Tinto, V. (2006). Research and practice of student retention: What next? Journal of College Student Retention: Research, Theory \& Practice, 8(1), 1-19.

Tinto, V. (2010). From theory to action: Exploring the institutional conditions for student retention. In Higher education: Handbook of theory and research (pp. 51-89). Springer, Dordrecht.

Tobolowsky, B. F. (2008). Sophomores in transition: The forgotten year. New Directions for Higher Education, 144, 59-67

Tomporowski, P. D. (2003). Effects of acute bouts of exercise on cognition. Acta Psychologica, 112(3), 297-324.

Torres, V. (2003). Influences on ethnic identity development of Latino college students in the first two years of college. Journal of College Student Development, 44(4), 532-547.

Tracey, T.J. \& Sedlacek, W.E. (1984). Non-cognitive variables in predicting academic success by race. Measurement and Evaluation in Guidance, 16, 171-178.

Tracey, T. J. \& Sedlacek, W. E. (1985). The relationship of non-cognitive variables to academic success: A longitudinal comparison by race. Journal of College Student Personnel 26, 405-410. 
Tremarche, P. V., Robinson, E. M., \& Graham, L. B. (2007). Physical education and its effect on elementary testing results. Physical Educator,64(2), 58-64.

Trimble, R. T., \& Hensley, L. D. (1990). Basic instruction programs at four-year colleges and universities. Journal of Physical Education, Recreation, and Dance, 61(6), 64-73.

Trimble, R. T., \& Hensley, L. D. (1984). The general instruction program in physical education at four-year colleges and universities: 1982. Journal of Physical Education, Recreation, \& Dance, 55(5), 82-89.

Tross, S. A., Harper, J. P., Osher, L. W., \& Kneidinger, L. M. (2000). Not just the usual cast of characteristics: Using personality to predict college performance and retention. Journal of College Student Development, 41(3), 323-34.

Trost, S. G. (2007). Active education: Physical education, physical activity and academic performance. Research brief prepared for the Robert Wood Johnson Foundation.

Trudeau, F., \& Shephard, R. J. (2008). Physical education, school physical activity, school sports and academic performance. International Journal of Behavioral Nutrition and Physical Activity, 5(1), 10-22.

United States Department of Education, National Center for Education Statistics. (2015). The condition of education 2015 (NCES 2015-144), Institutional Retention and Graduation Rates for Undergraduate Students.

United States. Department of Health. (1996). Physical activity and health: A report of the Surgeon General. DIANE Publishing.

University of Louisville. (2018). Information retrieved from https://catalog.louisville.edu/undergraduate/university-wide-unit-specificpolicies/classification-students/.

University of Louisville Institutional Research and Planning. (2018). Information retrieved from https://louisville.edu/oapa/institutional-research-and-planning/data

Upcraft, M. L., Gardner, J., \& Associates. (1989). The freshman year experience. San Francisco: Jossey-Bass Publishers.

Upcraft, M., Gardner, J., \& Barefoot, D. (Eds.). (2005). Challenge and support: Creating climates for first-year student success. San Francisco: Jossey-Bass.

Van Dusen, D. P., Kelder, S. H., Kohl III, H. W., Ranjit, N., \& Perry, C. L. (2011). Associations of physical fitness and academic performance among schoolchildren. Journal of School Health, 81(12), 733-740. 
VanKim, N. A., \& Nelson, T. F. (2013). Vigorous physical activity, mental health, perceived stress, and socializing among college students. American Journal of Health Promotion, 28(1), 7-15.

Vaughn, M. S., \& Parry, P. (2013). The statement of purpose speech: Helping students navigate the "Sophomore Slump". Communication Teacher, 27(4), 207-211.

Vaynman, S., \& Gomez-Pinilla, F. (2006). Revenge of the "sit": How lifestyle impacts neuronal and cognitive health through molecular systems that interface energy metabolism with neuronal plasticity. Journal of Neuroscience Research, 84(4), 699-715.

Vogt, W. P. (2005). The SAGE dictionary of statistics \& methodology: A nontechnical guide for the social sciences. Sage publications.

Vuong, M., Brown-Welty, S., \& Tracz, S. (2010). The effects of self-efficacy on academic success of first-generation college sophomore students. Journal of College Student Development, 51(1), 50-64.

Wang, X., \& Kennedy-Phillips, L. (2013). Focusing on the sophomores: Characteristics associated with the academic and social involvement of second-year college students. Journal of College Student Development, 54(5), 541-548.

Webster, A. L., \& Showers, V. E. (2011). Measuring predictors of student retention rates. American Journal of Economics and Business Administration, 3(2), 301-311.

Wegner, E., \& Sewell, W. (1970). Selection and context as factors affecting the probability of graduation from college. American Journal of Sociology, 75, 665679.

Welk, G. J., Jackson, A. W., Morrow Jr, J. R., Haskell, W. H., Meredith, M. D., \& Cooper, K. H. (2010). The association of health-related fitness with indicators of academic performance in Texas schools. Research Quarterly for Exercise and Sport, 81(sup3), S16-S23.

Westrick, P. A., Le, H., Robbins, S. B., Radunzel, J. M., \& Schmidt, F. L. (2015). College performance and retention: A meta-analysis of the predictive validities of ACT scores, high school grades, and SES. Educational Assessment, 20(1), 23-45.

Wilkins, J., Graham, G., Parker, S., Westfall, S., Fraser, R., \& Tembo, M. (2003). Time in the arts and physical education and school achievement. Journal of Curriculum Studies, 35(6), 721-734.

Wittberg, R. A., Northrup, K. L., \& Cottrel, L. (2009). Children's physical fitness and academic performance. American Journal of Health Education, 40(1), 30-36. 
Woodard, D.B., Love, P., \& Komives, S.R. (2000). Students of the new millennium. In D.B. Woodard, P. Love, \& S.R. Komives (Eds.), Leadership and management issues for a new century (pp. 35-47). San Francisco: Jossey-Bass.

Zurita, M. (2004). Stopping out and persisting: Experiences of Latino undergraduates. Journal of College Student Retention: Research, Theory \& Practice, 6(3), 301-324. 


\section{Dylan Joseph Naeger}

\section{Office}

SAC East $104 \mathrm{G}$

Health \& Sport Sciences Department

University of Louisville

Louisville, KY 40292 USA

Tel: 1-502-852-5050

Fax:1-502-852-4534

e-mail: dylan.naeger@1ouisville.edu

\section{EDUCATION}

Ph.D. 2018

The University of Louisville Major Area: Educational Leadership Specialization: Sport Administration

M.S. 2005

The University of Louisville Major: Sport Administration

B.S. 2001

Southeast Missouri State University Major: Secondary Education Specialization: Physical Education (K-12)

A.A. $1999 \quad$ Mineral Areal College

Major: Education

\section{PROFESSIONAL EXPERIENCE}

\section{University of Louisville, Health \& Sport Sciences Department, Louisville, KY Assistant Chair, January 2017-Present}

- Assist in overseeing aspects of a $\$ 3.5$ million operating budget

- Provide leadership to a Department producing over 28,000 credit hours annually 
- Oversee curriculum changes for the Health and Human Performance undergraduate degree impacting over 650 students

- Support the daily operations of the HSS Department, including aiding 25 full-time faculty, over 30 adjunct faculty, and 3 full-time staff

- Generate reports documenting both the day-to-day operations and unique initiatives of the HSS Department

- Implement new instructional approaches for the HSS Department

- Develop cost saving approaches for the HSS Department

- Monitor the distance education offerings of the HSS Department, which generates over $\$ 1,000,000$ annually

- Guide facility renovations and building projects

- Ensure syllabi compliance of all HSS course offerings

University of Louisville, Health \& Sport Sciences Department, Louisville, KY Activity Program Director, 2005-Present

- Schedule over 70 courses annually

- Secure facility locations for over 70 courses annually

- Supervise 40 graduate assistants and adjunct faculty

- Assist all program faculty with technology needs and grading protocols

- Devise and implement marketing strategies for the physical activity program

- Oversee all aspects of a \$70,000 annual operating budget

- Interview, hire, and train prospective graduate assistants and adjunct faculty

- Order and maintain all equipment and instructional materials necessary for over 70 courses annually

- Field all communication about the program from over 1,500 enrolled students annually

- Negotiate with the Recreation Sports Department and area businesses for facility usage

- Implemented current fee structure, allowing the activity program to be selfsustaining

\section{University of Louisville, Physical Education Program, Louisville, KY Instructor, 2005-Present}

- Instruct undergraduates in various core courses in the Health and Human Performance undergraduate degree

- Align all distance education courses with National Quality Matters Standards

- Generate over \$100,000 annually in distance education revenue for the HSS Department

- Incorporate technology in my instruction, including Blackboard, discussion boards, blogs, iClicker, and LiveText

- Member of Digital Pedagogy Faculty Learning Community, 2013-2014

- Selected and attended Delphi U Distance Education Training, 2008-2009

- Served as an academic advisor for over 30 physical education majors 


\section{University of Louisville, Health \& Sport Sciences Department, Louisville, KY Assistant Chair, August 2008-July 2015}

- Assist in overseeing aspects of a $\$ 2.9$ million operating budget

- Provide leadership to a Department producing over 28,000 credit hours annually

- Oversee curriculum changes for the Health and Human Performance undergraduate degree impacting over 650 students

- Support the daily operations of the HSS Department, including aiding 25 full-time faculty, over 50 adjunct faculty, and 4 full-time staff

- Generate reports documenting both the day-to-day operations and unique initiatives of the HSS Department

- Implement new instructional approaches for the HSS Department

- Develop cost saving approaches for the HSS Department

- Monitor the distance education offerings of the HSS Department, which generates over $\$ 700,000$ annually

- Guide facility renovations and building projects

- Ensure syllabi compliance of all HSS course offerings

\section{University of Louisville, Athletic Department, Louisville, KY Academic Services Tutor, 2005-2007}

- Tutored student athletes in Exercise Science, Health, Physical Education, and Sport Management courses

- Taught study skills, reading comprehension, note taking, and writing skills

\section{University of Louisville, Health \& Sport Sciences Department, Louisville, KY Graduate Assistant, 2003-2005}

- Taught Volleyball, Weight Training, Racquet Sports, Fitness Walking, Flag Football, Softball, and Ultimate Frisbee

- Developed a Racquet Sports course

- Monitored and evaluated five physical education student teachers at various local school settings

- Served as a research assistant for Dr. Chris Greenwell on various research and scholarship projects

\section{Kentucky Lions Eye Foundation, Louisville, KY Kentucky vs. Indiana High School All-Star Game Intern, 2004}

- Helped with the coordination of the annual All-Star Basketball Game

- Developed marketing strategies and advertising opportunities for the event

- Prepared and organized three press conferences

- Created advertising fliers, announcements, and press releases to generate publicity for the event 
- Conducted research on attendance data from past events

- Developed, administered, and analyzed a survey to determine the effects of time and place on the event

- Prepared a technical report with the survey findings for both the Kentucky and Indiana event organizers

\section{Ritenour School District, Buder Elementary School, St. Ann, MO Physical Education Teacher, K-5, 2002-2003}

- Taught and supervised 250 students daily

- Instructed twelve different classes daily

- Developed and implemented lesson plans

- Demonstrated appropriate classroom management skills

- Monitored and purchased equipment

- Coordinated an after-school program for over 50 students

\section{Ritenour School District, Ritenour Middle School, St. Ann, MO Long Term Substitute Teacher, 6-8, January 2002-May 2002}

- Responsible for remediation of low achieving students in language arts

- Taught test taking strategies

- Introduced reading comprehension tactics

- Worked on writing skills

\section{RESEARCH}

\section{A. Publications}

\section{Refereed Journals}

Ha, J.P., King, K.M., \& Naeger, D.J. (2011). The impact of burnout on work outcomes among South Korean physical education teachers. Journal of Sport Behavior, 34, (4), 343-357.

Greenwell, T. C., Lee, J., \& Naeger, D.J. (2007). Using the critical incident technique to identify critical aspects of the spectator's service experience. Sport Marketing Quarterly, 16, 190-198.

\section{Technical Reports}

Tokuyama, S., Naeger, D. J., \& Greenwell, T.C. (2009). USTA Kentucky Consumer Motivation Survey. Prepared for the United States Tennis Association of Kentucky. Louisville, Kentucky. 
Naeger, D.J., Miller, J.K., \& Greenwell, T.C. (2004). Kentucky vs. Indiana High School All-Star Classic Marketing Research Analysis. Prepared for the Kentucky Lions Eye Foundation. Louisville, Kentucky.

Naeger, D.J., Miller, J.K., \& Greenwell, T.C. (2004). Indiana vs. Kentucky High School All-Star Classic Marketing Research Analysis. Prepared for The Indianapolis Star. Indianapolis, Indiana.

Naeger, D.J., Miller, J.K., \& Tokuyama, S. (2004). Students Enrolled In University Activity Courses: Motives, Career Aspirations, and Course Satisfaction Analysis. Prepared for the Health \& Sport Sciences Department at the University of Louisville. Louisville, Kentucky.

\section{B. Presentations}

Naeger, D. (2014, April) GPA: The most overlooked acronym in sports. Presented at the American Alliance for Health, Physical Education, Recreation, and Dance (AAHPERD) National Conference, St. Louis, MO.

Naeger, D. (2014, April) Too much of a good thing: Realities of youth sports. Presented at the American Alliance for Health, Physical Education, Recreation, and Dance (AAHPERD) National Conference, St. Louis, MO.

Naeger, D. (2014, February) What comes first the student or the athlete? Presented at the Southern District American Alliance for Health, Physical Education, Recreation, and Dance (SDAAHPERD) Conference, Lexington, KY.

Kang, S.J., \& Naeger, D. J. (2012, November) All scrambled out: Creative approaches to running a golf tournament. Presented at the Kentucky Association for Health, Physical Education, Recreation, and Dance, Louisville, KY.

Naeger, D.J.; \& Kang, S.J. (2012, November) Utilizing our available resources: Implementing technology into the physical education curriculum. Presented at the Kentucky Association for Health, Physical Education, Recreation, and Dance, Louisville, KY.

Tokuyama, S.; Miller, J.; \& Naeger, D. (2011, June). They play but do they watch? An examination of tennis consumers. Presented at the North American Society for Sport Management (NASSM), London, Ontario.

Naeger, D. J. (2011, February). The youth sports conundrum: Going from "Can we go and play catch?" to "Do we have to go and play catch again?" Presented at the Southern District American Association of Health, Physical Education, Recreation, and Dance, Greensboro, NC.

Naeger, D.J. (2010, November). The role physical education has on student persistence. Presented at the Kentucky Association for Health, Physical 
Education, Recreation, and Dance, Lexington, KY.

Naeger, D. \& Tokuyama, S. (2010, November). Interscholastic sports: How do they impact the educational process? Presented at the Kentucky Association for Health, Physical Education, Recreation, and Dance, Lexington, KY.

Ha, J.P. \& Naeger, D.J. (2010, November). Teaching physical education and coaching: The dual role and its impact on burnout. Presented at the Kentucky Association for Health, Physical Education, Recreation, and Dance, Lexington, KY.

Naeger, D.J. \& Britt, D.W. (2009, October). More than balls and whistles: An examination of the impact physical activity courses have in student retention. Presented at The National Symposium on Student Retention, Buffalo, NY.

Tokuyama, S. \& Naeger, D. (2009, November). Who is more committed to playing recreational tennis? Presented at the Kentucky Association for Health, Physical Education, Recreation, and Dance, Lexington, KY.

Naeger, D. \& Tokuyama, S. (2009, November) Varying cultures in high school athletics. Presented at the Kentucky Association for Health, Physical Education, Recreation, and Dance, Lexington, KY.

Naeger, D.J., Greenwell, T.C., \& Miller, J.K. (2005, November). The influence of time and place on customer satisfaction and behavioral intentions. Presented at the Third Annual Sport Marketing Association Conference, Tempe, AZ.

Miller, J.K., Greenwell, T.C., \& Naeger, D.J. (2005, November). To stay or go: The influence of location continuity on event spectator characteristics. Presented at the Third Annual Sport Marketing Association Conference, Tempe, AZ.

\section{UNIVERSITY SERVICE}

\section{University Committees}

- Part-Time Faculty Senate Committee, 2009-2018

College of Education and Human Development Committees

- Student Grievance Committee, 2014-Present

- Standards and Admissions Committee, 2014-2015

- Policy and Review Committee, 2013-2014

\section{Department of Health \& Sport Sciences Committees}

- EXP Faculty Search Committee Member, July 2018-Present

- HSS Transfer Equivalency Representative, 2010-Present

- HSS Program Director's Committee, 2005-Present

- Physical Education and Teacher Preparation Program Committee, 2005-Present

- HSS Graduate Assistant Liaison, 2005-2015

- HSS Advisory Committee for HUSTLE Lab, 2013-2015

- Chair of the HSS Chair Search Committee, 2013-2014 
- Health and Human Performance Curriculum Committee, 2012-2014

- HSS Tuition Assistance Award Committee, 2010-2011

- HSS Honors and Scholarships Committee, 2009-2011

Representative for the Health and Sport Sciences Department at the College of Education and Human Development Welcome Event for new students, August 2012

Representative for the Health and Sport Sciences Department at the College of Education and Human Development Welcome Event for new students, August 2011

Representative for the Health and Sport Sciences Department at the College of Education and Human Development Welcome Event for new students, August 2011

Representative for the Physical Education Program at the L.E.A.D. event hosted by the College of Education, September 2010

Representative for the Health and Sport Sciences Department on the Community Based Learning and Sustainability Project for the College of Education, 2010

Representative for the Health and Sport Sciences Department at Campus Preview Day for the University of Louisville, 2009

Representative for the Physical Education Program at the Undecided Majors Fair Day at the University of Louisville, 2009

Representative for the Health and Sport Sciences Department at Campus Preview Day for the University of Louisville, 2006

Representative for the Health and Sport Sciences Department at the College of Education Open House, University of Louisville, 2006

\section{GUEST LECTURES}

Invited speaker, "Team Sports in the Physical Education Curriculum, Effective Strategies", University of Louisville's Theory and Analysis of Team Sport Skills Course, November 2010

Invited speaker, "Effective Teaching in the Physical Education Classroom", University of Louisville's Theory of Sport Pedagogy Course, October 2010

Invited speaker, "Career Possibilities with a Degree in Physical Education", University of Louisville's HSS Academic Orientation Course, September 2010

Invited speaker, "Team Sports in the Physical Education Curriculum, Effective Strategies", University of Louisville's Theory and Analysis of Team Sport Skills Course, November 2009

Invited speaker, "Effective Teaching in the Physical Education Classroom", University of Louisville's Theory of Sport Pedagogy Course, October 2009 
Invited speaker, "Career Possibilities with a Degree in Physical Education”, University of Louisville's HSS Academic Orientation Course, September 2009

Invited speaker, "Implementing Recreational Sports in the Physical Education Curriculum", University of Louisville's Theories of Sport Pedagogy Course, September 2009

Invited speaker, "Assessment Approaches in Physical Education”, University of Louisville's Theory and Analysis of Individual Sport Skills Course, March 2009

Invited speaker, "Social and Cultural Constraints of Development", University of Louisville's Human Growth and Motor Development Courses, October 2007

Invited speaker, "Social and Cultural Constraints of Development", University of Louisville's Human Growth and Motor Development Courses, March 2007

Invited speaker, "Social and Cultural Constraints of Development", University of Louisville's Human Growth and Motor Development Courses, October 2006

Invited speaker, "The Influence of Convenience on Customer Satisfaction and Behavioral Intentions", University of Louisville's Sport Administration Doctoral Research Seminar, January 2006

\section{TEACHING ACTIVITIES}

\section{Undergraduate Courses Taught at University of Louisville}

Diverse Populations in Physical Activity and Health

First Aid and Safety Education

Social and Psychological Dimensions of Sport

Human Growth and Motor Development

Test and Measurement

Skill Acquisition and Analysis

Physical Education Fieldwork

Fitness Walking

Flag Football

Racquet Sports

Softball

Ultimate Frisbee

Volleyball

Weight Training

\section{Graduate Courses Taught at University of Louisville}

Physical Education Student Teaching Supervision

Action Research Project

\section{PROFESSIONAL DEVELOPMENT TRAININGS}

2015 American Red Cross Instructor Training

2015 Minds in Motion Level One Training 
2014 Leveraging the Power of Recognition

2014 Motivational Techniques: Strategies for Motivating Yourself and Others

2014 Time for a Change: Strategies for Surviving and Thriving During Times of Transition and Change

2014 Digital Pedagogy Faculty Learning Community

2013 Digital Pedagogy Faculty Learning Community

2012 Time is Not the Issue: Time Management Strategies

\section{RELATED EXPERIENCE}

2011 Softball and baseball umpire for Jeffersonville GRC Little League

2008 Event management for Louisville Iron Man competition

2005 Event management for dog day in the park at Louisville Slugger Field

2005 Event management for Got Milk Tour

2004 Event management for Got Milk Tour

2003 Softball and t-ball umpire for the City of Fenton

2003 Guest services for UMB Bank Pavilion

2002 After school program counselor at Ladue School District

2002 Guest services for UMB Bank Pavilion

2002 Softball and T-ball umpire for the City of Fenton

2001 Official for Southeast Missouri State University Intramurals

2000 Director of after school program at Jefferson Elementary School

2000 Official for Southeast Missouri State University Intramurals

1999 Student Assistant Coach for Mineral Area College Men's Basketball

1998 Student Assistant Coach for Mineral Area College Men's Basketball

1997 Student Assistant Coach for Mineral Area College Men's Basketball 


\section{AWARDS AND RECOGNITIONS}

2018 Nominated as a Faculty Favorite, University of Louisville

2013 Selected as a member of the Digital Pedagogy Faculty Learning Community, University of Louisville

2010 Red and Black Student-Athlete Faculty Mentor, University of Louisville

2009 Honored as Faculty Guest Coach for University of Louisville Women's Basketball

2008 Selected to attend Delphi U Distance Education Training

2008 Red and Black Student-Athlete Faculty Mentor, University of Louisville

2007 Red and Black Student-Athlete Faculty Mentor, University of Louisville

2007 Nominated as a Faculty Favorite, University of Louisville

2006 Red and Black Student-Athlete Faculty Mentor, University of Louisville

2005 Red and Black Student-Athlete Faculty Mentor, University of Louisville

2004 Red and Black Student-Athlete Faculty Mentor, University of Louisville

\section{PROFESSIONAL MEMBERSHIPS}

SHAPE America

Kentucky Association of Health, Physical Education, Recreation, \& Dance 